Portland State University

PDXScholar

1988

\title{
A Case Study of Instructional Improvement through Peer Observation in a Suburban High School
}

Helen Jean Hanna

Portland State University

Follow this and additional works at: https://pdxscholar.library.pdx.edu/open_access_etds Let us know how access to this document benefits you.

\section{Recommended Citation}

Hanna, Helen Jean, "A Case Study of Instructional Improvement through Peer Observation in a Suburban High School" (1988). Dissertations and Theses. Paper 1252.

https://doi.org/10.15760/etd.1251

This Dissertation is brought to you for free and open access. It has been accepted for inclusion in Dissertations and Theses by an authorized administrator of PDXScholar. Please contact us if we can make this document more accessible: pdxscholar@pdx.edu. 
A CASE STUDY OF INSTRUCTIONAL IMPROVEMENT THROUGH PEER OBSERVATION IN A SUBURBAN HIGH SCHOOL

by

HELEN JEAN HANNA

A dissertation submitted in partial fulfillment of the requirements for the degree of

\author{
DOCTOR OF EDUCATION \\ in \\ EDUCATIONAL ADMINISTRATION AND SUPERVISION
}

Portland State University

1988 
TO THE OFFICE OF GRADUATE STUDIES:

The members of the Committee approve the dissertation of Helen Jean Hanna presented March 2, 1988.
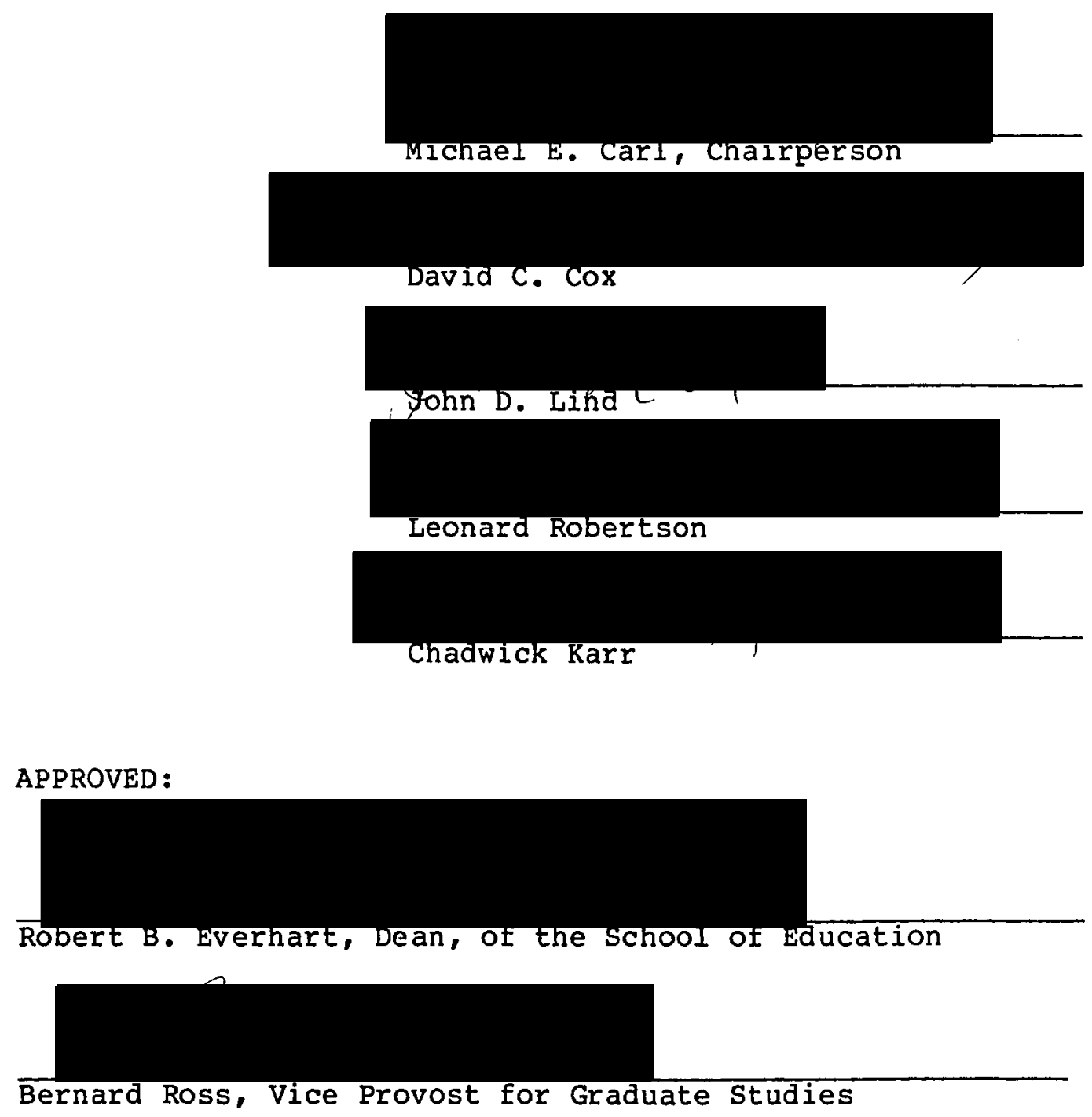
AN ABSTRACT OF THE DISSERTATION OF Helen J. Hanna for the Doctor of Education in Educational Leadership presented March 2, 1988.

TITLE: A Case Study of Instructional Improvement through Peer Observation in a Suburban High School

APPROVED BY MEMBERS OF THE DISSERTATION COMMITTEE:
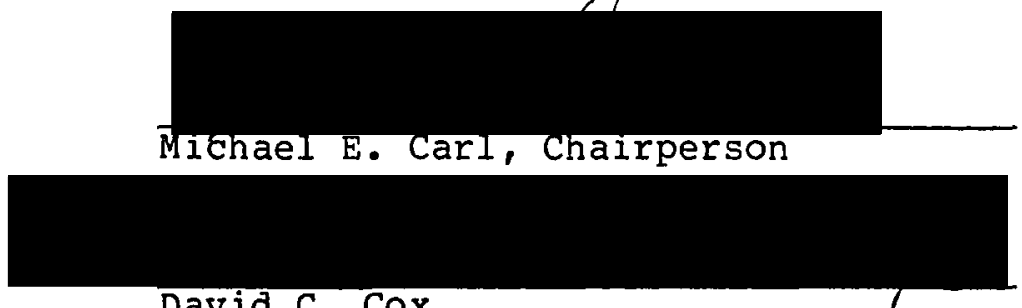

David C. Cox

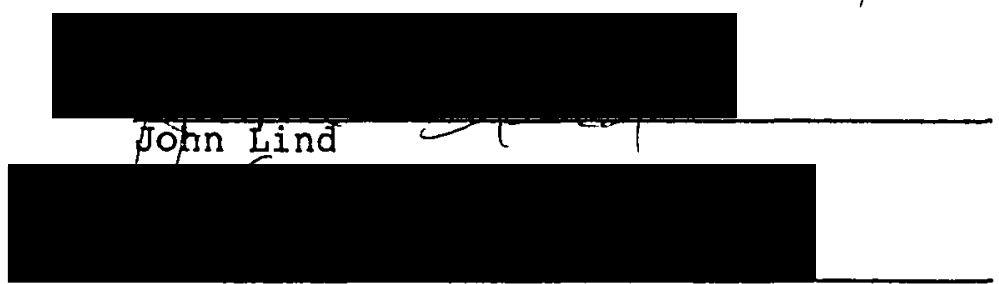

Leonard Robertson

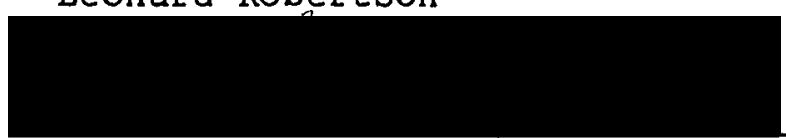

Chadwick Karr

This two-year case study investigated the effects of a peer observation process in a high school on the six selected areas listed below. Peer observation is a process to improve instruction by having teachers observe and critique other teacher's videotapes of classroom teaching. 
1. Changes in norms and expectations for sharing instructional ideas among teachers.

2. The perceived value of self-evaluation of videotapes and related peer discussions about teaching.

3. The perceived value of peer feedback exchanges for instructional improvement.

4. The use of other teachers as models for effective teaching.

5. The perceived value of peer exchanges in stimulating a desire to improve.

6. The effect of peer interaction on the school climate for teacher improvement.

The case study design was effective for investigating subjects in their natural setting which was a faculty of approximately 65 veteran teachers who had participated in one or more activities of the peer observation process. Research methods included the use of multiple sources of data from observations, questionnaires, surveys, peer discussion reports, and interviews. Lines of inquiry were triangulated across methods to strengthen the results and to search for divergent findings. Descriptive analyses were used to present and discuss the findings. Seventy-three percent of the staff participated the first year, 438 participated in the second year.

Results from the findings indicated that peer observation had the following effects in this setting: 
1. Standards of behavior among teachers changed from closed to open after experience with the process. Teachers exchanged ideas on teaching beyond that requested and in situations outside the process activities.

2. Videotape replay of classroom teaching and peer group discussions were perceived as valuable for both observed and observing teachers.

3. Teachers preferred feedback from peers because of the varied ideas from credible sources, the time to exchange teaching strategies, and the nonthreatening environment.

4. Teachers used other teachers as models for generating effective methods for immediate classroom use.

5. Teachers perceived exchanges to have stimulated a desire to improve on three levels; awareness, effort, and implementation.

6. A climate for instructional improvement evolved where teachers perceived a need to share information and generate ideas in a non-threatening manner.

The peer observation process was found to be an effective program for teacher improvement of instruction in this setting. 


\section{ACKNOWLEDGEMENTS}

It is difficult to imagine any school-based research that did not depend upon the cooperation and help of numerous individuals, all of whom deserve recognition. I owe a debt of gratitude, perhaps greater than most, to the staff of Lake Oswego High School, my colleagues of 13 years, for their forthrightness in answering questions, their inquiring nature, and their willingness to entrust with me their thoughts, opinions, experiences, and problems, without which none of what follows could have been possible. They constitute the essence of this study. My appreciation extends to the principal, Mr. Bill Korach, and his administrative staff who implemented the peer observation process and welcomed this investigation. School district interest in this program provided an additional incentive to complete this paper.

I am grateful for my committee of readers who encouraged pursuit of this investigation. They supported a case study design, offered suggestions, asked questions, advised, and gave hours of dedicated work to my writing, more often at the request of my time schedule than theirs. I am especially grateful to $\mathrm{Dr}$. Mike Carl for accepting chairmanship of my dissertation committee and providing the impetus 
iv

for getting this study started. Under the mentorship of

Drs. Carl, Dave Cox, John Lind, Chad Karr and Leonard

Robertson, the direction and form of this study evolved. It

is in holding the completed document that I am reminded

again of the many hours of precise work given to its for-

mat. I wish to thank Ms. Melinda Rice for accepting my

dependence upon her skills in the final stages.

Finally, I wish to dedicate this study to my friend,

Dr. Stephen N. Stivers, who wrote:

Wearying early of brighter street lights,

a moth came seeking the comfort

of my porch lamp's dimness.

"Recompense" in s'expliquer

I am grateful for the perpetual lamp he lighted during my endeavors and his patience for my ambitions. 
PAGE

ACKNOWLEDGEMENTS . . . . . . . . . . . . . . ii

LIST OF TABLES . . . . . . . . . . . . . . . . $\mathrm{x}$ CHAPTER

I INTRODUCTION

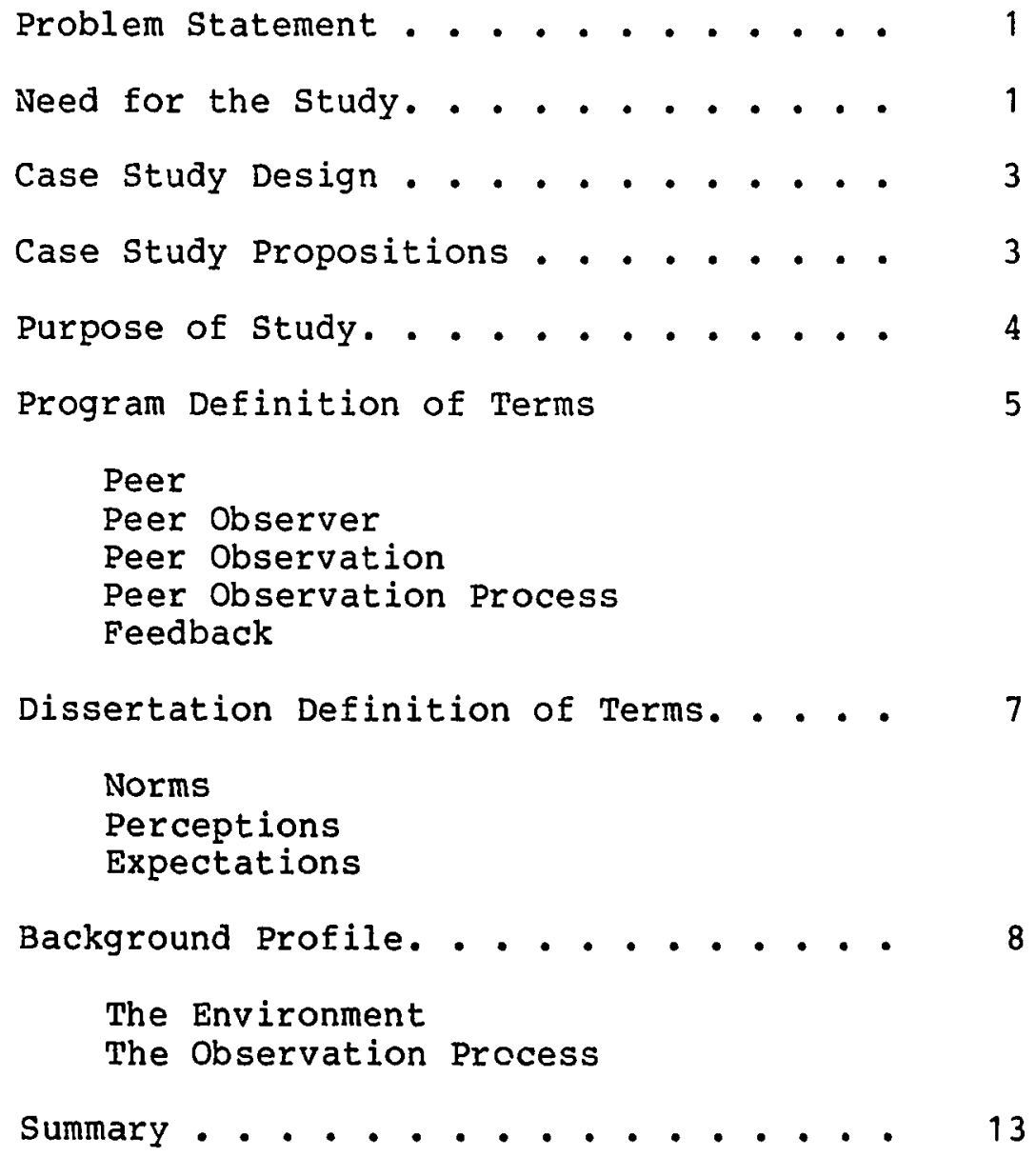


II REVIEW OF THE LITERATURE

Introduction. . . . . . . . . . 16

Group Supervision Approach. . . . . . 18

The Team Approach

The Peer Approach

Research Studies on the Peer Approach to Supervision

Summary of Recommerations

Summary of Findings

Peer Observation Feedback and

Behavioral Change . . . . . . . 25

Peer Observation Feedback for

Instructional Improvement

Peer Observation Feedback and

Teacher Attitudes

Peer Observation and the Work

Environment

Summary of Findings

Feedback Variables and Behavioral Change. . 38

Summary of Findings

The Effects of Types of Feedback on

Behavioral Change . . . . . . . 41

Videotape Feedback and Behavioral

Change

Micro-teaching Feedback and Behavioral Change

Modeling Feedback and Behavioral Change

Summary of Findings

Problems Associated With Peer

Supervision Programs. . . . . . . 49

Three Team Supervision Programs

in Operation. . . . . . . . 50

Summary of the Literature Review. . . . 53 
II METHODOLOGY

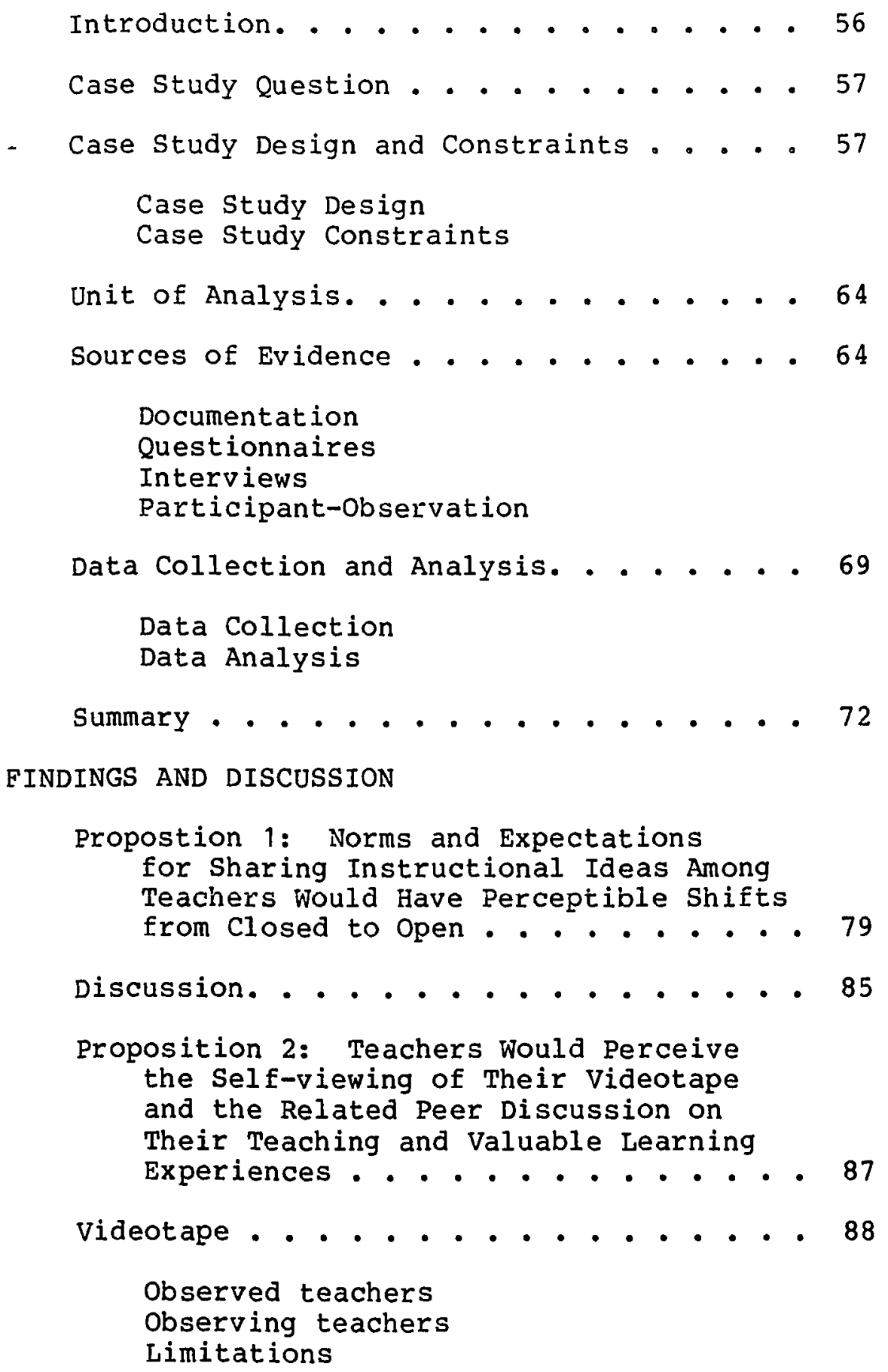


Chapter IV (continued)

Peer Discussion Group Sessions. . . . . 90

Observed teachers

Observing teachers

Limitations

Discussion. . . . . . . . . . 94

Proposition 3: Peer Feedback Would be Perceived by Teachers as Valuable for

Their Instructional Improvement . . . 96

Discussion. . . . . . . . . . 103

Propostion 4: Teachers Would Use other

Teachers as Models for Effective

Teaching After Viewing the Videotapes

of Peers............ 106

Discussion. . . . . . . . . . . 111

Proposition 5: Peer Interactions Would

Be Perceived as Rewarding to a

Teacher's Desire to Work Toward

Instructional Improvement . . . . . 112

Discussion. . . . . . . . . . 120

Proposition 6: Teacher Interaction Would

Stimulate New Ideas, Methods, and

Strategies and Create a $\mathrm{Cl}$ imate where

Changes in Teaching Were Possible . . 121

Discussion. . . . . . . . . . 128

V CONCLUSIONS, OBSERVATIONS, RECOMMENDATIONS

Conclusions . . . . . . . . . 130

Observations. . . . . . . . . . 132

Recommendations . . . . . . . . 136 
SUPPLEMENTAL REFERENCE NOTES . • . • • • • . • • 138

BIBLIOGRAPHY . . . . . . . . . . . . . 147 APPENDICES

A. Participant Volunteer Forms. . . . . . 157

B. Peer Discussion Report Forms . . . . . . 161

C. 1985 Principal Questionnaire . . . . . 165

D. 1985 Investigator Questionnaire. . . . . 169

E. 1986 Investigator Survey . . . . . . . 176

F. Interview Questions Department Chairs. . . 178

G. Interview Questions Principals . . . . . 180 


\section{LIST OF TABLES}

TABLE

PAGE

I Summary of Methods of Data Collection. . . . 65

II Comparison of Staff, Volunteers and

Participation in 1984-85 and 1985-86 . . . 76

II Methods of Investigation and Response

Return Rates 1984-85 and 1985-86 . . . . 79

IV Before/After Ratings of Instructional

Improvement In Awareness, Effort and

Implementation . . . . . . . . . . . 114 
O wad some Pow'r the giftie gie us

To see oursels as others see us!

Robert Burns, "To a Louse, On Seeing one

on a Lady's Bonnet at Church"

Two are better than one;

because they have a good

reward for their labour.

For if they fall, the one

will lift up his fellow: but woe

to him that is alone when he

falleth; for he hath not another

to help him up.

Ecclesiastes $4: 9,10$ 


\section{CHAPTER I}

INTRODUCTION

\section{PROBLEM STATEMENT}

This case study describes the effects of a peer observation process in a high school on selected areas of teacher

norms, perceptions, and expectations. Peer observation is a process to improve instruction by having teachers observe and critique other teacher's videotapes of classroom teaching.

\section{NEED FOR THE STUDY}

One reason the peer observation process warrants investigation is its unique approach of placing the teacher in the role of director of his/her instructional improvement. Implementing this process raises such questions as (a) does a peer observation approach create positive instructional change? (b) would teachers, who had not previously observed and discussed each other's instruction, be willing to do so? (c) what management requirements would evolve? (d) how would teacher interactions develop? (e) would there be perceptible staff changes in norms, attitudes, and expectations about teaching? and (f) would results of peer observations 
lead to identifiable changes in teaching quality as perceived by the participants?

Another need for this study is the opportunity to analyze the peer observation methodology as an alternative to the traditional administrator-directed process of instructional supervision. While this study does not directly compare peer-directed supervision with traditional supervision, investigating peer observation may provide new insights toward improving instructional supervision and stimulate interest among educators to review traditional methods with an intent toward potential change.

Knowledge of peer observation as an alternative methodology is needed in the following areas:

1. The need to determine whether peer supervision contributes toward instructional improvement.

2. The effects of peer observation upon leaders within the institution.

3. The impact of a peer observation process upon the institutional environment.

4. The need to determine whether inadequacies of traditional supervision might be eliminated by an alternative methodology 1 ike peer supervision. Three inadequacies appearing frequently in the literature are (a) the lack of administrative supervisory skill, (b) the lack of administrative time to supervise, and (c) the negative climate created by administrative supervision (for example Abramson, 
1972; Ban \& Soudah, 1978; Dornbusch, Deal, Plumley, \& Roper, 1976; Ellis, Smith, \& Abbott, 1979; Grossnickle \& Cutter, 1984; Hopfengardner \& Walker, 1984; Lempesis, 1984; McGee \& Eaker, 1977).

\section{CASE STUDY DESIGN}

A single-case study research design was developed from the principles documented by Yir (1984) to serve the exploration of this study.

\section{CASE STUDY PROPOSITIONS}

By formalizing the process for peer observation into specific activities that participants would experience in common, it was anticipated that the following selected research-based norms, perceptions, and expectations would result:

1. Norms and expectations for sharing instructional ideas among teachers would have perceptible shifts from closed to open.

2. Teachers would perceive the self-viewing of their videotape and the related peer discussion of their teaching as valuable learning experiences.

3. Peer feedback would be perceived by teachers as valuable for their instructional improvement.

4. Teachers would use other teachers as models for effective teaching after viewing the videotapes of peers. 
5. Peer interactions would be perceived as rewarding to a teacher's desire to work toward instructional improvement.

6. Teacher interaction would stimulate new teaching ideas, methods, and strategies and create a climate where changes in teaching were possible.

These anticipated outcomes shaped the investigation by narrowing the focus of attention to selected norms, perceptions, and expectations identified in the literature. It was expected that the peer observation process would emerge as an effective alternative for improving the quality of instruction because of the positive effect peer observation had on participant norms, perceptions, and expectations about teaching and about frequent and varied feedback opportunities.

PURPOSE OF STUDY

One value of this research will be to improve the understanding of what happens to an organization when it institutes a peer observation program. Furthermore, such an investigation could stimulate interest in and implementation of peer observation processes by its contributions to the following areas:

1. An addition to the minimal current research on peer observation as a process and as a methodology for working toward teacher growth. 
2. A greater understanding of the impact of peer feedback on teachers who are in the process of instructional improvement.

3. An understanding of school environmental requirements necessary to nurture instructional improvements, particularly among veteran teachers.

4. A formalized process model available for institutional implementation.

5. An exposure of potential weaknesses of a peer observation process which identifies problems to anticipate and factors to avoid in that process.

PROGRAM DEFINITION OF TERMS

Peer

The word peer is used here to mean any certified teacher who works within the building environment, either on part- or full-time basis. (At inception of the program, peer included certificated teachers and administrators.)

\section{Peer Observer}

These words are used to mean a person who has been asked for feedback on a videotaped lesson. A peer observer agrees to perform several functions: (a) Watch the videotaped lesson, (b) meet with the observed teacher and other peer observers, (c) discuss the lesson, (d) verbalize requested feedback, and (e) write comments about the lesson on prepared forms. 
Peer Observation

These words are used to mean teachers observing and critiquing other teacher's videotapes of classroom teaching for the purpose of instructional improvement. Observations occur when peers view a videotaped segment of teaching activity. It describes teacher-directed observation where the teacher may select the teaching activity to be taped, the peers who will view the tape, and the focus for observation and feedback discussion.

\section{Peer Observation Process}

These words are used to mean the steps and activities prescribed to complete the objectives of peer observation. The steps and activities include: (a) preparing a videotape of a classroom teaching activity, (b) requesting participation from peer observers, (c) submitting lesson objectives and feedback requests to peer observers, (d) organizing peer observers for videotape viewing, (e) scheduling a peer observation discussion session, and ( $f$ ) receiving and analyzing oral and written feedback on the videotaped lesson.

\section{Feedback}

This word is used to mean a return of oral, written, or visual information to the teacher being observed and to peer observers within the selected group. The observed teacher identifies specific elements in the videotaped lesson where a return of information was sought. Feedback 
requests varied but generally included a desire for information about (a) progress in skills and processes, (b) progress toward objectives and goals, and (c) indications of individual performances (Orlich, Harder, Callahan, Kravas, Kauchak, Pendergrass, \& Keogh, 1985, p. 247).

\section{DISSERTATION DEFINITION OF TERMS}

Norms

Behavioral rules accepted to some degree by most members of a group where adherence provides a high degree of regularity and deviation usually results in some kind of punishment by the group. Norms are valuable to social relationships and they reduce the need for any one individual overtly exerting power to control individual and group behavior (Orlich et al., 1985, p. 339). Prior to implementation of this process, participants were not accustomed to discussing instructional improvement with each other and those teachers who attempted exchanges were viewed with suspicion.

\section{Perceptions}

The way one receives information from the environment through channels which correspond to the six basic senses, codes it in the brain, and tests it against similar previous environmental events "in order to interact with and make sense of it" (Haring, 1974, p. 228). Participants in the study became aware of the peer observation process environ- 
ment primarily through visual, auditory, tactile, and kinesthetic modes, and integrated this information into previous instructional growth experiences.

\section{$\underline{\text { Expectations }}$}

"The state of mind of one who expects or anticipates; to look forward to as certain or probable; or to look for as right, proper, or necessary" (Funk \& Wagnalls, 1973, p. 467). Partisipants came to the program without prior experience in a peer observation process. They entered with a variety of anticipations, formulated individually and by program goals, which were affected as participants worked with the peer process activities.

\section{BACKGROUND PROFILE}

Brief descriptions of the environment and of the process activities at Lake Oswego High School provide a setting for the peer observation process studied here. Details of the environment and the observation process are given in the methodology section.

\section{The Environment}

In the fall of 1984, four administrators supervised 64 teachers who had an average age of 40 years. Eleven of the staff were part time. Most were veteran teachers averaging 17 years of teaching; an average of 13 years were at Lake Oswego. The staff had matured together professionally, 
experiencing a change of 4 principals and 4 superintendents within the last 12 years.

Lake Oswego High School is one of two grades 9-12 high schools in the district. During the period of this investigation, it offered a comprehensive educational program to approximately 1,000 students organized into a seven period instructional day with 48-minute class periods.

Each teacher was assigned five teaching periods, one period of supervised student study, one preparation period, and one 30-minute lunch period. Seven department chairpersons, paid for their leadership positions, performed liaison duties between the administrators and teachers. Generally, department chairs met weekly and the faculty convened semimonthly. Meetings occurred before or after school, and on an assembly supervision rotation basis. The instructional day was from 8:10-3:00 p.m., and the teacher contract day from $7: 30-3: 30$ p.m.

The Observation Process

The peer observation process departed from the district policy for improvement of instruction by shifting responsibility for instructional supervision from administrators to teachers. A majority of the staff had experienced the district instructional improvement procedure which consisted of (a) administrator-teacher conference, (b) administrator-classroom observation, and (c) administrator- 
teacher post-observation conference followed by written summative comments for evaluative purposes. Each Lake Oswego High School administrator directed and supervised the district procedures for approximately 16 teachers. They also shared supervision responsibilities for specialists and classified employees which increased the supervision load to over 25 people per administrator.

In the peer observation process, teachers were responsible for instructional supervision. Participation in the peer observation process was voluntary. However, an external motivation was offered to the permanent-status teachers to encourage participation. Those who volunteered would not be administratively supervised for instructional improvement using the district procedures. While encouraged to participate, temporary, probationary, part-time, and shared staff would not be offered the same conditions because of the evaluation requirements of their status, The peer observation process was consistent with terms of "management rights" under the contract, and the teacher association was not involved in planning or implementing this process.

Among the organizational demands of the peer observation process were the following teacher activites:

1. Scheduling for the videotaping equipment and taping date. 
2. Preparing lesson objectives and listing areas for requested feedback.

3. Videotaping the desired instruction and viewing the videotaped teaching segment.

4. Contacting four or five teachers for peer observing .

5. Delivering lesson objectives and feedback forms to peer observers.

6. Arranging for peers to observe the tape on their own time.

7. Scheduling a common time for a group discussion meeting •

8. Collecting written peer comments and submitting them to the office secretary.

Each volunteer was asked to observe a peer once and to be observed by a group of peers once. As the peer observation process functioned on the time lines of its members, the original schedule for March 15 completion, set to the district's calendar, was found to be impractical. As a result, deadines for completion of the process were extended to the end of the school year.

Teacher process activities were accomplished by meeting before and after school, during preparation periods, on assembly supervision rotation days, and during school inservice days. As participation activity increased during the year, demands on teachers' time increased. For example, 
while in the stages of arranging their own observation activities, teachers might also be participating in various stages of the process for one or two peers. As a result, those teachers with equipment viewed tapes of self and peers at home.

In the fall of 1984,46 teachers or about $87 \%$ of the full-time teaching faculty had committed to the peer observation process. At the end of the 1984-85 school year, 40 teachers had completed the process while another 7 had participated in one or more stages of the process. Two perception assessment instruments were administered to the staff. One, requested by the principal, utilized open-ended responses. The other, administered by the investigator, sought perceptions on process and content. At the close of the school year, the principal took a leave of absence from the district and the assistant principal was appointed acting principal for the 1985-86 school year.

Peer observation continued in 1985-86. During this year, participation in the process was placed within the framework of the district improvement of instruction program. This meant that all teachers were evaluated on instructional improvement and no special incentives were offered to teachers who selected to participate in the peer observation process. In the fall of 1985, 40 teachers or about $73 \%$ of the full-time staff, selected peer observation as an instructional improvement goal. At the end of the 
1985-86 school year, 25 completed the process and 4 others participated in one or more stages of the process. At the end of the 1985-86 school year, follow-up interviews were conducted with both principals and seven department chairperson. A brief staff survey was also taken to document participation and to solicit general or specific comments on the process in the second year.

\section{SUMMARY}

This two-year study investigated the effects of a peer observation process in a high school on selected norms, perception, and expectations of teachers. Peer observation is a process to improve instruction by having teachers observe and critique other teacher's videotapes of classroom teaching. This study was intended to provide insight into a process where the teacher directs $\mathrm{his} / \mathrm{her}$ instructional improvement and offer information on the value of alternative methods of instructional supervision.

After teachers participated in peer observation activities, it was expected that teachers would reflect changes in norms, perceptions, and expectations in six research-based areas:

1. Norms and expectations for sharing would shift from closed to open.

2. Self-viewing of videotapes and group feedback on teaching would be viewed as valuable. 
3. Peer feedback would be viewed as valuable for instructional improvement.

4. Teachers would use peers as models for effective teaching .

5. Peer interactions would be viewed as rewarding to a teacher's desire to improve.

6. Teacher interaction would stimulate new ideas, methods, and strategies for teaching and create a climate where changes in teaching were possible.

The intended value of this investigation was to improve the understanding of a peer observation process as it relates to the institutional organization, teacher improvement practices, the climate for nurturing instructional change, the process model for implementation, and the potential weaknesses of a peer observation process. Volunteers for the peer observation process were requested from 64 veteran staff members. Each participant was asked to be observed once and to observe a peer once. The process involved all teacher-directed activities: (a) taping a teaching segment, (b) requesting four to five peers to observe the tape and give oral and written feedback, (c) identifying areas where peer feedback was desired, and (d) arranging for a peer group discussion meeting where feedback could be exchanged. In 1984-85, 46 teachers volunteered to participate and 40 teachers completed the process. In 
$1985-86,40$ teachers volunteered to participate and 25 completed the process.

Sources of evidence used during the two-year investigation included assessment instruments administered to the staff at the end of each year, peer discussion group report forms, department chairperson and principal interviews, and participant observations. 
C̈HAPTER II

REVIEW OF LITERATURE

INTRODUCTION

The purpose of a review of literature is to present observations and research findings from others who have studied instructional peer interaction processes and to establish a research base which relates to the focus of this study.

Two observations from the literature provide an organizational structure for this chapter. One, because peer observation promotes the value of teachers observing teachers where opportunities for face-to-face peer feedback are included, feedback was considered an integral component of teacher improvement. Two, authors recommend that collegial interactions better accomplish desired instructional improvement than more traditional observation programs because of the presence of valued feedback. This review will present peer observation processes and characteristics in general and feedback characteristics in particular.

The review begins with a discussion of the two types of approaches promoted by writers in the field of peer 
supervision: the team approach and the peer approach to teacher supervision for instructional improvement. Factors in common to both approaches include teaching improvements, attitude and environment changes, time requirements, and results of feedback. Research studies on the peer supervision process approach included here lend support to the recommendations of educators.

The reriew continues with a comprehensive discussion of research findings on peer supervision feedback and the role of feedback in creating behavioral changes in teachers. The categories of behavioral change include instructional improvement results, attitude shifts, and environmental changes. Along with the presentation of behavioral changes effected by the peer supervision approach, research insights are included on the amount, source, and types of feedback that seem most effective in peer supervision relationships. Research on feedback modes is presented because of the key role of feedback from peers in the case under investigation. Categories of the types of feedback reported from the research include videotape, micro-teaching, and modeling. In reviewing the research, it was noted that studies involving peer observation generally compare peer feedback with other modes of feedback for instructional improvement.

The review concludes with documented problems in implementing peer supervision processes and three short 
descriptions of team supervision programs for teacher evaluation in progress at the time of this investigation. While some features of peer observation in other studies were similar to this study, no studies were found which involved an intact, veteran staff of secondary teachers in one building where the majority of teachers participated in multi-member peer observation grouping sessions.

This literature review included a manual search through August, 1987 and four ERIC searches conducted on the following dates: February 5, 1985, July 1, 1985, July 11, 1986, and February 11, 1988. Sources used included the following: Educational Resources Information Center, Current Index to Journals in Education, Resources in Education, Encyclopedia of Educational Research, Dissertation Abstracts International, Education Index, and Educational Administration Abstracts.

\section{GROUP SUPERVISION APPROACHES}

The research has identified two approaches to group supervision of teachers for instructional improvement: (a) a team approach where teachers and administrators share the supervisory responsibilities for improving instruction and (b) a peer approach which relies solely upon teacher supervision for the improvement of instruction. 
The Team Approach

The team approach to supervision for improvement of instruction, as reflected in the literature, promotes observation of classroom instruction by a small group comprised of teachers and administrators. Advocates of this approach recommend that it results in improved teacher performance in the classroom because of frequent and relevant feedback (Baltus, 1974; Diamond, 1975; Ellis, Smith, \& Abbott, 1979; Lawrence, 1985; Sharken \& Tremba, 1978) and it increases the teacher's ability to transfer new techniques into the classroom (Joyce \& Showers, 1981). Administrators are relieved from sole supervision of all teachers in a variety of subjects where they lack expertise (Ellis, Smith, \& Abbott, 1979; Lawrence, 1985). Teacher accountability is increased and program innovations are better monitored and assessed (Baltus, 1974; Diamoná, 1975; Sharken \& Tremba, 1978). Baltus (1974), Diamond (1975), and Sharken and Tremba (1978) promoted the team approach as valuable to both improvement of instruction and evaluation for retention where improvement goals, as monitored by the team, become a part of the teacher's permanent employment file.

The team approach does not alleviate the problem of time constraints, but it does shift the time burdens to all team members. Some relief in time demands can be found through the use of videotape for classroom observations, 
micro-teaching, and modeling (Baltus, 1974: Sharken \& Tremba, 1978). Administrators feel a relief from the demands on their time with the team approach (Lawrence, 1985), and the time devoted to team supervision appears to be used more productively (Lawrence, 1985; Sharken \& Tremba, 1978). Teachers indicated that time was the principle unexpected difficulty when they agreed to participate in peer observations (Benzley, Kauchak, \& Peterson, 1985). Sharken and Tremba (1978) suggested a team approach takes more time, requires greater commitment, and faces unique organizational difficulties.

Several positive factors in the supervisory climate emerged as valuable in a team approach to instructional improvement supervison. Ellis, Smith, and Abbott (1979) suggested that teachers lost fear for impending observations and decreased their need to change teaching styles for the observations. Principals felt free to exert leadership without clashes with teachers over evaluations (Lawrence, 1985). Teachers perceived that observations helped them improve their teaching and contributed to positive communication about teaching matters (Ellis, Smith, \& Abbott, 1979; Showers, 1985). Teachers viewed seriously their responsibility for improved teaching (Lawrence, 1985).

The Peer Approach

While some authors promoted a team supervisory approach to instructional supervision, others recommended a 
peer supervision approach where teachers woik together, either one-on-one or in small groups. Unlike the team approach, peer supervision approaches are conducted without administrative input. Thompson (1979) defined peer supervision as "essentially clinical supervision with a peer assuming the role vacated by the administrative supervisor" (p. 8).

The literature indicates that peer supervision enhances instructional improvement. Abramson (1972) and Ban and Soudah (1978) saw peer supervision as generating cooperation among teachers and producing more rigorous monitoring of teacher performances based upon specific targets for improvement. Peer observation is also promoted because of the opportunity for frequent feedback to teachers (Brophy, 1979; Warner, Cooper, \& Houston, 1980). Dornbusch, Deal, Plumley, and Roper (1976) emphasized the ability for teachers to get frequent, focused feedback from which systematic progress could be made toward improvement goals. Lempesis (1984) stated "I have determined over the years. . that teachers can learn better teaching methods and can teach better teaching methods simply by observing each other in action" (p. 155). Showers (1985) noted that peer supervision can lead to more practice on new strategies, greater skill, and greater long-term retention. Cruickshank and Applegate (1981) favored peer relationships for reflective thinking 
because it provided teachers with time to think about their own teaching behaviors, offered an opportunity to view other experienced teachers in action, and pointed teachers in the direction of self-improvement. Helling's (1976) manual promoted the belief that peer observers can offer specific feedback, selective guidance for improvement, and positive encouragement towards goals.

The literature indicates that the peer supervision approach creates a positive environment for improving instruction. Hofengardner and Walker (1984) stressed the need to de-emphasize the superior-subordinate relationship and emphasize a peer support network to achieve instructional improvement. McGee and Eaker (1977) perceived one-on-one peer supervision as a means of developing "cooperative teaching, enhancing trust relationships and reducing teacher anxiety by removing the threat" (p. 26) created by administrative supervision. Showers (1985) suggested that "teachers should coach each other. Others can be coached but the logistics of continuous observation/feedback favors peers as coaches" (p. 45). Peer supervision is seen as a way to engender a sense of professionalism among teachers (Lawrence, 1985; Thompson, 1979). Cruickshank and Applegate (1981) pointed to peer supervision as a means of renewing teacher self-esteem and interest in teaching. Peer 
supervision approaches promoted morale and effectiveness of faculty groups (Brophy, 1979).

The issue of time constraints has been addressed by few in the literature. Lempesis (1984) indicated the "main drawback to having teachers observe each other was the lack of time" (p. 156) so inservice periods were set aside during the year to accomplish peer observations. McGee and Eaker (1977) acknowledged that time must be provided for teachers to observe each other, but they did not indicate how this should be done. Abramson (1972) and Showers (1985) suggested that time and scheduling needs are the responsibility of the principal but neither indicated how scheduling arrangements could be accomplished.

\section{Research Studies on the Peer Approach to Supervision}

Research conclusions on peer observation and supervision programs support recommendations expressed in the literature. Brophy's (1979) study concluded that teachers working together as a group get useful feedback relevant to their needs, share expertise and experience, break down isolation barriers to professional development, and find that differing teachers can contribute to each other. The best results were found where teachers determined the focus of the class observation.

Nelson's (1971) study indicated that collegial supervision favorably affected teacher satisfaction, professional 
sharing, and communication adequacy when added to other organizational development training programs within the schools. Lawrence (1985) said of the Toledo, Ohio peer review plan:

What the teacher in the next room does now is seen as a legitimate part of every teacher's professional responsibilities. That awareness of what excellent teaching is (and is not) is the most significant change our program has made. And that knowledge of what it takes to be an effective teacher is something that can only be experienced firsthand. (p. 23)

Williams (1981) and Holm (1978) studied the impact of peer supervision on teacher attitudes. Holm (1978) reported that participants found peer supervision more beneficial than the formal evaluation system used, were more satisfied with evaluative feedback given by teachers, and more pleased with what they gained by observing their partner's teaching. Receiving negative feedback did not cause teachers to view peer feedback less favorably. Williams' (1981) study concluded that teachers' attitudes toward supervision, teachers' instructional behavior, and teachers' intrinisic job satisfaction can be affected postively by the treatment of a peer supervision model.

Peer supervision studies remain few. In 1977, Al fonso wrote:

Peer supervision has undergone a considerable amount of discussion, has made modest appearance in professional publications, and has had a limited number of apparently successful 
attempts, but has been subjected to almost no critical anaiysis. (p. 54)

Two years later Thompson (1979) indicated that, although he advocated peer supervision, such processes needed to be examined by researchers. He had "found only seven reports on attempts at peer supervision of which five offered empirical data to substantiate their conclusions" (p. 10).

Summary of Recommendations

A peer approach to instructional improvement is recommended over an administrative/teacher team approach. The peer approach provides a better opportunity for teachers to receive more frequent, varied, focused, and valued feedback about teaching concerns, and it creates a more positive environment for the instructional growth process. Providing adequate time to employ the peer process is an acknowledged problem.

Summary of Findings

Peer supervision to improve instruction offered teachers useful, relevant feedback opportunities in which to share expertise, improve faculty communications, and improve teacher attitudes about supervision for instructional growth.

PEER OBSERVATION FEEDBACK AND BEHAVIORAL CHANGE

Studies on peer observation feedback have investigated the effects of collegial feedback approaches on teachers in 
the three general areas organized below: (a) Instruction, (b) attitude, and (c) working environment. Within these general categories, studies speak to issues of inservice training, evaluative functions, student performance results, time requirements, and problems associated with a peer observation approach. While the peer group arrangements in these studies vary from one-on-one to small-group observations, all but one study involved in-person peer observations of the classroom. Studies on peer observation differ in design to include experimental, interview, and case study investigations.

Peer Observation Feedback for Instructional Improvement

Peer observation affects the performance of teachers when learning new behaviors. Young (1970) studied the performance outcome of six intern teachers who participated in videotaped micro-teaching peer observation sessions as compared with five intern teachers observed by a supervisor in micro-teaching sessions. The findings indicated that peerobserved interns performed a significantly greater number of specific teaching behaviors in the first sequence of teachreteach, and in the second sequence of teach-reteach, peerobserved interns performed significantly better verbal and nonverbal reinforcing behaviors than those observed by a supervisor.

Sparks (1983) studied the class time behavior of 19 junior high school teachers all of whom received initial 
workshop training on the effective use of teaching time. One group received peer observation, another received trainer-provided coaching, the third received only the workshop. Results of this study reflected that most teachers in the workshop plus peer observation improved in the use of time, and fewer than one-half of the teachers in the other two groups showed improvement in behavior on use of class time. The study reported that improving teachers tended to believe in the practices and expressed a sense of selfefficacy where the non-improvers tended to reject the practices and expressed low expectations as an outcome. Sparks concluded that peer observation enhanced teacher improvement efforts.

Brophy (1979) trained teachers to observe colleagues in the classroom on questioning behaviors toward students who answered, did not answer, or answered with a wrong response. The results indicated that teachers improved questioning strategies with low-participant students without adversely affecting high-participant students. Student feedback to teacher behavioral changes was positive and affected further teacher improvement. Brophy concluded that teachers profited from peer observation techniques that maximized student learning, when the feedback was relevant to their needs and involved areas of interest, and where teachers determined the focus of the observation. Brophy further observed that peer observation encouraged shared 
expertise; enhanced professional development attitudes; and contributed to the morale and effectiveness of the faculty as a group.

Research studies on effective inservice training models included peer observation as a feature of the investigations. Feldons and Duncan (1978) investigated instructional behavior changes stimulated by inservice training and goals directed by teacher. Twenty elementary teachers were trained in classroom observation techniques as well as a systematic observation process. Treatment groups included peer observation and feedback, goal setting with peer observation, and goal setting with peer observation and feedback. Teachers determined their own goals for improvement. Results of this study indicated that significant changes in behavior occurred in the groups that received feedback, goal setting, or feedback and goal setting treatments. Each of these groups received peer observations, and the authors concluded that peer observation feedback promoted instructional behavior change of those teachers who chose for themselves the nature and direction of the change. Mohlman, Kierstead, and Gundlach (1982) investigated a staff development model which involved small-group workshops, peer observations, post-observation analysis and conferencing, and experimentation with new practices. In teams of three, 14 junior high and one senior high school teachers 
performed the steps of the model using student behavior onand-off-task as the focus for teacher improvement. The results of this study indicated that peer observation was successful in improving teaching by decreasing student offtask behavior, increasing academic-instruction, and increasing awareness of expectations and differential treatment of students. The authors add that the group sharing and support was of most value, specific and practical techniques were easily transferred to the classroom, and the collegial spirit generated by this model served as a source of reinforcement for teacher improvement. Research studies on effective inservice training models included peer observation and coaching as a focus of investigation. Peer coaching is distinguished from peer observation by the repeated classroom observations among the same colleagues over extended time. Mohlman, Kierstead, and Gundlach (1982) arranged 20 junior high school teachers into three treatment groups which included workshop only, workshop with peer observation, and workshop with trainerprovided coaching. The training focused on teacher techniques of raising student time-on-task. The results indicated that teachers with peer observations in the classroom showed the most gain because peer observations were studentfocused. On-site coaching from a trainer was not as effective as peer observations. The study concluded that peer observation was a fairly powerful intervention for 
improving instructional behavior when it was non-threatening and coupled with small-aroup problem-solving workshops.

Showers (1984) investigated the effectiveness of a training model for teacher improvement which employed teachers instead of trainers as coaches to colleagues when learning to transfer new strategies to the classroom. Six peer coaches and 21 teachers from middle and junior high schools were instructed in two new models of teaching and they chose a third model of their own. While teaching and coaching took place, uncoached teachers were observed and students in all groups measured. The results indicated that teachers could be trained to coach their peers in a school environment and that on the whole, peer coaching significantly increased the ability of teacher to transfer new models into their teaching repertoires. Students of coached teachers performed slightly better than students of uncoached teachers,

In a similar study on peer coaching, Showers (1983) focused on problems encountered by peer coaches and colleagues while trying to transfer training to the workplace. Teachers were tested for high and low conceptual levels, and over five weeks of observations and conferences, 17 experienced junior high school teachers practiced three new models of teachng. Results indicated that coaching seems to have been a necessary condition for transfer of training, and teacher conceptual level did not override this 
treatment. Teachers perceived difficulties of adopting new strategies because of the appropriateness of the models for their curriculum, the time consuming nature of the process, changes in student response to the new strategies, and personal feelings about the models to be adopted.

\section{Peer Observation Feedback and Teacher Attitudes}

Studies which investigated teacher attitudes explored the effects of a peer observation process as a means to change teacher response to supervision. Horton (1974) experimented with the attitudes of 40 selected teachers toward self and peer evaluation using two treatment groups and one control group. The treatments consisted of workshop training followed by peer observations and workshop training alone. Pre- and post-tests were administered to all participants. The results indicated that those with peer observations became more critical of themselves and their negative attitudes decreased. They began to see themselves more accurately because of the peer observation feedback and their verbal behavior changed from a teacher-centered to a student-centered environment in the classroom. Students of teachers who received peer feedback changed in a positive direction and their post-test scores were significantly different from students of teachers not receiving peer feedback. 
Holm (1978) studied attitudinal changes of interns and teachers participating in peer observation with interns and teachers not receiving peer observation feedback. Teachers worked in pairs, selected their own criteria on which to be evaluated, observed each other, provided feedback, and developed plans for improvement. The results of this study indicated that peer observations improved the use of evaluative feedback from colleagues, it was perceived as more beneficial than administrator observations, and peer observations provided a valuable opportunity for teachers to gain knowledge by observing their partners. Negative feedback from peers did not cause teachers to view teacher evaluations as less sound. Holm (1978) cautioned that teacher commitment to the peer observation process is vital for a thorough and careful job in each step of the process.

Research describes the effect of utilizing clinical supervision formats for peer observation programs. Following the clinical supervision guidelines of Cogan (1973) and Goldhammer (1969), Smyth and Colin (1983) engaged 14 teachers from five schools in a peer observation process. Working in pairs, the teacher performed cycles of observations, analysis, and data discussions on improvement goals. The results indicated that peer supervision was a powerful means of converting ideas into action. Teachers tried new ideas and developed personal knowledge toward change. The authors concluded that the program benefits of 
trust, collegiality, and collaboration are best achieved through voluntary involvement by teachers. Smyth and colin (1983) emphasized the necessary support role from principals in the form of available planning time, attention to nurturing the process, and fostering encouragement and feedback from others outside the school. Ellis, Smith, and Abbott (1979) developed an instructional improvement program based on the methods of clinical supervision and peer observation. In teams of three, a teacher with a particular need was paired with two teachers who could offer assistance in that area. Observations occurred over a five-month period. At the end of one year, the authors found that teacher attitudes had changed toward supervision. Teachers did not feel a need to alter style when observed, they lost much of their fear for impending observations, they felt at ease inviting fellow teachers into class to observe them, and teachers felt classroom observations by their peers helped improve their teaching. Dodge (1981) experimented with the effects of a peer supervision training model on anxiety, satisfaction, and type of feedback received. Ten counselors in two groups were provided workshop experience in supervision, a manual on supervision techniques, and individual and group supervision. One group of five counselors came from five different schools, the other group of five were from the same school. Results of the peer supervision training program 
showed that the members' anxiety level did not decrease over both groups. However, there was a significant increase in the amount of time each group devoted to delivering constructive feedback and there was a significant improvement in the quality of feedback given by each group. Those participants from the same school showed significant increase in the satisfaction level for peer supervision as compared with the group of counselors from different schools.

Williams (1981) followed similar lines of inquiry in testing the effects of a peer supervision model on aspects of human relations, instructional behavior, and observation methods. Sixty-two volunteers from elementary and middle schools were compared with 41 randomly selected teachers from five elementary and middle schools. The experimental group was exposed to a peer supervision model, and all participants were measured by tests of attitude, appraisal of teaching, and intrinsic job satisfaction. The results indicated that teachers exposed to peer supervision scored significantly higher on attitudes toward supervision, teacher's instructional behavior, and teacher's instrinsic job satisfaction than those not exposed to the peer supervision model. The differences in scores were attributed to the impact of peer supervision on teacher behavior, attitude, and satisfaction. 
Peer Observation and the Work Environment

Few have researched peer supervision in relation to the organizational structure of the school. One study by Nelson, Schwartz, and Schmuck (1974) studied collegial supervision under the conditions of two types of organizational development in primary schools: (a) organizational development training for all staff members, and (b) group development training provided only to the leadership group. The two groups were compared for teacher satisfaction, professional sharing, communication adequacy, and student attitudes as peer supervision interventions occurred. The evidence suggested that training in collegial supervison can improve attitudes and professional interdependence, and these effects were even stronger when collegial supervision was combined with organizational development training for the entire staff. Under these conditions, the study concluded that collegial supervision interest spread through the teachers in the upper grades and participant satisfaction with their colleagues and with the sharing of ideas and techniques was improved. In schools with group training for leaders only, there was not spreading of favorable effects from peer supervision.

A second study by Storm (1981) developed a peer observation program on the premise that clinical supervision was better purveyed by a fellow teacher with no evaluative 
mission than by an administrator who must attempt to create a sense of collegiality in spite of acknowledged evaluative responsibilities. The author developed a model for peer clinical supervision through inservice workshops with elementary and high school teachers. There was substantial resistance to the peer supervision proposition among secondary staff and positive response to it by elementary staff. One source of resistance may have come from the notion of teacher autonomy, and that conventional supervision had a residual effect on the peer model. How teachers actually carried out the task of peer observation showed an unmistakable imprint of their prior evaluation-based experience. This unexpected spill-over effect helped explain general teacher apprehension about the aims of peer observation and their tendency to avoid the process. A second source of resistence may have resulted from the organization of the school. Loose-coupling and organizational anarchy offer an explanation of skepticism revealed by secondary teachers. Storm (1981) concluded that peer observation can be a positive force to change instructional behavior but only after numerous critical variables are recognized which bear on its success.

A third study by Little (1982) offered insight into workplace conditions and norms of collegiality and experimentation. This extensive case study provided a basis for identifying the norms of interaction in the school as a work 
setting and the prospects of practices for school improvement. Little classified six urban schools by success and staff development involvement and formulated characteristics of the desirable high success and high staff involvement schools. The characteristics relevant to peer observation practices are the building work practices which encourage teacher interaction, provide a location for teachers to convene, schedule a time for teacher talk, discuss teaching practices on a concrete level, select interactions relevant to teachers, and hold a high degree of reciprocity or equality of effort. Little concluded that teacher will gain competence on the job in an environment where there is a norm of collegiality and a norm of continuous improvement. Staff development occurs when it stimulates or strengthens positive work practices while building knowledge and skill in instruction.

\section{Summary of Findings}

Peer observation feedback changed teacher behaviors. Peer feedback improved the performance of teachers learning new skills, enhanced professional attitudes, and improved the morale and effectiveness of the faculty. In peer coaching arrangements, peer observation was effective in increasing the ability of teachers to transfer new strategies when coaching occurred in a non-threatening environment. Peer observation improved teacher attitudes about supervision, 
enhanced the ability of teachers to view themselves more accurately, fostered peer relationsiips where trust and collaboration developed, and increased teacher job satisfaction levels. Peer feedback was effective where the program was voluntary and when teachers were allowed to select their own goals for instructional improvement.

\section{FEEDBACK VARIABLES AND BEHAVIORAL CHANGE}

Feedback to teachers is integral to the purpose of a peer observation approach to instructional improvement. If teachers receive peer feedback, will teaching behaviors be improved because of this feedback? Research studies investigating the impact of feedback on worker performance offer general agreement that feedback is an important ingredient to improving performance output. For example, Bigby (1981) studied types of feedback on worker performances. The findings revealed that under all conditions, feedback improved performances. When goal setting was added to feedback, participants improved performances over feedback alone. Bigby reported that worker satisfaction levels improved under both feedback and goal setting interventions from levels before these treatments. Educational research which applies the impact of feedback on teacher performance output offers similar agreement on the role of feedback in changing performance behaviors. 


\begin{abstract}
Moore, Schaut, and Fritzges (1978) concluded that feedback can bring about teacher behavioral changes. Inservice teachers gave significantly greater attention to high-need students than to low-need students by initiating more continued questioning to students giving wrong responses. The researchers concluded that when teachers are given feedback associated with ti:eir behavior, both their behavior and ultimately the students' behavior changes. Good and Brophy (1974) studied teachers to see if they could
\end{abstract} change in response to feedback alone without any retraining or continuing supervision. Results of this study indicated that teachers changed behavior with the target students. Good and Brophy concluded that the consultation feedback approach for awareness of teacher behavior was effective to target students without detriment to non-target students. The type and amount of feedback affects behavior. In a five-year study of 174 intern teachers, Fulier, Peck, Brown, Menaker, White, and Veldman (1969) measured three kinds of psychological feedback on teacher preparation, personality, and behavior. The investigators concluded that those with the most feedback were most positive to testing, filming and feedback. In addition, feedback was valued positively by prospective teachers and receiving personalized feedback increased positive attitudes. 
The source or feedback affects behavioral change. Tuckman and oliver (1968) experimented with teachers receiving feedback from students, supervisors, students and supervisors, and no feedback. The results of studying 286 teachers indicated that student feedback led to a positive change among teachers, supervisor feedback added nothing when combined with student feedback, and when supervisor feedback was given alone, it produced change in a direction opposite to the feedback. Teachers receiving feedback changed more than teachers not receiving feedback. Following the line of research where student feedback influenced teacher behavior, Daw and Gage (1971) questioned whether teacher feedback would influence principal behavior. The results of their investigation of 455 elementary principals indicated that feedback from teachers effected changes in the principal's behavior. Principal improvement behavior was ascribed to the feedback alone and was not a function of the measurement interval, age, experience; or leadership styles of principals.

\section{Summary of Findings}

Feedback was effective in changing teacher behavior when it stimulated teacher awareness of certain behaviors, occurred frequently and in a variety of modes, when it was personalized, and when the source of feedback was valued. 
THE EFFECTS OF TYPES OF FEEDBACK ON BEHAVIORAL CHANGE

Where feedback can be effective in changing teacher behavior, some types of feedback appear to be more effective than others in promoting instructional change. Researchers have investigated the effects of different types of feedback on influencing behavioral change. The types of feedback most studied are: (a) videotape replay of lessons, (b) micro-teaching lessons, and (c) modeling demonstrations. Experimental studies generally compare types of feedback interventions to each other or to no feedback, and findings reflect the degree of effectiveness of one type of feedback to another.

Videotape Feedback and Behavioral Change

Because of its accurate replay capabilities, videotape technology has inspired research into its effectiveness as a feedback tool for self and supervisor viewing. Fuller and Baker (1970) have summarized the two basic approaches to research in the area of videotape feedback as (a) modeling, where stimuli, response, reinforcement, and reward are utilized to obtain desired responses and (b) self-theory, which sees man having within himself the ability to recognize discrepency between his and desired behavior thus committing himself to change. Examples of both approaches are presented in this review. 
Salomon and McDonald (1969) studied the reactions of intern teachers to self-viewing their performances on videotape when no standards of good teaching were set for the interns. The findings indicated that when no standards are set, intern reactions to self-viewing of teacher performance were determined largely by the viewer's predisposition. The researchers suggested that self-viewing on videotape will not lead to desirable attitudinal and behavioral changes unless it serves as feedback about the amount of departure there exists from a standard or desired performance. McDonald, Allen, and Orme (1967) confirm the ineffectiveness of self-feedback condition when training interns to evaluate their teaching on videotape. The authors concluded that in self-viewing, the interns do not know when to give feedback to themselves.

Eder (1971) studied the effectiveness on changing foreign language teacher behavior when using the videotape and self-criticism alone. The findings indicated that selfviewing was ineffective in producing desired changes in teacher behavior.

Collie (1972) studied the effect of videotape replay on self-evaluation of teaching. Undergraduate education majors who had seen the videotape replay rated themselves significantly higher than those who had not. The researcher concluded that videotape replay provided informational feed- 
back to those who receive it as compared to those who did not.

Videotape self-viewing effectiveness improved when participants were offered guidelines for evaluating teaching behaviors. McDonald, Allen, and Orme (1967) found that interns responded most effectively to training where cue discrimination reinforcement was provided by the instructor at the time of videotape viewing. McDonald and Allen (1967) confirmed the value of videotape feedback when supplemented with written and verbal instructions. They added that the optimum treatment was verbal and written instructions combined with the desired behaviors modeled on videotape. Videotape self-viewing affects evaluation accuracy. Carl (1972) tested student teacher ability to observe and collect verbal behavior information from videotape recordings on self and on a peer after being trained to identify and code behaviors. The results indicated that student teachers were able to record teacher questions and responses accurately when observing themselves on videotape and when observing a peer on videotape. Participants recorded accurately without prejudice to whether they perceived the information as positive or negative in relation to their teaching behavior.

Krajewski (1971) investigated intern teacher behavior change using the Flanders Interaction Analysis Matrix, attitude and self-perception gains, and student and supervisor 
ratings of videotaped teaching segments. The results indicated that interns receiving videotape feedback were less idealistic toward the evaluation of self and were more nearly accurate in their perception of self as well as more positive in attitude.

Walz and Johnson (1963) studied the reactions of counselors after self-viewing a counseling session. The results indicated that counselors accepted others' judgments of their professional skills more readily after self-viewing and they became less positive in their own self-evaluation. Videotape feedback complements other methods of feedback. Shreeve (1978) compared methods of feedback to determine their effect on performance of medical students. Methods of feedback used were instructor, checklist, and videotape. The findings indicated that while no single feedback modality was totally effective at changing performance, checklist and videotape feedback together were as effective as instructor feedback and, except for confidence ratings, every measure where instructor feedback was effective, either videotape or checklist was also effective. Kagan and Krathwohl (1967) used videotape replay with counselors to help participants relive the experience and interprete feelings, motives, and behaviors. His study confirmed the value of videotape replay when combined with other sources of feedback for analyzing behavioral outcomes. 
Three studies report no effect from the use of videotape replay as compared to other feedback modes. In supervision situations, Hill (1972) found no difference in behavioral changes of secondary education majors exposed to videotape replay experiences as compared to students receiving traditional supervision. The students taught five, five-minute micro-teaching lessons of which three lessons were specific in structure and emphasis. Levine (1978) investigated the effects of verbal classroom behavior of teachers in classroom observations and videotape selfobservations. After all participants received workshop training on observing teaching performances, neither the teachers in the study who received videotape feedback nor the teachers who did not receive videotape feedback significantly altered their verbal classroom behavior as compared to the control group receiving no treatment. Roush (1969) investigated the role of videotape on intern teacher behavior. The findings of this study indicated that videotape feedback to teacher-interns did not produce behavioral changes significantly different from those who did not receive any feedback. Additional inputs of critiques and type script feedback did not produce behavior change significantly different from those who received videotape feedback.

\section{Micro-teaching Feedback and Behavioral Change}

Research has provided insight into the value of microteaching for behavioral change. McDonald (1973) concluded 
from his research that the use of micro-teaching was effective as a means of practicing the techniques to be learned and of applying behavioral modification principles. Barron (1967) concluded that micro-teaching was effective as part of the training of interns to enhance growth in teaching effectiveness. The findings showed that those who microtaught lessons experienced significant growth in openness as compared to their counterparts who observed in school classrooms.

Tremba (1975) found micro-teaching and modeling equal1y effective in changing the questioning behavior of in-service social studies teacher when combined with structured videotape feedback. The teachers were practicing the skill of asking higher-level questions.

Ward (1970) studied 78 elementary teachers in 15 schools to determine the effect of micro-teaching sessions on teacher questioning. The results indicated the effectiveness of the treatment depended upon the amount of time in which subjects utilized the evaluative procedures of micro-teaching. While the distributed time group proved superior to the one-shot experiment, no significant residual effect was found to exist one month after the study was over in either of the time treatment groups.

Modeling Feedback and Behavioral Change

Research studies have examined the effects of written, pre-recorded, and in-person modeling on changing teacher 
behavior. Koran, Snow, and McDonald (1971) measured the frequency, variety, and quality of analytical questioning among 121 intern teachers by comparing groups receiving written modeling, videotape modeling, and no modeling. On all tests, written and videotape modeling groups had higher results than the group without modeling. On all tests, the videotape modeling group scored higher than the written modeling group. The authors concluded that the level of learning of a specific teaching strategy varied as a function of the model presentation where written modeling was less effective than videotape modeling. McDonald and Allen (1967) confirmed the notion that learning varied as a function of model presentation when studying groups of interns exposed to symbolic or written and verbal instruction only, perceptual or videotaped modeling only, and a combination of symbolic and perceptual modeling. The results reflected that the least effective condition to learning was repeated exposure to written instructions. Improved conditions to learning occurred by adding verbal cues and visual models. The most optimum treatment to bring about the learning of desired behaviors was symbolic and perceptual modeling procedures combined. Videotape modeling effectiveness has been studied as a tool of observation and learning. Bailey (1969) compared in-person observation with videotape observation among 50 college methods students. In-person observers made visits 
to local schools, and videotape observers analyzed selected teaching-learning situations. Results showed that students who observed classroom teaching-learning situations on videotape achieved significantly higher scores on essay tests than students who observed in schools. There was a statistically significant difference on 11 of the 18 functions of observation between the two groups. Young (1968) trained pre-service teachers to lecture by emphasizing repetition and redundancy. The procedures involved training teachers without giving direct supervisorstudent conferences, training by means of recorded supervisory comments on the videotape recording, and training by modeling teaching skills and focusing attention. Results indicated the most effective modeling procedure was a combination of viewing the specific illustrations on videotape accompanied by supervisor comments at the time students viewed their videotapes of teaching.

Eder (1971) concluded, after working with foreign language teachers, that the use of modeling with videotape is significantly more effective than videotape alone in producing desired changes in teacher behavior. Ward (1970) found elementary teachers changed behavior positively when exposed to a model videotape, purposeful direction, and self-evaluation with and without videotape replay. The length of time subjects utilized these procedures influenced the teacher's learning. Tremba (1975) concluded that 
modeling videotape and micro-teaching videotape were equally effective in changing the questioning behavior of social studies teachers.

\section{Summary of Findings}

Videotape self-viewing feedback was ineffective in changing behaviors when standards for performance were not set. When teaching standards were known, videotape selfviewing feedoack effectiveness improved; teachers became less idealistic, more accurate in self-assessments, and more accepting of other's judgments after self viewing. Videotape feedback was complemented by other methods of feedback, however supervisor feedback added the least impact when measuring behavioral change. Micro-teaching feedback was effective in changing behaviors when practicing specific techniques. Modeling feedback was least effective in changing behavior when used alone. Modeling feedback increased in effectiveness when written or verbal comments were added and was most effective in changing behavior when accompanied with videotape replay.

\section{PROBLEMS ASSOCIATED WITH PEER SUPERVISION PROGRAMS}

In addition to concerns over time commitments noted earlier (Abramson, 1972; Lempesis, 1984; McGee \& Eaker, 1977; Showers, 1985), several authors addressed limitations to peer supervision programs. Holm's (1978) study revealed that problems remain with putting this program into the 
current school system. Holm emphasized that teachers cannot participate in this program in a haif-hearted way, and they must commit to doing a thorough and careful job at each step of the way.

Lawrence (1985) stated that skeptics "question whether teachers actually would render reliable and valid (read: rigorous) evaluations of people they might have worked alongside for years" (p. 23). Diamond (1975) described the negative aspects of peer observations as being time consuming, having questionable validity, and lacking peer competence to observe and give feedback.

Showers (1985) warns that peer coaching "is not a simple additive that can be tacked on to the school with a 'business as usual' attitude, but rather represents a change in the conduct of business" (p. 48). McFaul and Cooper (1984) suggested peer supervision will have little success at improving instruction. The authors concluded that peer programs are bound to fail where "the needs of collegiality and trust in a peer supervision approach are incongruent with the prevailing isolation of teachers and with the fragmentation and hierarchical power structures of schools" ( $p$. 4).

THREE TEAM SUPERVISION PROGRAMS IN OPERATION

The research reflects results of programs where peer observation and supervision practices perform an evaluative 
function. The three programs described here represent a team approach where administrator/tcacher teams supervise and evaluate instructional improvement.

Mattaliano (1982) described the program at Leahy Elementary School in Lawrence, Massachusetts where four teams of six teachers supervise each other in a clinical supervision format with the principal as evaluator and supervisory leader of each team. Faculty feedback concluded that peer supervision was valuable for seeing each other teach, learning to supervise and analyze instruction, rewarding colleagues, developing non-threatening relationships, and receiving individual help toward professional growth. Mattaliano emphasized the importance of the evaluator role of the prinicpal and the need for strong principal support.

McPike (1984) described the Toledo, Ohio plan in an interview with Dal Lawrence, president of Toledo Federation of Teachers. The Toledo plan started in 1981 and has two components: (a) The intern program where all beginning teachers are assigned to experienced teacher who supervise and evaluate them, and (b) the intervention program which helps veteran teacher with problems. The program is overseen by a joint labor-management review panel on which teachers hold the majority vote. In comparing this peer supervision program with the old system, McPike noted that new teachers are given a better opportunity to succeed with 
a high degree of individual attention in correcting problems, teachers with subject-matter expertise are offering ideas and strategies, veteran teachers with problems are receiving help to improve instruction, and principals were freed from the burdens of lack of time and expertise to supervise and evaluate. Lawrence (1985) explained that the shared governance in the Toledo plan has created a stronger relationship between teachers and principals, and a more competent, concerned instructional staff. He noted that the Toledo plan nearly failed at inception because of administrator resistance to loss of power. The Toledo plan was the model for the Cincinnati school system peer review plan. Since 1975, the Salt Lake City School District has employed a peer evaluation system which combines instructional improvement with summative evaluation. This program is similar to the Toledo Plan, both having the dual purpose of teacher improvement and teacher evaluation. Benzley, Kauchak, and Peterson (1985) interviewed 39 teachers who participated as peer evaluators inquiring about the personal dimensions of being a reviewer and the impact of the peer review process on professional relationships. The findings reflected some problems related to the personal dimensions of being a peer reviewer. Peer reviewers expressed concern for extended absences from their classrooms, extensive time commitments, emotional and physical stress in judging peers, disagreements among team members, and obtaining quality 
substitutes. The authors concluded that there was a high level of teacher acceptance for this process, most felt it was fair, and most would participate again. Indirect gains from being a peer reviewer included self-reflection, professional involvement, and a personal perspective for improving one's own teaching.

SUMMARY OF THE LITERATURE REVIEW

The concept that teachers can successfully supervise teachers for purposes of instructional improvement is validated in the literature. While team approaches are effective, peer supervision is desired because of the positive benefits which accrue in improving instruction, creating an environment conducive to change, and developing a climate of trust and collegiality. Benefits documented are frequent and specific feedback, more rigorous monitoring, more practice on new strategies, the opportunity to view others teach, cooperation and trust relationships, and engendering professionalism and teacher self-esteem.

Perhaps more valued than other benefits is the feedback opportunity provided by peer supervison. Peer feedback improves teaching behaviors. Students of teachers receiving peer feedback perform better than students of teachers not receiving peer feedback, and peer feedback increases the teacher's ability to learn new strategies. Peer feedback improves the use of evaluative information from colleagues, 
encourages more accurate critiques of teaching behaviors, and stimulates teachers to try new ideas. Fears and anxieties are decreased in peer supervision approaches, and, in general, attitudes toward observations and toward job satisfaction improve. Peer supervision encourages sharing with other teachers in the organization and teacher talk about instruction increases.

The amount, source, and type of feedback affect the changes that teachers will make. Teachers who receive the most feedback are the most positive toward supervision and show the greatest change. Multiple sources of feedback (students, peers, supervisors) can influence change, however supervisor feedback added the least impact when measuring behavioral change. The use of videotape as a means of feedback is effective. When videotape replay is used in conjunction with written, oral, and modeled behaviors, it is the most effective means of creating teacher change. Selfviewing of videotapes has improvement value when performance standards are known. Observers can accurately assess teaching behaviors from videotape replay and the judgments of others are more readily accepted. Micro-teaching feedback is useful in practicing specific techniques and in developing growth in openness among colleagues. Modeling feedback is most effective when used in videotape replay accompanied by verbal analysis. 
These recommendations and research findings offer insight into the effects of peer observation interactions on instructional improvement where group structure, behavioral change, feedback variables, and sources of feedback are considered. The results of the case study under investigation add to this research base by considering the effect of peer observation for instructional improvement on selected norms, perceptions, and expectations of a veteran high school teaching staff. 
CHAPTER III

METHODOLOGY

INTRODUCTION

A review of the literature documented that teaching behaviors improved, positive attitudes about supervision feedback developed, and collaboration with peers on instructional matters increased after teachers participated in a peer observation process for instructional improvement. Would similar changes occur when the peer observation process was implemented at Lake Oswego High School?

The plan of investigation to determine the effects of a peer observation process on selected areas of norms, perceptions, and expectations among teachers was to (a) identify the teachers who would volunteer for the peer observation process, (b) obtain their agreement to be participants in this case study investigation, (c) document the activities and experiences of participants while they were being observed and were observing peers, (d) analyze the data for changes in teachers' perceptions, and (e) compare these analyses with behavioral changes in the six selected areas related to norms, perceptions, and expectations. 


\section{CASE STUDY QUESTION}

What will be the impact of peer observation on selected norms, perceptions, and expectations of teachers who teach within a specific high school setting?

\section{CASE STUDY DESIGN AND CONSTRAINTS}

Case Study Design

Guided by Yin's (1984) definition below, it was determined that a single-case study research design would be appropriate for the present study.

A case study is an empirical inguiry that:

- investigates a contemporary phenomenon within its real-1ife context; when

- the boundaries between phenomenon and context are not clearly evident; and in which

- multiple sources of evidence are used. (p. 23)

The rationale for the design meeting the requirements specified by Yin is described below:

Case studies focus on contemporary events. Peer observation is a process of helping teachers at the time when and in the context where instruction occurs. Classroom instruction was videotaped and teachers viewed and discussed the taped instruction within the context of regular teaching assignments and normal school-day routines.

Where distinctions between event and context are not clear, case studies are the preferred strategy of design when the investigator has little or no control over relevant behaviors or the context in which the behaviors occur. The 
present investigation seeks to explain the effects of peer observation. Effects may be influenced by the content, mechanics, and other factors of the program not clearly distinguishable from each other. As an interactive process peer observation included a variety of individually tailored activities with multiple groupings of teachers and interchanging group members. Interaction among teachers included variables such as group composition, teaching activity, requested feedback, and taping and observational arrangements which were not within the investigator's ability to control.

Where distinctions between event and context are not clear, case studies provide a means of linking operational events over time. Teachers were observed and viewed peers at times convenient to their schedules over the course of each school year. Data gathering activities occurred over a period of time and after a variety of teacher experiences with the process. Relevant behaviors in the process could not be manipulated, and teacher involvement by incident or frequency was not the means by which results of the effects of peer observation would best be obtained. Case studies allow for a variety of sources of evidence which research designs such as experiments, surveys, and histories do not. The sources of evidence being relied upon here are (a) direct observation, (b) systematic interviewing of key informants, (c) on-going written 
documentation of peer discussion groups, (d) principal's questionnaire, and (e) investigator assessment instruments. Further, the use of multiple sources of evidence provided support for the results obtained from investigating selected issues. The process of triangulation in single investigations enables better consideration of relevant rival causal factors relating to issues of validity.

\section{Case Study Constraints}

Peer observation for instructional improvement is an interactive process involving multiple variables. The study analyzed data about the peer observation process to determine changes in selected norms, perceptions, and expectations about teaching. The conditions of a single case study with uncontrolled variables where results are based upon qualitative research methods may cause some concerns about factors of validity and reliability. Three constraints to be considered when conducting this investigation were identified and their mitigation explained.

One constraint of this study was the single-case design. Single-case designs 1 imit the extrapolation of findings to other populations. The ability to extrapolate findings in order to generalize utility for a larger population relates to the external validity of the research. Yin (1984) offers an approach for case studies: 
The external validity problem has been a major barrier in doing case studies. Critics typically state that single cases offer a poor basis for generalizing. However, such critics are implicitly contrasting the situation to survey research, where a 'sample' (if selected correctly) readily generalizes to a larger universe. The analogy to samples and universes is incorrect when dealing with case studies. This is because survey research relies on statistiral generalization, whereas case studies.. rely on analytical generalizations. (p. 39)

To mitigate potential weaknesses of external validity, the case study findings are generalized to accommodate documented theory and research about peer supervision and the role of feedback in changing behavior. Where peer observation generalizations are supported by theory and research, it is reasoned that conclusions from this case study will apply to a larger population of similar high school settings.

It is acknowledged that the peer observation process which developed was a product of the staff and ambience of Lake Oswego High School. While the operations of the process might be repeated successfully, there are factors which might influence the results of a collegial interactive process that are outside the limits of this study. Several of these factors are leadership style, building climate, and staff disposition. Given this bias, I have provided procedural documentation which verifies the belief that if peer observation is being considered as a means for improving instruction in other schools, a process for peer observation 
implementation will emerge in the context of the operation of the particular school system.

A second constraint to this study was the extensive use of qualitative research methods which decreased the control over rival factors. Concerns over conditions of internal validity suggested by Denzin (1970) are "time and its passage; the situations of observation; characteristics of those observed; characteristics of the observer; and interaction among any of the preceding four elements" ( $p$. 21). The investigation of the peer observation process is not a causal study, in that the intent is not "to determine whether event X led to event $Y^{\prime \prime}$ (Yin, 1984, p. 38), rather it is a descriptive-exploratory study which is subject to the broader problem of making inferences. Any time an event cannot be directly observed, an inference is involved. Based on interview and documentary evidence collected, the investigator will make inferences.

The correctness of inferences and the consideration of rival explanations need to be examined. To mitigate potential weaknesses of internal validity, I employed the tactic of pattern matching among multivariate methods of data collection. My observations coupled with on-site written reports, interviews, surveys, and assessment instruments provide sources of evidence within which the findings are linked over time and among peer group interactions. 
In addition, investigator obtrusion was minimized. Little mention was made of the on-guing investigation; and an attempt was made by me to maintain a low profile by incorporating peer group reports into the process activities, by utilizing data gathered by the principal, and by participating in the process under the same conditions as my colleagues.

A change of principals in the second year was an unforeseen event, and the effect of this change is unknown. However, since the peer observation process activities were entrenched by the end of the first year and not altered in the second year, the role of the principal was not expected to affect data collection and analyses of the process.

A third constraint to this study was the degree of reliability obtained. Yin (1984) states:

The goal of reliability is to minimize the errors and biases in a study. The general way of approaching the reliability problem is to make as many steps as possible as operational as possible, and to conduct research as if someone were always looking over your shoulder. (p. 40)

The approach here is to provide a model of the peer observation process for potential implementation in school settings. As such, the case study offers a procedural overview to aid the potential user in process implementation while detailing procedural steps of the working model. In addition, a base of previous research was established 
against which findings of this case can be compared and inherent biases minimized.

Organizational activities of the process were the province of the principal, which minimized investigator influence. Participation was voluntary, and no selection procedures were employed to encourage or discourage participation. All disciplines of the teaching staff elected involvement in the process with a majority of teaching disciplines represented. A majority of the total staff participated thus providing a large percentage of this school's teaching staff from which to secure data and analyze findings.

To minimize investigator influence during the data collection phase, I took several precautions. One precaution was to operationalize peer observation reports to instill the idea among participants that written feedback was integral to the process and not to provide investigative results. A second precaution was the use of multivariate methods of data collection which offered a means of triangulating similar lines of inquiry. Data secured without my presence (peer discussion reports, principal's questionnaire, investigator's assessment) were matched with data gathered through systematic interviewing by me. Finally, my observations were used as verification for patterns which emerged from other sources of information. 
UNIT OF ANALYSIS

This case study described the effects of peer observation process on selected norms, perceptions, and expectations of the participants of a high school staff. The unit of analysis in 1984-85 was identified as the 46 teachers who volunteered in writing (Appendix A) from a staff of 64 teachers. The unit of analysis in 1985-86 was the 40 volunteers from a staff of 67 .

The two-year study began in the fall of 1984 when the peer observation process was introduced to the staff and it concluded in June of 1986. The data collected included two school years of peer observation experiences.

\section{SOURCES OF EVIDENCE}

Four sources of evidence were the focus of data collection: (a) documentation, (b) questionnaires, (c) interviews, and (d) participant-observation. Varied sources of evidence provided a means to triangulate issues, receive data as events occurred, and minimize investigation obtrusion. Table I below provides a summary of the sources of evidence described in this section. 
TABLE I

SUMMARY OF METHODS OF DATA COLLECTION

\begin{tabular}{|c|c|c|c|}
\hline Instrument & $\begin{array}{c}\text { Date } \\
\text { Administered }\end{array}$ & Purpose & Source \\
\hline $\begin{array}{l}\text { Peer discus- } \\
\text { sion written } \\
\text { reports }\end{array}$ & $\begin{array}{l}\text { Continuous } \\
1984-85\end{array}$ & $\begin{array}{l}\text { Documentation of peer } \\
\text { discussions at the } \\
\text { time they occurred }\end{array}$ & $\begin{array}{l}\text { Investi- } \\
\text { gator }\end{array}$ \\
\hline $\begin{array}{l}\text { Principals' } \\
\text { Survey }\end{array}$ & June 1985 & $\begin{array}{l}\text { Assessment by } \\
\text { principal for } \\
\text { continuation of } \\
\text { program }\end{array}$ & $\begin{array}{l}\text { Lake } \\
\text { Oswego }\end{array}$ \\
\hline Questionnaire & June 1985 & $\begin{array}{l}\text { Participant response } \\
\text { to process, content } \\
\text { and feedback received }\end{array}$ & $\begin{array}{l}\text { Investi- } \\
\text { gator }\end{array}$ \\
\hline Survey & June 1986 & $\begin{array}{l}\text { Tabulation of partici- } \\
\text { pation in the second } \\
\text { year and follow up }\end{array}$ & $\begin{array}{l}\text { Investi- } \\
\text { gator }\end{array}$ \\
\hline $\begin{array}{l}\text { Interviews- } \\
\text { Department } \\
\text { Chairs }\end{array}$ & Summer 1986 & $\begin{array}{l}\text { Key informant response } \\
\text { to guided questions } \\
\text { corroboration }\end{array}$ & $\begin{array}{l}\text { Investi- } \\
\text { gator }\end{array}$ \\
\hline $\begin{array}{l}\text { Interviews- } \\
\text { Principals }\end{array}$ & Summer 1986 & Corroboration & $\begin{array}{l}\text { Investi- } \\
\text { gator }\end{array}$ \\
\hline $\begin{array}{l}\text { Participant- } \\
\text { Observation }\end{array}$ & $\begin{array}{l}\text { Continuous } \\
1984-86\end{array}$ & $\begin{array}{l}\text { Key knowledge and } \\
\text { corroboration }\end{array}$ & $\begin{array}{l}\text { Investi- } \\
\text { gator }\end{array}$ \\
\hline
\end{tabular}




\section{Documentation}

Two types of documents were used for data collection. The peer discussion report form (Appendix B) provided written evidence from each teacher in a peer group detailing the observed lesson, areas of feerback noted, topics of group discussion, and the observed teacher's reaction to peer oral and written observation feedback. Report form collection responsibilities were delegated to the observed teacher eliminating investigator contact. The observed teacher collected written report forms from peers at the end of the discussion session, reviewed written comments for personal feedback, submitted all peer report forms to the office secretary who stored the forms in a file folder for future investigative analyses. The intent of the report form was to document the peer observation process at the time the lesson was observed and critiqued.

A second document was administered by the principal. The peer observation process was established as a building goal for the 1984-85 school year. The principal's questionnaire (Appendix C) provided both an end-of-the-year reaction to the process as a tool for instructional improvement and a faculty commitment to the process as a school goal for the 1985-86 school year. 
Questionnaires

Two participants assessment questionnaires were administered by me, one at the end of each year of the study. The 1985 questionnaire (Appendix D) was designed to collect data on teachers who comr -eted the process and on teachers who participated in one or more activities of the process. It was designed for comprehensive data collection on perceptions of process, content, and evaluation of peer feedback received in the observation activities.

The 1985 questionnaire was field tested by four teachers from different departments before administration to the faculty. Results of the field test offered no substantive changes to the questionnaire. It was described at a faculty meeting and distributed in teacher mailboxes with return responses requested in one week.

The 1985 participant questionnaire (Appendix E) surveyed participating and non-participating teachers and solicited open-ended comments on the peer observation process. This questionnaire was designed as a follow up to data collected the previous year.

\section{Interviews}

At the end of the 1986 school year, interviews were conducted with seven department chairpersons and the two principals involved in this study. The interviews were focused with questions submitted prior to the interview, but 
they remained open ended assuming a conversational style. Transcripts typed from the taped interviews were edited by me for grammatical purposes and permission was granted by each interviewer for distribution to interested parties under separate cover when such requests related to purposes of this study. The intent of the interview was to follow up on previous evidence, to corroborate insights by key informants, and to search for contradictory evidence.

Interviews of department chairpersons were conducted during the summer of 1986. Questions focused on insights into feedback, modeling, and instructional improvement (Appendix F). Department chairpersons were asked for the facts of these matters as well as to propose insights into these occurrences. They were considered to be key informants and a source of corroboratory evidence.

Interviews of principals were conducted during the summer of 1986. Questions focused on procedural and conceptual matters of the peer observation process (Appendix G). Principals were asked to compare the value of the peer observation process to the administrator-directed approach to instructional improvement. Principal interviews were considered a source of corroboratory evidence.

\section{Participant-Observation}

As a veteran staff member, I performed the role of participant-observer with minimal obtrusion. Having had 
leadership functions among the staff over the years, it did not appear unusual to teachers for me to perform research functions. Key knowledge of the peer observation process was obtained through participation. I, as teacher, videotaped a teaching activity, organized teachers to observe, and completed the process for pear feedback on the lesson in both years of this study. In addition, I was asked to provide peer observation feedback in group sessions for nine different teachers. Observations were made in informal exchanges among teachers during lunch, in the halls, at break, and before or after school. Occasionally teachers would seek me out to make a specific comment; generally discussions were ongoing without notice of me. I used my observations as corroboration of evidence obtained by other sources.

DATA COLLECTION AND ANALYSES

\section{Data Collection}

Data collection was designed to gather evidence of the effect of peer observation on norms, perceptions, and expectations of teachers. Answers to the case study questions required investigation of two areas: (a) participant perceptions on the mechanics of the process and (b) participant perceptions of learning experiences within the process. By analyzing evidence from written summaries of peer sessions, 
staff questionnaires, surveys, interviews, and investigator observations, a pattern of matched responses to issues of structure and content was triangulated.

The data collection instruments were written to capture evidence about the propositions of this study. Questions asked were designed to jetermine whether teacher perceptions collectively reflected that the peer observation process (a) opened communication about teaching, (b) reinforced their desire to improve teaching techniques, (c) provided a variety of valued and useful feedback, and (d) fostered a climate where improvement of teaching could occur.

\section{Data Analyses}

Participant responses to the varied data gathering techniques were analyzed collectively. The following three stages of analyses occurred (Miles \& Huberman, 1984a):

1. Data reduction. Each method of data collection was reviewed for patterns of responses using participant wording whenever possible. Patterns of responses were clustered into three categories: (a) content, (b) structure, and (c) other. Using a variation of the case cluster method (McClintock, Brannon, \& Maynard-Moody, 1983), the categories were subdivided into recurring elements of interest for purposes of triangulation. Responses on each instrument were coded by category, element, and method of data collection 
and tabulated on color-coded $3 \times 5$ cards. Elements of interest pertinent to the framework of this study on norms, perceptions, and expectations were identified within instruments (Miles \& Huberman, 1984a) and triangulated across methods (Jick, 1983) for a collective analyses of the responses.

2. Data display. A master 1 isting of clusters of categories and elements of interest was established. Tabulations of collective responses were reported and discussed using tables and descriptions of participant responses where the data presentation would best be served.

3. Conclusion drawing and verification. The grouped responses across methods reflected tabulations of clusters of interest which were compared to the six research-based propositions of selected norms, attitudes, and expectations of teacher change. Descriptive analysis was also used to offer a measure of verification to conclusions drawn during the process of triangulation (Jick, 1983).

When consolidating and analyzing the multiple sources of evidence collected during this investigation, three verification tactics were used (Miles \& Huberman, 1984a). One was a search for confirmation of a proposition finding among other sources of data. A second was the search for conflicting evidence concerning support for a finding and determining rival causes for the findings. A third was a search for evidence which reflected the degree of intensity 
which a finding was supported. Findings which supported the propositions provided the basis for answering the case study question. Findings which did not support the propositions or were serendipitious were offered as insights not directly under study in this area.

\section{SUMMARY}

This case study addressed the questions of what will be the impac's of peer observation on selected norms, perceptions, and expectations of teachers about teaching within a specific high school setting. It was determined that a case study design would be effective because case studies are the preferred method where investigations pursue contemporary phenomenon within its real-life context where the investigator has little or no control over relevant behaviors within the context and where multiple sources of evidence are used. Potential design constraints of internal and external validity and reliability were mitigated by generalizing findings to documented theory and research, matching patterns among multivariate methods of data collection, and minimizing investigator obtrusion.

The unit of analysis under study in 1984-85 was the 46 teachers who volunteered to participate in peer observation out of a staff of 64 teachers. The unit of analysis in 1985-86 was 40 volunteers from a staff of 67 teachers. The study began in the fall of 1984 and ended in June of 1986. 
During these two years, sources of evidence were collected which included peer group report documents, end-of-the-year questionnaires, interviews of department chairpersons and principals, and participant observations.

Data collection was designed to gather evidence of the effect of peer observation on norns, perceptions, and expectations about the process of peer observation and the learning experiences within the process. The varied data gathering techniques sought evidence to determine whether teachers perceived peer observation to have (a) opened instructional communication, (b) reinforced teacher desire to improve, (c) provided a variety of valued and useful feedback, and (d) fostered a climate where improvement of teaching could occur.

Participant responses to the varied data gathering techniques were analyzed collectively. Responses were classified by structure and content categories first and divided into elements within these categories. Patterns of responses were matched across instruments and compared to the six research-based propositions of selected norms, perceptions, and expectations for teacher change. A search was conducted for conflicting evidence in support of a finding, rival causes for the finding, and evidence which reflected the degree of intensity to which a finding was supported. 


\section{FINDINGS AND DISCUSSION}

This case study describes the effects of a peer observation process on selected areas of teacher norms, perceptions, and expectations in a high school setting. Six propositions in areas of norms, perceptions, and expectations were studied for the effects of peer observation. These findings are presented in six parts corresponding to each proposition. Before findings are presented, four issues warrant discussion.

One issue is a change in methodology. The original plan was to identify those teachers electing to participate in the process each year as the unit of analysis under investigation and to follow them on an individual basis for peer observation effects. However, as peer observation activities commenced, it became clear that investigating specific individual volunteers presented problems in data gathering and limited the data available for analysis. Therefore, the unit of analysis was expanded to include all teachers who participated in any of the peer observation activities. It was reasoned that insights into the effects of peer observation on the total staff would be more thorough if data were received from all teachers who were 
exposed to the process activities. This allowed for input from teachers who did not volunteer initally but were subsequent participants, teachers who volunteered but did not complete the full process, and initial non-respondents who later participated. Further, the task of monitoring the peer observation activities of selected individuals was logistically impossible as participants met at times convenient to their schedules and the task of isolating selected participant feedback from other non-selected teacher participants interacting together in the same activities did not seem feasible.

A second issue is a change in the name of the process from "peer coaching" to "peer observation." This change was initiated by the investigator after the first year. The process was introduced to the faculty as "peer coaching" where teachers worked with teachers in the manner of a coach to an athlete. This repetitive activity implies continuous, on-going contact with the same people as defined by the originator of the term (Showers, 1984) which was not the format of this program. The term "peer observation" was offered as an alternative to describe more accurately the process of the program under study. There is carry-over usage of the term "peer coaching" on instruments and participant responses. Where this appears, "peer coaching" is intended to mean "peer observation." 
A third issue is the decrease in teacher participation from the first year to the second year of this study. Table II below represents the staff counts, the number of staff volunteers, and the actual results of participation each year with corresponding percentage rates for comparisons. Data were compiled from school personnel listings in 1984-85 and 1985-86, and participant response tabulations.

TABLE II

COMPARISON OF STAFF, VOLUNTEERS AND PARTICIPATION IN 1984-85 AND 1985-86

$\underline{1984-85}$

53

11

64
Staff Counts

Full-time teachers Part-time teachers Total teaching staff

8f (64) 1984-85

72

20

8

q (46) 1984-85

87

15

9

102

40
7
4

47
Staff Volunteered

Elected to participate El ected not to participate No response

Participation Results

Completed full process Completed partial process Elected to participate, did not complete full/partial Total participation $\underline{1985-86}$

55

12

67 
part-time, and probationary teachers. At the end of 198485, there were 47 teachers who had participated indicating a participation rate higher than had volunteered $(102 \%)$ and a drop-out rate of 98 or 4 teachers. The unanticipated participation was due to requests for peer observers among teachers who had not originally rlanned to participate or among non-respondents.

In 1985-86, 16 teachers elected not to participate. ${ }^{2}$ Among this group were full-time tenured, part-time, and probationary teachers. The prominent reasons given for nonparticipation were (a) the time commitment, and (b) the process was not suited to their teaching assignment. At the end of 1985-86, there were 29 teachers who had participated, a 298 drop in participation rate from the previous year. Of the 11 who volunteered to participate but did not complete the full or partial process, 8 expressed the lack of time as a reason. In the words of two respondents:

"There was a negative time factor in this process." 3

"I never found time to complete my tape as I did the year before." 4

The higher rates for non-participation, no response, and drop outs in the second year may also be explained by decreased motivation. Responses indicated that there was less interest in the program, less effort by teachers, and the tasks were too difficult to complete. Comments from those responding: 
"Interest waned. Less emphasis and less administrative attention to it." 5

"Just never got around to completing this goal." 6

"I did not follow through . . I simply did not plan ahead to do all necessary to be videotaped." 7

"The mechanics of getting i.lings started . . and finding others interested . . or having the time has made it difficult to carry out peer observation." 8

The last issue to be discussed before presenting the findings concerns how results are reported. For each method of investigation, the potential number of participants was determined (volunteers, total staff, department chairs). Actual responses from individuals were counted and compared with possible responses for a percentage return rate. Throughout the presentation of findings, comparisons will be made to the number of participants responding. For example, 39 participants marked that all feedback requested was received (out of 39) indicating a 1008 feedback request/ received rate.

Because the number of participants responding varied with the method of investigation, Table III below is provided as a summary of possible and actual respondents to methods of investigation and the percentage rate of return for each method used. In reporting results where multiple responses were possible, the number of responses on each 
particular item is compared to the number of respondents who could have identified or selected that item.

TABLE III

METHODS OF INVESTIGATION AND RESPONSE RETURN RATES 1984-85 AND 1985-86

Method of Investigation

$1984-85$

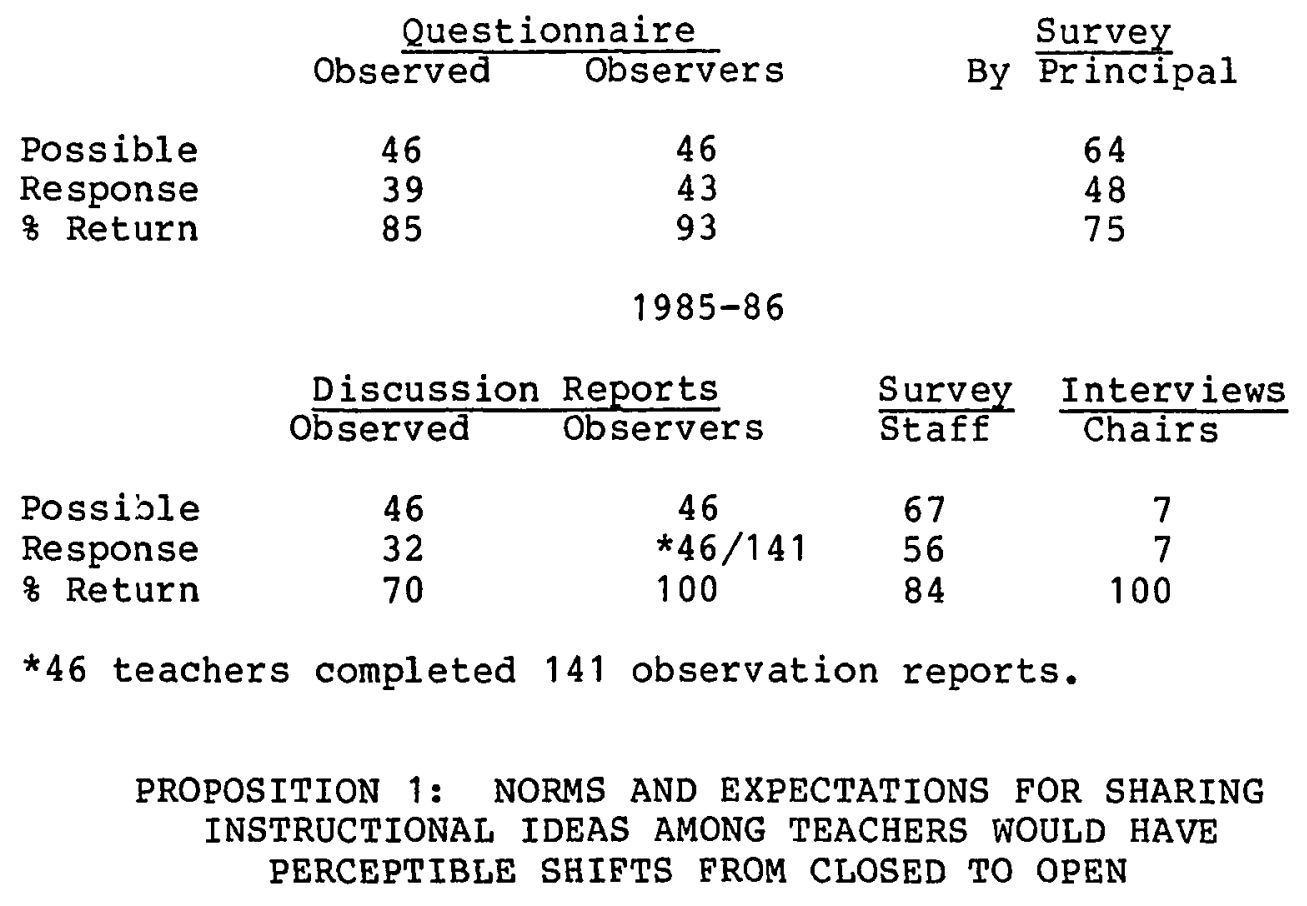

Proposition 1 inquired about the effect of peer observation on standards of behavior among teachers when discussing instructional issues about teaching. In this particular setting, teachers in general had not observed each other in teaching situations and thus had little basis for discussions on improving teaching. Classroom observations which 
had occurred were performed by administrator/supervisors for evaluative purposes. Instructional improvement discussions between teachers and administrators were received with anxiety because of "evaluation" overtones. Teachers seeking help or ideas from peers were vulnerable to unspoken notions of incompetence. If given an op ing, would faculty members become receptive to discussions with peers about their own instructional improvement? When teachers were engaged in the peer observation process activities, the evidence indicated that teachers felt they were expected to share instruction ideas, that teachers did share instructional ideas as requested, and that teachers exchanged ideas on instructional topics beyond that which was requested. When teachers were not directly engaged in peer observation activities, the evidence indicated that teacher exchanges on instructional topics increased from years prior to implementation of the peer observation process.

Observed teachers indicated that feedback was received in all areas requested and additional feedback was received in areas not requested. From the investigator questionnaire administered at the end of the first year, 939 observed teachers out of $39(1008)$ reported that feedback was received for each item of feedback requested and that 1008 reported feedback received on items where feedback was not 
requested. Of the 16 feedback choices on the questionnaire, the items most often selected as a request for feedback by the 39 observed teachers were the instructional topic listed below:

27 requests for "Active participation of students"

19 requests for "Clarity of lesson objectives"

16 requests for "Appropriate level of difficulty" $41 \%$

15 requests for "Monitoring students, adjusting $38 \%$ the lesson"

From the 16 feedback choices on the questionnaire, items that the 39 observed teachers most often received feedback on when feedback was not requested were the instructional topics 1 isted below:

11 feedback on "Tone or climate of the lesson" 288

9 feedback on "Lesson alternatives" 238

9 feedback on "Suggestions for change" 23\% When observed teachers were asked why they thought feedback was given when not requested, 1033 responded ( 858$)$ with reasons. Grouped responses are listed below:

7 responded that observer feedback on specific $21 \%$ parts of the lesson was given in relation to the whole lesson

6 responded that many ideas came up, teachers $18 \%$ evaluated themselves at the same time they observed others 
6 responded that observers chose to mention items not requested

3 responded that observed teachers were not specific in their requests for feedback

3 responded that observed teachers asked for additional feedback in Lne discussion group

From the discussion reports completed after group meetings, 11 all 32 observed teachers identified areas for which feedback was requested and received $(100 \%)$. Of these, 26 indicated they received the type of feedback requested (818). When asked "In what way was the process helpful to your teaching?" the most commonly mentioned items were the following : 12

10 good alternative, specific ideas to try $31 \%$

9 feedback on what to continue doing that $28 \%$ is good

8 suggestions about the content of the lesson $25 \%$

5 suggestions for working with students 168

5 the value of self-evaluation from the tapes $16 \%$ Observing teachers provided evidence that exchanges of instructional ideas occurred in the peer observation process. On the investigator questionnaire, 43 observers were asked to list items discussed as a group that were helpful to their own instructional improvement. The categories most often 1 isted were grouped below: 13 
15 lesson alternatives and different methods $37 \%$

14 techniques for active student participation $33 \%$

10 techniques for reinforcement to students $23 \%$

10 monitoring students, adjusting the lesson 238

8 techniques for leading discussions 198

Forty-six observers completed $14 i$ discussion report forms. 14 Forty-one observers responded that they gave to the observed teacher the feedback that was requested (898). The five observers who did not give feedback requested explained their reasons below:

2 did not understand the lesson objectives

1 had a lack of content knowledge of the lesson

1 did not receive the requested feedback ahead of time

1 gave mostly praise on the lesson.

When teachers were questioned about instructional exchanges while not directly engaged in the peer process activities, the evidence indicated that participants perceived the peer process as an effective means to encourage the sharing of instructional ideas. On the survey issued by the principal to the total staff (64),15 48 responses were received $(75 \%)$. Forty-five teachers voted to continue the peer observation process in the next year $(94 \%)$ and 3 voted to discontinue the process $(6 \%)$. Open-ended comments and suggestions were categorized and the grouped responses 
indicated that teachers valued the communication of instructional information among their peers. Responses were grouped below: 16

32 process gives feedback for teaching improvement

17 effective process to anclyze teaching

17 a valuable tool to share ideas

9 meaningful, good alternative, innovative

7 flexible, less stress, non-evaluative, voluntary

7 videotape effective for observing self, others 158

Interviews with the seven department chairpersons corroborated previous evidence that the peer observation process was an effective tool for sharing instructional ideas. All chairpersons identified the peer process as a means to share ideas for instructional improvement. Specific observations about teacher exchanges within the peer process activities were summarized below: 17

7 group feedback was encouraging and educational $100 \%$

5 videotape effective for instructional improvement

5 observing others helped improve teaching 718

5 instruction was now discussed in department $71 \%$ meetings 
5 process has potential, effects will take time

Specific comments from department chairpersons offer corroborative evidence that instructional ideas were shared among teachers outside the peer observation process activities:

" - it gave something lor teachers to talk about with each other, other than chit-chat." 18

". - it was just nice for the people in the department to get to hear others talk about their instruction." 19

"Some of the informal discussions afterward have been really good, the ones that we have had in our department meetings. - . it gives people something to talk about with one another that is relative to what they do every day. $" 20$

"It has led into many other areas, not necessarily just the discussion of what was on the videotape but also comments concerning our department area plus education as a whole." 21

". - one of the main goals of peer observation is to give a teacher validation for what they're doing well and a chance to share that, some visibility, and a chance to build up trust among their peers." 22

Discussion

It was proposed that by means of the peer observation process, norms and expectations for sharing instructional 
ideas among teachers would have perceptible shifts from closed to open. The answers to several underlying questions were sought: (a) Would teachers who had not previously engaged in discussions on instructional improvement be willing to do so in this process? (b) What format would evolve for discussions about ins'-uction among teachers? (c) What was the content of teacher exchanges on instruction? (d) Would teachers go beyond the scope of the process activities in these exchanges? and (e) Would instructional improvement discussions be considered "appropriate" among peer interactions?

The evidence suggested that as a result of the peer observation process, teachers not accustomed to discussions of instructional improvement with peers were willing to analyze another's teaching and offer feedback to the observed teacher. Further, all observed teachers reported receiving more feedback in instructional areas than they had requested indicating a desire by observers to communicate ideas beyond those requested. While the original "rules" were to offer only feedback which was requested, the trend seemed to be to go beyond areas requested because separating parts from the whole was difficult and feedback in group settings spawned additional ideas not initally considered. No evidence emerged where teachers were critical of the additional feedback not requested, and findings indicated 
across methods that there was an openness to both requested and non-requested feedback.

The evidence indicated that the content of the majority of the feedback given related to instructional areas involving teacher responsibility for change. Some feedback addressed aspects of student responsibilities for change in the area of active participation, but the techniques suggested were teacher directed.

Teacher participation in the peer observation process activities showed evidence of carrying over into other group/individual contacts. For example, the content of department meeting discussions had changed from less housekeeping items to more instructional topics, and informal teacher groupings discussed more instructional topics than before the peer observation process. The openness to communication about instruction among the faculty as a whole appeared to be an accepted behavior given the findings on high feedback response rates, high group discussion rates, and widespread documentation of instructional topics exchanged.

\footnotetext{
PROPOSITION 2: TEACHERS WOULD PERCEIVE THE SELF-VIEWING OF THEIR VIDEOTAPE AND THE RELATED PEER DISCUSSION ON THEIR TEACHING AS VALUABLE LEARNING EXPERIENCES
}

Proposition 2 inquired about the effects of two of the peer observation activities for helping teachers analyze and 
improve instruction. Would participants perceive instructional improvement value in observing videotaped lessons? If so, what was identified as valuable? Would participants perceive instructional improvement value in having smal1group discussions over the observed tapes? If so, what was identified as valuable about these discussions?

The evidence indicated that videotape replay for selfviewing and for observing others teach was a valuable learning experience. The evidence also indicated that the related peer discussion on the videotaped teaching segment was a valuable learning experience for both observed and observing teachers.

\section{Videotape}

Observed teachers. Of the 39 observed teachers responding to the investigator questionnaire, 12 indicated that the videotape helped improve their level of awareness of their teaching $(318) .23$ of the 32 observed teachers responding on the discussion reports, 8 identified the videotape as helpful to self-evaluation of their teaching $(25 \%) .24$

Observing teachers. Of the 43 observers responding to the questionnaire, 33 indicated that "I most liked seeing others teach" $(77 \%) .25$ Among this group who rated the peer 
process above the administrator-teacher observation process, 7 indicated that the value of videotaping alone provided self-awareness of teaching (168).26 From the 46 observing teachers responding on the discussion reports, 19 reported that the video was helpful to watch teachers in other departments $(418) .27$

of the 48 respondents to the principal's survey, 7 identified the videotape as effective for themselves and watching others (158).28 Among the 7 department chairpersons, 5 indicated that the videotape was effective as feedback for self-improvement and 5 indicated that the videotape was an effective means of observing others (718).29 Both principals predicted that the videotape would be perceived as effective feedback for self-improvement and as an effective means of observing others teach. 30

Teachers observing peers rated the value of the videotape lessons high when it was viewed as a tool for observing other teachers teach, an activity of high value. The intensity of response to the value of the videotape was lower when participants were asked to rate the role of the videotape in improving levels of awareness and teaching. When the videotape was considered as the sole source of analysis of the lesson taught, some limitations surfaced among the responses.

Limitations. From the discussion report forms of the 46 observers, 3113 indicated that the videotape should give 
a view of the students and hear what they say (28\%): 4 felt. the entire lesson and not just a sesment of it should be taped $(98)$, and 4 felt the video segments were too long (98). Of the 48 respondents to the principal's survey, 323 indicated a weakness in the use of video in the pre- and post-viewing stages where little contact was made about the lesson to be watched $(6 \%)$. Of the 48 responses, 3 indicated difficulty in scheduling the video for taping and arranging for the tape viewing $(6 \%)$.

\section{Peer Discussion Group Sessions}

Observed teachers. Of the 39 observed teachers responding on the investigator questionnaire, 3334 identified a valuable specific technique they received from their peer group in the feedback discussion (87\%). In addition, the following general areas were identifed as being ones in which valuable feedback was received on observed teachers' lessons:

$$
\begin{array}{ll}
14 \text { constructive criticism, alternative } & 368 \\
\text { suggestions } & \\
12 \text { ideas for clarity of instruction } & 318 \\
10 \text { areas where coaches gave postive } & 268 \\
\text { reinforcement } &
\end{array}
$$

When asked if this feedback had "value in other lessons they teach," 20 responded with specific techniques that they received which have value in other lessons (51z).34 The 
areas mentioned most often as being useful feedback for

other lessons were the following:

6 techniques for student participation $15 \%$

5 techniques for reinforcing student behavior $13 \%$

The 32 observed teachers responding on the discussion report forms indicated that the ser discussion was helpful in the following ways: 35

10 alternatives and specific ideas were good $31 \%$

9 learning what to continue to do well $28 \%$

8 suggestions on content were helpful $25 \%$

Observing teachers. From the investigator questionnaire, 3639 of the 43 observing teachers rated the discussion groups between "somewhat" productive to "very productive" (918). On a scale ranging from 1 (low) to 5 (high), these ratings corresponded to the following responses:

3 "somewhat" productive discussions 308 13 responses

4 "productive" discussions

19 responses

5 "very productive" discussions

7 responses

$60 \%$ of the respondents indicated a high rating (4 or 5 ) to the discussion groups. Reasons for the high ratings were summarized below:

10 discussions gave new ideas, perspectives, views 
6 learned from watching and hearing others

Observing teachers responding on the questionnaire indicated the following grouped items from the peer discussions as most useful in their instructional improvement: 37

16 lesson alternative, changes, new methods $37 \%$

14 techniques for active stident participation 338

The 46 observing teachers responding on the discussion report forms 38 isted 27 specific items for teacher use that they felt were helpful to their own teaching (598). In addition to the specific items listed, other group discussion topics identified as valuable were summarized below:

18 techniques for active student participation 39 \%

13 listening to ideas from other coaches $28 \%$

13 forcing one to be clear in their objectives $28 \%$

The department chairpersons corroborated the evidence on the value of the discussion groups with the following comments:

"I thought the discussions were the most important . . . 39

"The discussions within the group, I thought, were really good." 40

"The discussions after the tape viewing have really been excellent also." 41

"I think this is one of the high group points, if not the highest point . . it has always been amazing the 
number of good comments and the variety of approaches that are expressed." 42

Limitations. All instruments had findings indicating that peer group discussions were perceived to have high value in the process of instructional improvement. An examination of the 141 discussior report forms from 46 observers revealed areas where participants felt peer group discussions could be improved.43 These areas summarized below came from teachers who had observed and discussed between 1 to 12 lessons with their peers, an average of 3 observations per teacher:

19 a need for more time in discussion sessions $41 \%$

12 a need for more clarity of feedback requested $26 \%$

10 a need for more leadership in group discussions

10 a need for a different group size

Of the 25 teachers who completed the full process in the second year, all indicated that some adjustment should be made in the group composition $(100 \%) .44$ of these 25 participants, 13 had peer groups composed of department members only and 12 had interdepartmental peer groups. Specific comments from several department chairpersons corroborated limitations to the value of peer group discussions :

"The feedback, I think, was rather shallow." 45 
"I think it depends upon the number of people in the group and those who are feeling comfortable with the peer teaching process." 46

"Given the limited amount of information we had prior to the observation, observers tried to give the feedback that was requested . . I'm not ceal certain that we zeroed in on what the receiver really wanted." 47

\section{Discussion}

It was proposed that teachers, by means of a videotaped teaching segment, would perceive that self-viewing of their tape was a valuable learning experience and that the experience of having teachers observe, critique, and discuss the videotaped segment in a group would be identified by both observed and observing teachers as valuable to their own teaching. Results of the findings across instruments indicated that the value of the use of the videotape for self-evaluation and peer group discussion was high, yet limitations to the use of videotape were reflected within instruments.

Limitations on the use of videotape became more apparent as the process continued throughout the two years. The initial reaction was positive from a staff whose exposure to video technology for instructional improvement was minimal. Few teachers, aside from those engaged in coaching sports, had seen themselves teach on videotape 
replay. As the process continued, teachers identified the value of videotape replay as a tool to observe themselves and others while giving instruction (which was desired by teachers), but they expressed reservations about its use in analyzing the effects of the instruction taped. Awareness about the videotape 1 imitations iecame more sophisticated and a need for student responses was expressed. Peer group discussions were perceived to have high value for instructional improvement. Discussions gave teachers specific techniques and ideas to help the observed teacher on the lesson analyzed and to help observing teachers in other areas of teaching. Discussions were rated as being productive and participants were able to provide specific data to identify how the group discussions were valuable. As the process continued over the two years and more teachers had participated in two or more peer group discussions, limitations to the group discussions emerged among instruments. These limitations to the value of peer group discussions were most often cited as a need for more time for the discussion, a need for more clarity in the specific requests for feedback, and a need for more leadership from the observed teacher at the time of the group discussion. 


\section{PROPOSITION 3: PEER FEEDBACK WOULD BE PERCEIVED BY TEACHERS AS VALUABLE FOR THEIR INSTRUCTIONAL IMPROVEMENT}

Proposition 3 directed inquiry into whether peer feedback was perceived by participants to be a key factor for improving instruction. Was feedback received from peers in this process different from feedback received by administrators in the traditional methods of supervision for instructional growth? If feedback was different, what were the identified differences? Prior supervision experiences were homogeneous among participants in the peer process. The supervision format procedures familiar to participants consisted of a pre-observation conference, an observation, and a post-observation conference followed by a summative evaluation report.

When participants compared peer feedback with administrator feedback for instructional improvement, the results indicated strong preference for feedback from peers. Participants entered the program with a desire to improve instruction and to try something new. Results of participant comparisons between programs indicated that where the peer process was rated high, the administrator-teacher observation process was rated low. The findings indicated that the peer process feedback led to instructional improvement because of the varied feedback from credible sources, 
the time to assess instruction and exchange specific techniques, and the non-threatening environment founded on peer reciprocity. The findings indicated that participants perceived administrative feedback to be weak in areas of instructional improvement, communication to be one sided and evaluative, and the time given by administrators to be a formality.

The motivations of teachers to participate in the process indicated a pre-disposition to a desire for instructional improvement and a desire to try a new program. Eleven items were 1 isted on the investigator questionnaire from which 39 respondents selected the items most closely relating to their personal motivations to participate. 48 The motivators most often selected were summarized below:

27 "Instructional improvement" 69 \%

13 "Non-threatening, voluntary" $33 \%$

11 "Curiosity" $28 \%$

10 "Principal's interest in the program" $26 \%$

10 "District process didn't work" 268

Participants were not motivated by the items summarized below: 49

0 "Wanted to feel a part of the group" 1008

0 "Afraid of negative evaluation if I didn't" 1008

When participants were asked to rate the peer process as compared to the administrator-teacher observation process 
for achieving instructional improvement, the peer process was rated higher. Forty-four responses were received and summarized below: 50

37 rated the peer above the administrator process 848

6 rated the two processes the same $14 \%$

1 rated the administrator above the peer process $2 \%$ When participants were asked to explain their ratings, 39 responded with a variety of reasons for the higher peer process ratings. These were categorized below: 51

13 variety of opinions, choices to approaches 338

11 group has enthusiasm, reciprocity, ownership $28 \%$

9 more time to talk instruction/concerns $23 \%$

8 non-threatening, not evaluated $21 \%$

7 videotaping alone provides self-awareness $18 \%$

6 peers have more validity, in classroom 158 regularly

5 specific feedback and suggestions to use $13 z$ Specific comments by participants related to their high ratings of the peer process suggested that participants valued the multiple sources of feedback, the time given for instructional assessment, and the lack of an evaluative purpose.

"It is more valuable because it's done by people who are in the classroom on a regular basis. It's also nice to 
have four or five people offering suggestions rather than just one." 52

"Less threatening; benefit of receiving feedback from 5-6 people, not just one; fosters a feeling of 'we're all in this together'; lots of positives are given." 53

"If peer coaching is dore " 211 it will bring about more improvement because of more input, less threatening, choice of feedback desired, and choice of coaches." 54

"Working with peers enhances the credibility of the feedback--they are teachers doing the same job with similar concerns and understandings." 55

The 39 participants offered reasons for the low ratings of the administrator-teacher observation process. These were categorized below: 56

9 no specific feedback on instruction and 238 techniques

4 observation pressure, anxiety, little $10 \%$ improvement

3 a formality, vague and general $8 \%$

3 one-way communication, administrator only 88

3 evaluation has little effect on improvement 88

Specific comments from participants related to their low ratings of the administrator-teacher observation process suggested that this process is limited by adequate administrator time, the amount and type of feedback received on 
instruction, and a climate of anxiety fostered by the evaluation function. Some of these comments are given below:

"Administrator observation forces you to perform one day, anxiety level is high and little can be learned in the process." 57

"That's top priority with them [teachers] where administrators have so many other tasks to attend to as we11." 58

"Administrator/teacher model is superficial with very 1ittle time spent on the teaching process whereas the peer coaching model is concentrated on the teaching process for a long period of time." 59

- . the reciprocity factor is important. When a person can give feedback and feel helpful to someone else, there is more willingness to open up, to allow others to provide responses/ suggestions to one's own teaching. It is not the hierarchical system where the 'expert' judges the underling. 60

The peer coaching process elicits specific feedback and suggestions. I got tired of hearing how I was doing a good job from administrators. That's nice, and may be flattering, but is certainly not helpful to instructional improvement. 61

"The administrator-teacher is evaluation and threatening to many teachers--they are not thinking instructional improvement. " 62

Department chairpersons offered evidence which corroborated the higher value ascribed to the peer observation 
process by participants. Specific comments below reflected that two key factors were (a) an emphasis on instructional improvement rather than evaluation and (b) time devoted to improvement.

"Administrators just don't have the time other than making their mandatory visits to the classroom to give enough help." 63

" . . I feel administrators usually only get into the classroom once and it's really not fair to the teachers, it's not a fair evaluation of what's going on in their class." 64

". . I think administrators have some difficulty with evaluation and if given the chance, they'd like to get rid of the responsibility altogether." 65

" - removing the evaluative process from the peer coaching, in fact we have even gotten away from the word 'coaching', it should be 'sharing'." 65

- There were some of the people in the department that were a bit threatened. But when they saw early on that it was not going to be involved in the evaluative process, and ... when they saw all the ideas that were given during the follow-up discussions, the added things and the good things and the support that was given, they wholeheartedly endorsed the peer coaching model." 67

The principals offered corroborative comments which supported the participants' preference for the peer observation process over the administrator-teacher observation process. 
" . precious 1 ittle happens as far as improvement

in the traditional instruction cycle." 68

I am very negative about administrator/supervisor observation . . . it comes so rarely, so infrequently, that unless you are working intensely with a person, I'm not sure there is enough continuity to be able to offer meaningful feedback on an on-going basis to help someone. 69

"We felt that there probably was more value in teachers sharing with teachers than an administrator going into a classroom on a formal basis and sharing some perceptions or ideas or suggestions with the teacher."70

"In effect, peer observation broadens the base of experience that teachers can draw on to help themselves improve instead of the narrow critical evaluation model."71

"It allows more people to have input, to have a wider range of experiences brought to bear on a person's instruction." 72

The six participants who rated the peer and administrator-teacher processes the same represented minority opinions. Two commented with the following:

"I found both to be of little value."73

"I don't feel either one of these processes are [sic] the answer." 74

of the remaining four, one responded with a comment on the rating given: 
"While I have had limited experience with both systems, I feel that differing ends are achieved. . . the peer process yielded instructional suggestions . . administrator evaluation is more interested in student behavior." 75 one participant rated the administratorteacher process higher and gave une following reason:

"In the administrator-teacher process, there is less chance of the focus of discussion to be blurred. It seems to be more efficient in the use of time." 76

\section{Discussion}

At the onset of this investigation, care was taken to avoid directing participant attention to comparisons of the peer process with the familiar administrator-teacher observation process. It was hoped that teachers would view the activities of the peer process with fresh insight separate from long-term experience with another instructional growth process. Questions about comparisons of processes were asked at the end of each year for the purpose of assessing whether the peer process had potential for instructional improvement. If it had improvement potential, were peer feedback interactions a key factor in this potential for teacher improvement? Inevitably questions about comparative merit must be included in this line of inquiry. Results of the findings indicated a readiness of participants, department chairpersons, and principals to share their personal 
views of the two teacher improvement processes. The weaknesses of the adminsitrative-teachei observation process emerged as a by-product of analyzing the benefits of the peer process for instructional improvement.

Participants were motivated to particiate in the peer process because of a desire to il prove instruction and to try a different approach to improvement. Participants indicated they were not motivated by social or job security coercion. Participants rated the peer process higher than the administrator-teacher observation process for its ability to achieve instructional improvement. The findings from all instruments indicated this rating was higher because of peer exchanges; more people offered a variety of opinions, the group encouraged reciprocity, time was devoted to instructional concerns, and the environment was nonthreatening and non-evaluative. The administrator-teacher observation process was rated low in achieving instructional improvement compared to the peer process because of weaknesses in the type of feedback received, the limited time devoted to instruction, the anxiety created by evaluation factors.

If a group of administrators observed each teacher in an effort to provide the conditions created by a peer group, such as a variety of opinions on the instruction observed, reciprocal exchanges, and time on instructional concerns, 
would instructional improvement be achieved? The evidence indicated that peer exchanges brought to the participating teachers a sense of collegiality which encouraged teacher growth. Administrators as evaluators seem to affect negatively the collegiality of a peer group. Several comments from department chairs and principals addressed the key role of collegiality among peer exchanges:

"Role of the principal is supportive, non-evaluative, non-threatening and that goes for the rest of the administration." 77

". - I think it is difficult for a principal to really be a part of that collegial atmosphere and still perform in the role of evaluation."78

"The traditional role, where the administrator is an evaluator, also expects him to be helping with improvement of instruction which really strains that trust relationship that one needs in order to be able to grow."79 With the old evaluation model, it is that somehow this administrator is going to come in who I think in many ways, in most ways, in all ways probably, is at best a peer with the other teachers in the building in terms of what they know about instruction and the experiences that they've had. 80 
PROPOSITION 4: TEACHER WOULD USE OTHER TEACHERS

AS MODELS FOR EFFECTIVE TEACIING AFTER VIEWING

THE VIDEOTAPES OF PEERS

Proposition 4 considered the effects on participants of viewing videotaped lessons of effective teaching. Did teachers desire to model the lessons of peers? Were the videotaped lessons perceived as a means of observing behaviors to be modeled? Would veteran teachers reveal attitudes about modeling partial or entire lessons presented by peers?

Teachers indicated a strong interest in observing the styles and methodologies used by other teachers within and without their own teaching areas. There were indications that teachers used other teachers as models for generating effective ideas, methods, and techniques for classroom use. However, there was little evidence to indicate that teachers viewed other teachers as models for imitation of entire lessons.

The findings indicated that teachers were selective in what they perceived as useful and the reasons for the utility. When observers saw a teacher effectively employ a technique on videotape that they might readily borrow, observers isolated that technique as valuable and one to be imitated. Less consideration was given to reproducing the strategies leading to the use of the technique, and few expressed a desire to reproduce the lesson. 
Observing teachers indicated evidence of using other teachers as models for learning new techniques. On the investigator questionnaire, 8133 of the 43 observers responded "I most liked seeing others teach" (778). The reasons for enjoying the observations of peers were summarized below: 82

16 lesson alternatives, changes, different methods

13 variety of opinions gave choices to approaches

7 videotaping alone provides awareness

5 specific feedback and suggestions to use

From the 141 discussion reports returned, observing teachers indicated that the process of observing and critiquing another's teaching was helpful to their own teaching in the following ways: 83

50 techniques in content areas

19 watching teachers in other departments

18 techniques for student participation

16 strategies in classroom management

13 use of a variety of techniques

5 will use lesson presented

Specific comments from observers in group discussions offered insights into areas where modeling was perceived as effective and why it had value. Observers seemed to place 
more emphasis on the value of seeing effective techniques to borrow than on effective lessons to replicate.

[This teacher] demonstrated a wonderful way to teach introductory and concluding paragraphs. Coincidentally, I had just asked . . . for any tips or tricks for teaching that very skill! I took good notes and will use the model next week! I wish I had seen it before I finished the hero unit. 84

I teach the same unit and [this] plan was excellent. I expect to use the same writing assignment and similar presentation at the next opportunity. It would be nice, especially for first year teachers, to have a library of some of these exemplary lessons. 85

"I picked up an idea about 'thought pads' and how to use writing as a way to prepare students for the lesson." 86

"Dividing the class up for discussion, taking opposite sides--excellent! I will use it." 87

"Offered an alternative way of presenting concepts, used deductive reasoning. This could be used for many units." 88

"'Put your thumbs up', or 'place your palms down'. It made me aware that I need to plan more active participation or use a wider variety." 89

"Some good group ideas, 'write down on own paper', 'discuss with your neighbor'." 90

"I like the stipulated time requirements, i.e. 15 seconds, 30 seconds." 91

"Two good techniques: 'why' questions to flesh out thesis statement, 'so what' to do likewise." 92 
"The clever use of a mnemonic device revealed a technique I had never employed."93

"Able to see another teacher's approach to student discipline." 94

"Some specific classroom management techniques which gave me some ways I might change the things I have tried."95

"I saw how effective an overhead can be--I've never learned to use one." 96

"Observing her use of the blackboard, her use of makeshift models, and her strong ability to monitor and adjust gave me some good models of these teaching behaviors."97

of the 45 teachers responding to the principal's survey, 7 indicated that viewing the videotape was effective in observing others (16\%).98 specific comments reflected that techniques and strategies were learned but not necessarily replicated by watching others.

"I have thoroughly enjoyed watching the videos this year. Of the five I have been invited to watch, I have learned something from each one of them." 99

"It's useful to see other's strategies for teaching the same type of thing." 100

"I think the greatest benefit is to see other teachers in action." 101

"I have learned new ideas, techniques, and concepts that have helped me in my own teaching." 102 
Department chairpersons were asked directly about

whether teachers used other teachers as models for effective teaching after viewing the videotapes of their peers. Comments from chairpersons corroborated previous evidence presented. Teachers used other teachers more as models for conveying techniques and ideas tiat were immediately transferable than as models for emulating teaching behavior.

There are some instructors . . who I think are uneasy related to . . how to give presentation, large- and small-group discussion, discussion of films they use. Perhaps these tapes could be put together demonstrating or modeling how these types of procedures might appropriately be carried out.103

"Some of the videotapes were very good models for

teaching behaviors. Others gave an opportunity to help those teachers, to give them ideas for improvement of their teaching." 104

If it was a good videotape and a good lesson, then there are obvious modeling capacities. But for us, it was more a point of departure for discussions. It was also good to see how someone else does something, something you might never have tried to see it done and to see the possibilities. 105

I think modeling is the very strongest part of the peer observation process. Most of us are visual learners and so seeing something is a very effective means of learning. Not that there is any kind of blueprint. You can watch someone do something very effectively, talk about its effectiveness, and yet realize there is no way you can possibly duplicate that same thing in your classroom. It isn't always that you can take something that someone else has done and replicate it in your own classroom. 106 
"I think it is excellent. I don't think anyone should necessarily copy anyone's style, but I think observation and example are still the most powerful learning devices there are and here it is, right out in front of you."107

In working with a beginning teacher, it would seem if you had agreed there were some things that the teacher wanted to improve upon, having tapes that illustrate those aspects . . . is handy. If you have teachers that are veteran teachers, I often wonder if the emotional impact is the same. By picking something that we might flag as the standard, then it gives us insights but yet looking at a tape and trying to emulate or be that, isn't necessarily the best way to approach the problem. For teachers who have taught for many years like teachers at LOHS who are effective teachers, we're not talking about changing their whole teaching style.108

The principals indicated that the videotaped lessons would provide models of effective teaching. They commented:

"The modeling effect is not just looking at your own teaching as a model but to be able to see other outstanding teachers." 109

"There are some modeling strengths in that you can see an individual communicating effectively, sort of one-way communication model and you can see many different models of that." 110

\section{Discussion}

Teachers found merit in all lessons observed and reported to peers what they $l$ iked and what they would use. Observers had a tendency to select strategies or techniques 
from the videotaped lesson that were easily transferable to their own lesson. Teachers who obscrved peers in their content areas seemed to select content-specific techniques while teachers observing peers from outside their own department areas selected classroom management techniques and lesson strategies as valuablt.

There was no indication in the findings that teachers were searching among the peer observations for the "good" or "effective" models. There was a distinction made between the value of effective teaching models for beginning teachers and for veteran teachers. For example, it was suggested that a collection of "good" tapes might be useful as demonstration models . . for begining teachers. Another participant remarked: "I think that some of those [videotapes] would be good demonstration tapes, but I'm not real certain that having a collection of 'good lessons' communicates the essence of what teaching is."111

\section{PROPOSITION 5: PEER INTERACTIONS WOULD BE PERCEIVED AS REWARDING TO A TEACHER'S DESIRE TO WORK TOWARD INSTRUCTIONAL IMPROVEMENT}

Proposition 5 inquired about the effects of a peer observation process on a teacher's desire or attitude to work toward instructional improvement. Did teachers perceive that working with peers encouraged their personal efforts to improve? Were teachers motivated to change 
instructional behaviors because of their exchanges with peers?

The evidence indicated that teachers perceived the peer observation process as rewarding to their desire to improve. Participants perceived the peer process to have encouraged their improvement tow.d better teaching by increasing their level of awareness about good instruction, their efforts to learn new techniques, and their actual implementation of improved techniques.

The evidence indicated that the composition of peer groups did not affect participant receptivity to feedback or effort to improve. Departmental peer groups were valuable when content-specific feedback was desired and interdepartmental peer groups were valuable in obtaining a broad perspective on organizational strategies and varied input. Questionnaire respondents perceived the peer observation process to have encouraged personal awareness about improving, motivated teacher's efforts to change, and stimulated actual implementation of methods in the classroom. At the end of the first year, observed teachers were asked to rate themselves both "before" and "after" the peer observation process experience in the following three areas: (a) instructional improvement awareness, (b) conscious effort to implement improved instructional techniques and (c) actual implementation of improved instructional techniques. The result in Table IV from 39 observed teachers indicated 
positive changes in all three areas after teachers

experienced the peer process. 112

TABLE IV

BEFORE/AFTER RATINGS OF INSTRUCTIONAI IMPROVEMENT

IN AWARENESS, EFFORT AND IMPLEMENTATION

Instructional Improvement Awareness

\begin{tabular}{|c|c|c|c|c|}
\hline & & Before & After & 8 Change \\
\hline \#3 & Reasonably aware & 18 & 7 & -28 \\
\hline \#4 & Aware & 14 & 24 & +26 \\
\hline$\# 5$ & Very aware & 4 & 8 & +11 \\
\hline
\end{tabular}

Effort to Implement Improvements

Before After $\quad$ Change

$\begin{array}{lllll}\text { \#3 } & \text { Periodic effort } & 18 & 9 & -9\end{array}$

\#4 Regular effort $\quad 15 \quad 24 \quad+24$

\#5 Constant effort $4 \quad 5 \quad+3$

Actual Implementation of Instructional Improvements

Before After $\&$ Change

\#3 Some implementation $25 \quad 14 \quad-11$

\#4 Often implemented $11 \quad 22 \quad+28$

\#5 Every lesson $\quad 1 \quad 2$

Data from Table 4 indicated that negative change occurred "after" the peer observation experience for the \#3 rating. This is explained by the positive percentage changes reflected for the \#4 and \#5 ratings. Participants rated 
themselves higher than \#3 after experience with the process. For example, of the 18 participants who rated themselves as "reasonably aware" (\#3) before peer observation, 11 of these participants rated themselves after peer observation as being "aware" (\#4) or "very aware" (\#5). Participants perceived peer observation to have positively affected their levels of awareness, effort, and implementation of instructional improvements.

On the investigator questionnaire, 38 participants identified areas where positive change was noted after experience with the peer process. These were grouped below: 113

9 improvement in all three areas

14 improvement in level of awareness $37 \%$

9 improvement in level of effort to change $24 \%$

6 improvement in actual implementation of $16 \%$ changes

Twenty-nine participants wrote specific comments about reasons for their perceived improvements. Reasons for changes in awareness about instructional improvements were summarized below: 114

10 seeing myself and others increased my 348 awareness

9 the process makes you aware, use of feedback 318

8 more people brought more ideas, discussions $28 \%$ 
Reasons for changes in efforts to implement instructional

improvements were summarized below: ${ }^{115}$

5 the process gave impetus to try new things $17 \%$

4 I gave more effort to improve

Reasons for changes in actual implementation of improved techniques were summarized below. $i 16$

3 once aware, it leads to making changes

2 ideas from others that are immediately useable $7 \%$

Specific comments from respondents reflected that the peer process motivated teachers to improve:

"Other's expertise... seeing the lesson from other's perspectives. . valuable ways of doing the lesson." 117

"There was growth in all three areas principally because I wanted to be prepared before being taped, wanted to do a good job on the tape, and then desired to continue better performance throughout the semester." 118

"More awareness and use of feedback information to make instructional improvements." 119

"The cooperative, non-judgmental, and sincere attempts to respond to my feedback requests led to valuable discussions of possible strategies as well as providing more impetus to try something different." 120 
"When you become more aware you want to exert more effort on lesson planning and implewenting certain things in lessons where a certain plan would work better." 121

"Never knew before what others could and couldn't do. Discussions raised good points, let alone observations." 122

The composition of the peer group did not seem to affect participant desire to learn from the process and to improve instruction. The evidence indicated that peer group feedback was influential to a teacher's desire to improve instruction and that peer group composition was primarily important to the kind of feedback desired by the observed teacher.

At the end of the first year, 41 observed teachers reported the following peer group combinations: 123

22 Had department members only

19 Had interdepartmental members

At the end of the second year, 25 observed teachers reported peer groups composed of the following: 124

13 Had department members only

12 Had interdepartmental members

In each year, peer group compositions were similar, approximately half of the groups were department members only and half composed of interdepartmental members. Participants were asked to give reasons for the peer group combinations. Twenty-two participants gave the following summarized reasons for selecting department members only: 125 
14 convenience 648

4 requested by department chairs $18 \%$

4 teach same lessons/know content $18 \%$

of the 19 participants who selected interdepartmental peer groups, 14 gave the following summarized reasons for their choice:

8 people that respect/candid suggestions $57 \%$

6 get a wider perspective 438

Participants were responsive to departmental and interdepartmental peer groups and the feedback received from each. There were indications that participants were motivated to improve by both types of group combinations depending upon the feedback desired. Participants believed that interdepartmental groups gave broader feedback with more variety and input, and departmental groups were better for receiving content-specific feedback.

Participant comments from the principal's survey confirmed that peer group composition was important to the type of feedback desired by the teacher. Respondents' commented on peer group composition as follows:

"I had to do my evaluation with my department which is OK but, I hope that this isn't a trend. I believe the original goal of being evaluated by teachers from different departments is also good." 126 
"Continue to use the same peer coaching plan as this year but have people choose different people to view their tape and make suggestions." 127

"Work with related departments, i.e. (math, physics, chem., etc.)."128

"Teachers with same course sharing same lesson."129

"Tape by content areas within department."130

"Work within departments until process is familiar and then go cross disciplines." 131

Department chairperson corroborated previous evidence that peer exchanges were perceived as rewarding to a teacher's desire to work toward instructional improvement.

"The reinforcement that people got is great. It also gave people ideas . . about things to discuss and to share with each other and to motivate us to try these new ways also." 132

"Most teachers have very 1 ittle knowledge about what goes on in other classrooms and so that new awareness has been really important. . . "133

". . one of the things you get... is reinforcement that you are correct. . there is always something new to learn with it."134

"My perceptions are that having someone look at a tape about you at least gives you visibility and attention which you wouldn't otherwise have, so there is reward in that sense. I think that we often tended . . to give positive feedback 
so that again gives the receiver affirmation as

to what they are doing or what they believe in. 135

". . it got people thinking about how they present lessons. I focused on using small groups and I wanted to figure out ways to make it more concise with better use of time and I got some good suggestions out of it."136

" . it rejuvenates you, it gives you new enthusiasm, it gives you new interests, certainly a lot more awareness of increased possibilities of ways to do things than you had before." 137

". - you can't help but improve when you get to see other people perform . . with the idea of helping them along and with helping yourself."138

\section{Discussion}

The evidence across instruments supported the proposition that peer interactions were perceived as rewarding to a teacher's desire to work toward instructional improvement. Participants perceived that peer exchanges stimulated greater awareness of teaching possibilities, encouraged efforts to learn techniques, and motivated teachers to make changes in the classroom. Department chairpersons supported these findings. The desire among participants to improve instruction did not seem to be conditioned by the composition of the peer group giving feedback. 
Generally, participants selected their own peer group members. An initial concern with this procedure was that teachers would select only those peers with whom they had established close relationships thereby potentially shielding themselves from negatively critical feedback about their teaching. In practice, peer groups were selected by factors having more to do with teaching schedules, inservice time, assembly duty supervision, and convenience to one's proximity than friendships. Because of the time constraints of the peer process program, it became increasingly unlikely that groupings would be manipulated for favorable feedback. This, in turn, set a positive tone among participants about the importance of the role of the peer observers in helping teachers improve and it removed potential temptations to socialize with friends through the peer observation process.

PROPOSITION 6: TEACHER INTERACTION WOULD STIMULATE NEW IDEAS, METHODS, AND STRATEGIES AND CREATE A CLIMATE WHERE CHANGES IN TEACHING WERE POSSIBLE

Proposition 6 considered the effects of the peer observation process on creating a climate for change. Would the peer process activities establish an environment in which teachers felt free to learn instructional improvements, to experiment with new techniques, and to ultimately improve their teaching methods? 
Participants perceived that the peer observation process activities created a climate where instructional changes were possible. The findings revealed that observers perceived their role to be one who helps the observed teacher in a non-threatening manner. Observed teachers indicated they were encouraged to improve instructional techniques because of the positive reinforcement received from observecs. Participants indicated that growth would continue with further opportunities to participate in the peer process.

The results provided indications that instructional improvements had occurred in the classroom as the peer process environment was evolving. Participants listed techniques currently employed because of their peer process experience. Department chairpersons noted positive environmental changes from the peer activities which enhanced the potential for improved instructional changes among participants.

The peer process activities created a climate where changes in improved instruction could occur. One indication of the climate was the "helping" attitude established among participants. From the investgator questionnaire, 43 observers were asked to "describe the role of a peer coach as you know it to someone not familiar with the idea." The descriptions were grouped below: 139 
24 feedback to fellow teachers in areas where they want improvement

9 a group effort to give suggestions and comments in a non-threatening way

8 emphasizes improving rather than evaluating 198

7 see yourself, see others teach and learn from this exchange

Respondents commented about the "helping" environment as they described the role of a peer observer:

"To make observations which you think might be helpful to a teacher interested in instructional improvement." 140

"The peer coach provides feedback to a fellow teacher about an aspect of teaching that teacher seeks to improve." 141

"I would say that it is an opportunity to see yourself teach which in itself is valuable. It is also an opportunity to have colleagues offer constructive evaluation."142

"To have a chance to see the many good things the teacher does in the classroom while providing an opportunity to hear about, and possibly utilize alternative techniques that might enhance learning." 143

Peer coaching is a very interesting and positive way to help teachers see what they do and to suggest alternative that might be more effective. It also gives the $\overline{c o a c h}$ a chance to see 
other teachers in action and to do some private comparisons and "evaluation" of his own teaching. 144

There were indications that a positive climate, while learning to improve, was important to participants. The 32 observed teachers responding on the discussion report forms indicated the following two areas as most helpful:145

10 specific ideas to try, good alternatives

9 learned what to continue doing well

One participunt remarked:

It was a positive experience--a time to get some positive feedback and realize $I$ am doing a good job--from my colleagues. It made me realize how seldom, if ever, teachers or administrators provide positive reinforcement for each other. This came as a boon to a teacher who is always striving to be more effective. 146

The staff indicated a firm vote to continue the process a second year because of its potential for instructional improvement. Comments to the principal's survey spoke to the positive climate, opportunities to improve, and the need to give the process time to be effective.

"[It is] just beginning to be seen as helpful rather than stressful. Coaching sessions have been encouraging and educational." 147

"We've only just begun to feel comfortable with the concept." 148 
"I need more time/experience in front of the video camera--to feel at ease both in watching myself teach and having others watch me and eventually more readily accept evaluator's suggestions, critiques of others."149

"We are just getting started. It can be of more help to some teachers than anything we have done."150

There were indications that while the climate for improvement was developing, changes were being made in the classroom by participants. The 39 observed teachers responding to the investigator questionnaire indicated specific techniques they were using that resulted from participation in the peer observation process. These were grouped into two general areas below: 151

16 classroom techniques used with students

15 lesson planning/organizational ideas Similar results were indicated by the 43 observers responding on the investigator questionnaire to items that were useful to their teaching. These were grouped into the same categories: 152

34 lesson planning/organizational ideas 798

24 classroom techniques used with students 568 Participants documented instructional changes they had made during this process. Examples were listed as follows: 153 teacher modeling of examples, grouping students for problem work, more student discussions, having students define 
terms, avoiding repetition, active student participation (raise hands, palms/thumbs up or down, share with neighbor, student-peer helper), use parts-to-whole approach, maintaining eye contact, organizing lesson on board, using clustering techniques, brainstorming, reinformcement tactics, and moving focus to students.

Department chairpersons saw indications of an environment developing within the peer observation process which they believed was conducive to improving instruction among teachers. Characteristics of this emerging environment were noted to be the removal of evaluation anxiety, the building of trust among peers, peer receptivity to exchanges of instructional ideas, and collegial respect. Department chairpersons commented:

"As it's set up now, it is only remotely identified with evaluation and I think if, at this state, we can get at those fears and get rid of them.. I think we can then get on with the idea of peer coaching."154

I think this is positive [peer observation], I'd like to see a whole turn-around in the evaluation process. As long as people are afraid of the process and hiding how they do things from other people, we're never going to improve. People have a lot to share with each other and most people are really longing for the ability to share with their colleagues share ideas in common, share their concerns. 155

I think it makes people both more sure of themselves in what they are doing in the classroom, 


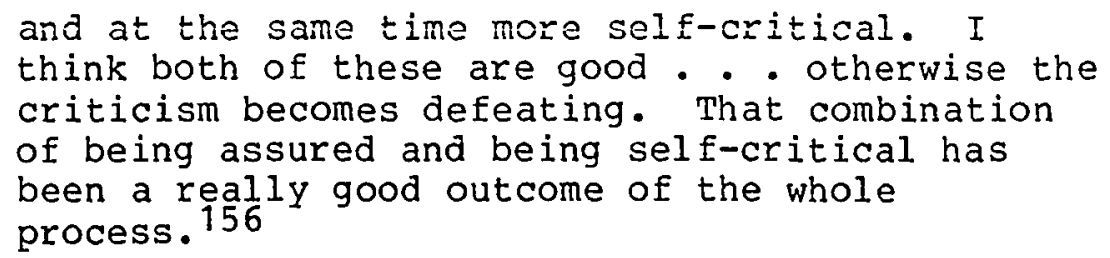

"I don't think people in our department felt

threatened at all with being observed this way . . I think it is unlimited as to what you can do with it and how you can use it." 157

We gained an awareness for what each other was doing and certain positive things that occurred that the observer noted I think serve to refresh the observer's mind on techniques and approaches. I think there were some hints given to the receiver. To build up trust, however, takes a long time. Teaching becomes so personal, it is hard to separate it from ourselves. 158

I've seen other types of models used, most of them tend to have a teacher with another teacher, one the so-called coach and the other one the student. This never gets across the whole staff, and furthermore, it looks as though one teacher is the master teacher and the other is not. I like [our] model where everybody is considered to be a good teacher but all of us can improve. 159

When participants were asked how the process could be more helpful to them, two items emerged across instruments most often: 160 (a) repetition of the process several times a year and (b) more time provided for the peer process activities. One chairperson spoke to this dilemma: 
The real benefit of peer observation is that I'm hoping this process will evolve into attending to that really very controversial issue of teacher evaluation. The end result will be better teaching. Problems are the time constraints. It may boil down to the school day, the school schedule having to change to accommodate this procedure if indeed we get serious about it [better teaching]. 161

\section{Discussion}

Evidence across instruments indicated that the peer observation process created an environment conducive to learning and experimenting with improved instructional methods. A "helping" attitude evolved which was perceived as important to teachers' receptivity to suggestions and alternatives, teachers felt encouraged by positive feedback from peers in areas of strength, levels of anxiety were reduced, and trust relationships were evolving. Participants indicated a need for patience with the peer observation process. It was perceived that personal and professional growth take time and that effective peer observation relationships are dependent upon mutual respect and trust which will develop in a nurturing environment. Participants felt they would develop more effective teaching skills if observations and critiques of teaching were performed several times during the year. However, participants acknowledged that the limited time provided for the peer process activities affected their ability to maximize the opportunities to learn from these activities. 


\begin{abstract}
Although participants were provided some time on inservice days each year to perform peer observation activities and assembly supervision duty was rotated among half the staff to allow for in-school peer activities, the majority of time given to peer activities occurred before or after school and during teacher preparation periods.
\end{abstract}


CHAPTER V

CONCLUSIONS, OBSERVATIONS, RECOMMENDATIONS

CONCLUS + JNS

Peer observation for the improvement of instruction affected teacher norms, perceptions, and expectations about teaching in a high school setting. Standards of behavior among teachers not accustomed to discussing instructional issues changed from closed to open after experience with the peer observation process. Teachers felt they were expected to share instructional ideas, did share their professional observations as requested, and exchanged ideas on teaching beyond that which was requested and in settings outside the peer observation process environment. There was an openness to both requested and non-requested feedback from peers.

Videotape replay of classroom teaching contributed to an open instructional environment. Teachers offered groups of peers the opportunity to observe and critique their teaching techniques in exchange for ideas, suggestions, alternatives, and strategies for improvement. Teachers perceived the videotape replay for self viewing and for observing others as a valuable experience. The related peer 
discussions were inciteful for both observed and observing teachers. Teachers indicated a strung preference for feedback from peers for instructional improvement purposes because of the amount of varied and useful information from credible sources, the time to assess instruction and exchange specific techniques, anc the non-threatening environment among colleagues.

In this setting of veteran teachers, participants indicated strong interest in observing the styles and methodologies used by other teachers within and outside their own teaching areas. Teachers used other teachers as models for generating a collection of effective ideas, methods, and techniques for immediate classroom use. Less consideration was given to reproducing or imitating the strategies leading to the use of techniques or to copy entire lessons as presented. Teachers distinguished between the value of effective teaching models for beginning teachers and for veteran teachers.

Teachers approached the peer observation process with a desire to improve instructional abilities. This desire to inprove was stimulated on three levels by peer observation activities: (a) awareness about improving, (b) efforts to change teaching strategies, and (c) actual implementation of new ideas into the classroom. Teachers were rewarded for their desire to improve after exchanges with peers and they 
perceived the peer process to have encouraged their improvement toward better teaching in these three areas. The composition of peer groups did not affect participant receptivity to feedback or effort to improve. A climate existed through peer exchanges where teachers perceived their role as one to help, reinforce, share information, and generate teaching ideas in a non-threatening manner. Instructional improvements were perceived to have occurred in the classroom as the peer process environment was developing and the potential for teacher improvement using the peer observation process was perceived as high.

\section{OBSERVATIONS}

While the concept of peer observation is not new, this study is important for its contribution to the small body of research now available in this field. One reason for the scarcity may be the difficulty in studying an interactive process like peer observation which relies upon social, political, professional, emotional, and environmental interactions to produce an outcome of improved instruction. This study offers insights into the use of an alternative approach to improving the quality of instruction among teachers and the effects of this model on a staff of veteran teachers. Further, this study offers potential users a methodology and a process for employing the same concept of peer observation in schools nationwide. 
Some observations about this study as an educational innovation seem important. Implementation of the peer observation process in this staff would be expected to follow similar patterns of adoption studied by others (for example: Annese, 1971; Carlson, 1970; Miles, 1971; Rogers, 1955; Schmuck \& Runkel, 1970). The S-curve explanation (Carlson, 1970 ) suggests that adoption rates of innovations depend upon the adopting unit, the communication channels established by the principal, and the position of the adopting unit. It may be expected that approximately 2.58 of a unit will adopt in the first year (Rogers, 1971) and that 100\% adoption of an innovation may take seven years (Carlson, 1970). Rogers (1965) suggests that the time span of adoption is very slow in education because of the lack of assigned change agents. And participation in an innovation does not equate with adoption and may indicate a desire for information or mere acquiescence to participation pressure (Annese, 1971).

In this study, participation was initially high because of teacher interest in gathering information about the program, the principal's enthusiasm as the recognized change agent, and department chairperson leadership. As interest, enthusiasm, and leadership declined over the second year, subsequent decreases in participation were noted. This decline may suggest that principals wishing to innovate with peer observation must expect to play an effective change 
agent role as well as possess the skills to develop those teachers who are initial innovators into change agents for continued teacher adoption of the program.

Successful innovations possess perceived utility to those effecting the change (Annese, 1971). The peer observation process was perceived to be an effective means of improving instruction among teachers as noted by participants in the findings. There is a natural means to encouraging participation in this process because of the group feedback arrangement. One teacher must rely upon three or four peers to help complete the observation-discussion-feedback process. Therefore, those not intending to participate might easily become participants at the request of a colleague, as happened among the staff studied here. This reciprocal arrangement has balance as long as each teacher participates an equal number of times. There was evidence of imbalance among the teachers of this study. Most participated in one peer observation session while a minority participated as many as seven, nine, or twelve times. The time demands on those participating frequently were excessive, and utility for the value of the process began to give way to lack of novelty and time pressures.

This study did not contribute to the dilemma of time commitments for a process which requires a great deal of time. Initial efforts were made to accommodate for demands 
on time by adjusting teaching schedules. As the process continued, there was less adjustment for time constraints and more expectation that teachers would accommodate to allow for peer process activities. It is suggested that teachers began to drop out, not because they believed the value of the process was less, bu because adoption of the peer process innovation was not complete. Teachers had not yet determined that peer observation process activities would permanently be among the expected professional tasks which they must perform. Therefore, teachers were less inclined to give additional time outside the instructional day to participate in peer group sessions.

Potential users of the peer observation process will recognize the boundaries of the focus of this study. In the two years of active participation, peer observation opened communications about instruction among teachers, established instructional dialogues as a norm for behavior among teachers, challenged teachers to risk sharing instructional intimacies, and set a tone among this staff that all teachers can learn and improve from their peers. Once a similar base is established, users of the peer observation process will recognize a need to go beyond the limits of this study in developing strategies to measure the improvement progress of individual teachers as they proceed through the peer observation process activities from year to year. 


\section{RECOMMENDATIONS}

This study may be viewed from the perspective that it is a document about teachers and the world within which they work. One aspect of teaching is the desire to improve the quality of instruction. This st: Jy has focused on specific interactive effects of one alternative model for the improvement of instruction. As this study is placed in its proper perspective, it is hoped researchers to follow will be challenged to build upon areas introduced here.

Some specific recommendations for further study relate to peer observation and surrounding isssues. Single-case studies lack generalizability. Additional studies using total school faculties would offer comparative findings and provide a base for multiple-case study designs. A long-term perspective is needed on the peer observation process as an alternative model for improvement of instruction. Can peer observation for improvement of instruction be merged successfully with methods for evaluation of teachers for continued employment? What is the natural evolution of a peer observation process, how does it change over time and what needs do these changes meet toward the goal of instructional improvement? Are there effective methods of assessing the type of improvements needed among teachers and the degree to which improvements were achieved? From a leadership perspective, how does a peer observation process affect 
the values, skills, and administrative functions of the building principal? What is the diffusion potential of a peer observation process throughout a single-building staff and to multi-building teaching units? These questions suggest points of departure for future contributions to our understanding about teachers and the environment in which improvement of instruction occurs. 
The butterfly and I had 1 it upon, Nevertheless, a message from the dawn,

That made me hear the wakening birds around, And hear his long scythe whispering to the ground,

And feel a spirit kindred to my own;

So that henceforth I worked no more alone;

But glad with him, I worked as with his aid, And weary, sought at noon with him the shade;

And dreaming, as it were, held brotherly speech With one whose thought I had not hoped to reach.

'Men work together,' I told him from the heart,

'Whether they work together or apart.'

Robert Frost

"The Tuft of Flowers" 


\section{SUPPLEMENTAL REFERENCE NOTES}

Statements and interpretations of the findings in Chapter 4 are documented by reference citations corresponding to the multi-variate methods of investigation used in this case study. These methods include the following: (a) Investigator Questionnaire 1985, (b) Investigator Survey 1986, (c) Principal's Survey 1985, (d) Peer Discussion Reports, (e) Interviews-Department Chairperson, and (d) InterviewsPrincipals. Documents from each method were categorized, summarized, and tabulated for analyses. Citations from these stages of synthesis are referenced first by method and followed by subsequent groupings. Quotations from participants are cited to the method and coded respondent. Readers interested in reviewing documents of this study may contact the author at the following address: Alumni Association, Portland State University, PO Box 751, Portland, OR 97207.

1 Survey of teachers not electing to participate, 1984.

2 Investigator survey 1986, categorized teachers NG.

3 Investigator survey 1986, response, teacher $1 \mathrm{GI}$.

4 Investigator survey 1986, response, teacher 5GI.

5 Investigator survey 1986, response, teacher 5F.

6 Investigator survey 1986, response, teacher $2 \mathrm{GI}$.

7 Investigator Survey 1986, response, teacher 9GI. 
\& Investigator Survey 1986, response, teacher $14 \mathrm{NG}$.

9 Investigator Questionnaire 1985, Frequency

Distribution Summary.

10 Investigator Questionnaire 1985, Observed Teachers, Categorized Summary.

11 Peer Discussion Reports, Observed Teachers, Categorized Summary, Question 2.

12 Peer Discussion Reports, Observed Teachers, Categorized Summary, Question 3.

13 Investigator Questionnaire 1985, Observers, Categorized Summary, Question A.

14 Peer Discussion Reports, Observers, Categoized Summary, Question 2.

15 Principal's Survey 1985.

16 Principal's Survey 1985, Categorized Summary.

17 Interviews-Department Chairperson, Categorized Summary .

18 Interview-Department Chairperson G; page 2.

19 Interview-Department Chairperson $\mathrm{K}$, page 2.

20 Interview-Department Chairperson $R$, page 3.

21 Interview-Department Chairperson $\mathrm{L}$, page 2.

22 Interview-Department Chairperson $M$, page 3.

23 Investigator Questionnaire 1985, Observed Teachers Qualitative Summary, Question G. 
24 Peer Discussion Reports, Observed Teachers, Summary, Question 3.

25 Investigator Questionnaire 1985, Categorized Summary Question $\mathrm{C}$.

26 Investigator Questionnaire 1985, Categorized Summary Question D.

27 Peer Discussion Reports, Observers, Categorized Summarv, Question 3.

28 Principal's Survey, Categorized Summary.

29 Interviews-Department Chairperson, Categorized Summary

30 Interviews-Principals, Categorized summary .

31 Peer Discussion Reports, Observers, Categorized Summary, Question 4.

32 Principal's Survey, Categorized Summary.

33 Investigator Questionnaire 1985, Observed Teachers, Categorized Summary, Question C.

34 Investigator Questionnaire 1985, Observed Teachers, Categorized Summary, Question D.

35 Peer Discussion Reports, Observed Teachers, Summary, Question 3.

36 Investigator Questionnaire 1985, Observers, Categorized Summary, question B.

37 Investigator Questionnaire 1985, Observers, Categorized Summary, Question A. 
Peer Disclission Reports, Observers, Categorized Summary, Question 4.

39 Interview-Department Chairperson $K$, page 2.

40 Interview-Department Chairperson $R$, page 3 .

41 Interview-Department Chairperson L, page 2.

42 Interview-Department Chairperson $\mathrm{S}$, page 2.

43 Peer Discussion Reports, Observers, Categorized Summary, Question 4 .

44 Investigator Survey 1986, Summary.

45 Interview-Department Chairperson $C$, page 2.

46 Interview-Department Chairperson G, page 1.

47 Interview-Department Chairperson $M$, page 2.

48 Investigator Questionnaire 1985, Frequency

Distribution Summary.

49 Investigator Questionnaire 1985, Frequency

Distribution Summary.

50 Investigator Questionnaire 1985, Observers, Categorized Summary, Question D.

51 Investigator Questionnaire 1985, Observers, Categorized Summary, Question Da.

52 Investigator Questionnaire 1985, response, teacher 9.

53 Investigator Questionnaire 1985, response, teacher 2c.

54 Investigator Questionnaire 1985, response, teacher 13.

55 Investigator Questionnaire 1985, response, teacher 36 .

56 Investigator Questionnnaire 1985, Observers, Categorized Summary, Question Da. 
57 Investigator Questionnaire 1985, response, teacher 4.

58 Investigator Questionnaire 1985, response, teacher 33.

59 Investigator Questionnaire 1985, response, teacher 12.

60 Investigator Questionnaire 1985, response, teacher 23.

61 Investigator Questionnaire 1985, response, teacher 3.

62 Investigator Questionnaire :985, response, teacher 32.

63 Interview-Department Chairperson G, page 2.

64 Interview-Department Chairperson $K$, page 3.

65 Interview-Department Chairperson C, page 3.

66 Interview-Department Chairperson S, page 3.

67 Interview-Department Chairperson $S$, page 1.

68 Interview-Principal B, page 2.

69 Interview-Principal J, page 3.

70 Interview-Principal B, page 1.

71 Interview-Principal $J$, page 1.

72 Interview-Principal $J$, page 1.

73 Investigator Questionnaire 1985, response, teacher 31.

74 Investigator Questionnaire 1985, response, teacher 5c.

75 Investigator Questionnaire 1985, response, teacher 1c.

76 Investigator Questionnaire 1985, response, teacher $7 \mathrm{c}$.

77 Interview-Department Chairperson $S$, page 3.

78 Interview-Department Chairperson $R$, page 4 .

79 Interview-Principal $B$, page 4.

80 Interview-Principal J, page 1.

81 Investigator Questionnaire 1985, Observers,

Categorized Summary. 
82 Investigator Questionnaire 1985, Observers: Categorized Summary, Questions A; D.

83 Peer Discussion Reports, Observers, Categorized Summary, Question 3.

84 Peer Discussion Reports, Observer response, teacher 66.

85 Peer Discussion Reports, Observer response, teacher 41.

86 Peer Discussion Reports, Observer response, teacher 17.

87 Peer Discussion Reports, Observer response, teacher 93.

88 Peer Discussion Report, Observer response, teacher 71.

89 Peer Discussion Report, Observer response, teacher 20.

90 Peer Discussion Report, Observer response, teacher 100.

91 Peer Discussion Report, Observer response, teacher 34.

92 Peer Discussion Report, Observer response, teacher 89.

93 Peer Discussion Report, Observer response, teacher 19.

94 Peer Discussion Report, Observer response, teacher 136.

95 Peer Discussion Report, Observer response, teacher 88 .

96 Peer Discussion Report, Observer response, teacher 26.

97 Peer Discussion Report, Observer response, teacher 38.

98 Principal's Survey 1985, Categorized Summary. 
99 Principal's Survey 1985, Response, Reason 16.

1C) Principal's Survey 1985, Response, Reason 23.

101 Principal's Survey 1985, Response, Reason 31.

102 Principal's Survey 1985, Response, Reason 35.

103 Interview-Department Chairperson $C$, page 2.

104 Interview-Department Chair $\ddot{z}=x \operatorname{son} G$, page 1 .

105 Interview-Department Chairperson $\mathrm{K}$, page 2.

106 Interview-Department Chairperson $R$, page 2.

107 Interview-Department Chairperson 1, page 1 and 2.

108 Interview-Department Chairperson $M$, page 2.

109 Interview-Principal B, page 5.

110 Interview-Principal J, page 4.

111 Interview-Department Chairperson M, page 2.

112 Investigator Questionnaire 1985, Observed Teachers, Categorized Summary, Question E.

113 Investigator Questionnaire 1985, Observed Teachers, Categorized Summary, Question E.

114 Investigator Questionnaire 1985, Observed Teachers, Categorized Summary, Question G.

115 Investigator Questionnaire 1985, Observed Teachers, Categorized Summary, Question G.

116 Investigator Questionnaire 1985, Observed Teachers, Categorized Summary, Question G.

117 Investigator Questionnaire 1985, response, teacher 12.

118 Investigator Questionnaire 1985, response, teacher 17. 
119 Investigator Questionnaire 1985, response, teacher 20.

120 Investigator Questionnaire 1985, response, teacher 23.

121 Investigator Questionnaire 1985, response, teacher 33.

122 Investigator Questionnaire 1985, response, teacher 37 .

123 Investigator Questionnaire 1985, Observed teachers, Categorized Summary, Question I.

124 Investigator Survey 1986, Summary.

125 Investigator Questionaire 1985, Observed teachers, Categorized Summary, Question I.

126 Principal's Survey 1985, Response, Suggestion 1.

127 Principal's Survey 1985, Response, Suggestion 8.

128 Principal's Survey 1985, Response, Suggestion 11.

129 Principal's Survey 1985, Response, Suggestion 14.

130 Principal's Survey 1985, Response, Suggestion 15.

131 Principal's Survey 1985, Response, Suggestion 22.

132 Interview-Department Chairperson $K$, page 2.

133 Interview-Department Chairperson $R$, page 2.

134 Interview-Department Chairperson $L$, page 1.

135 Interview-Department Chairperson $M$, page 2.

136 Interview-Department Chairperson $K$, page 3 .

137 Interview-Department Chairperson $R$, page 3.

138 Interview-Department Chairperson L, page 2.

139 Investigator Questionaire 1985, Observers, Categorized Summary, Question E.

140 Investigator Questionnaire 1985, response, teacher 7 . 
141 Investigator Questionnaire 1985, response, teacher 3.

142 Investigator Questionnaire 1985, response, teacher 9.

143 Investigator Questionnaire 1985, response, teacher 12.

144 Investigator Questionnaire 1985, response, teacher 15.

145 Peer Discussion Reports, Observed Teachers, Categorizeđ Summary, Question 3.

146 Investigator Questionnaire 1985, response, teacher 39.

147 Princinal's Survey 1985, Response, Reason 11.

148 Principal's Survey 1985, Response, Reason 13.

149 Principal's Survey 1985, Response, Reason 23.

150 Principal's Survey 1985, Response, Reason 24.

151 Investigator Questionnaire 1985, Observed Teachers, Categorized Summary, Question J.

152 Investigator Questionnaire 1985, Observers, Categorized Summary, Question A.

153 Investigator Questionnaire 1985, Observed Teachers, Qualitative Summary, Question J.

154 Interview-Department Chairperson C, page 3.

155 Interview-Department Chairperson $\mathrm{K}$, page 3.

156 Interview-Department Chairperson $R$, page 3 .

157 Interview-Department Chairperson $L$, page 2.

158 Interview-Department Chairperson $M$, page 3.

159 Interview-Department Chairperson 5 , page 3.

160 Peer Discussion Reports, Observers, Categorized Summary, Question 3.

161 Interview Department Chairperson $C$, page 2 and 3 . 


\section{BIBLIOGRAPHY}

Abramson, P. (1972, September). When teachers evaluate each other. Scholastic Teacher, 24-26.

Alfonso, R. J. (1977). Will peei supervision work? Educational Leadership, 34, 594-601.

Annese, L. E. (1971). Principal as a change agent. Clearing House, 45: 273-7.

Bailey, L. C. (1969). The feasibility of using videotape recordings as a substitute for direct observation in a home economics methods course (Doctoral dissertation, Ohio State University, 1969). Dissertation Abstracts International, 30, 10A, 4298.

Baltus, D. F. (1974, April). Accountable evaluation for improvement. Paper presented at the annual convention of the National Association of Elementary School Principals, Anaheim, CA.

Ban, J. R., \& Soudah, J. R. (1978). A new model for professionalizing teacher evaluation. Peabody Journal of Education, $\underline{56}(1), 24-32$.

Bandura, A. (1971). Analysis of modeling processes. In A. Bandura (Ed.), Psychological modeling: Conflicting theories (pp. 2-56). Chicago: Aldine-Atherton, Inc.

Barron, B.G. (1967). An investigation of the effect of videotape and micro-teaching techniques on 'openess' in students enrolled in an elementary language arts methods course (Doctoral dissertation, University of Southern Mississippi, 1967). Dissertation Abstracts International, 28. 09A, 3522.

Benzley, J., Kauchak, D., \& Peterson, K. (1985, April). Peer evaluation: An interview study of teacher evaluating teachers. Paper presented at the annual meeting of the American Educational Research Association, Chicago, IL.

Best, J., \& Kahn, J. (1986). Research in education. Englewood Cliffs, NJ: Prentice-Hall. 
Bigby, D, G。 (1981). Improving productivity through feedback and goal setting (Doctoral dissertation, University of Houston, 1981). Dissertation Abstracts International, $\underline{42}$. 08B, 3476 .

Blair, V. R. (1984). Peer observation as a means of changing teacher effectiveness behaviors (Doctoral dissertation, University of Florida, 1984). Dissertation Abstracts International, 45, 07A, 1970.

Bloom, B. S. (1976). Human chatacteristics and school learning. New York: McGraw-Hill.

Borg, W., \& Gall, M. (1983). Educational research: An introduction. New York: Longman Inc.

Brophy, J. E. (1979). Using observation to improve your teaching (Occasional Paper No. 21). East Lansing: Michigan State Universty, Institute for Research on Teaching.

Carl, M. E. (1972). The self-coding and peer-coding accuracy of student-teachers using selected categories of teacher talk from 'guided self-analysis' and videotape recordings (Doctoral dissertation, University of Oregon, 1972). Dissertation Abstracts International, $\underline{33}, 05 \mathrm{~A}, 2210$.

Carlson, R.O. (1970). The adoption of educational innova-

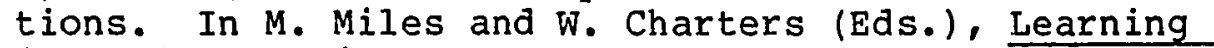
in social settings (pp. 672-690). Boston: Allyn \& Bacon.

Cogan, M. L. (1973). Clinical supervision. Boston: Houghton Mifflin.

Collie, W. E. (1972). The effect of videotape replay on a teacher's self-evaluation of his teaching performance (Doctoral dissertation, University of Kentucky, 1972). Dissertation Abstracts International, 33, 05A, 2212.

Cruickshank, D. R., \& Applegate, J. H. (1981). Reflective teaching as a strategy for teacher growth. Educational Leadership, 38(7), 553-554.

Daw, R. W., \& Gage, N. L. (1971). Effects of feedback from teachers to principals. In A. H. Yee (Ed.), Social interaction in educational settings (pp. 321-330). Englewood Cliffs, NJ: Prentice-Hall. 
Denzin, N. K. (1970). The research act: A theoretical introduction to sociological methods. Chicago: Aldine.

Diamond, S. (1975). Classroom observation - a means to improve instruction. NASSP Bulletin, 59(395), 29-33.

Dodge, J. R. (1981). The effects of a group peer supervision training program on group anxiety, group satisfaction, and type of feedback responses for trained counselors (Doctoral disser cation, Univerity of Virginia, 1981). Dissertation Abstracts International, $42,08 \mathrm{~A}, 3439$.

Dornbusch, S. M., Deal, T. E., Plumley, D., \& Roper, S. S. (1976). The collegial evaluation program: A manual for the professional development of teachers (Field Test Edition.) Palo Alto, CA: Stanford University, Stanford Center for Research and Development in Teaching.

Eder, M. D. (1971). A study of the effectiveness of the videotape recorder with and without modeling in the inservice training of teachers (Doctoral dissertation, University of Maryland, 1971). Dissertation Abstracts International, 32, O6A, 2941.

Ellis, E. C., Smith, J. I., \& Abbott, W. H. (1979). Peer observation: A means for supervisory acceptance. Educational Leadership, 36(6), 423-426.

Feldens, M. G. F., \& Duncan, J. K. (1978). A field experiment: Teacher-directed changes in instructional behavior. Journal of Teacher Education, 29(3), 47-51.

Fitts, P. M. (1968). Factors in complex skill training. In R. G. Kuhlen (Ed.), Studies in educational psychology (pp. 390-404). Waltham, MA: Blaisdell.

Fuller, F., Baker, H. (1970). Counseling teachers: Using video feedback of their teaching behavior (Report No. 0010). Austin: University of Texas, Research and Development Center for Teacher Education.

Fuller, F. F., Peck, R. F., Brown, O. H., Menaker, S. L., White, M. M., \& Veldman, D. J. (1969). Effects of personalized feedback during teacher preparation on teacher personality and teaching behavior (Report Series No. 4). Austin: University of Texas, Research and Development Center for Teacher Education. 
Gagne, R. M. (1968). Skill training and principles of learning. In R. G. Kuhlen (Ed.), Studies in educational psychology (pp. $384-390$ ). Waltham, MA: Blaisdell.

Goetz, J., \& LeCompte, M. (1984). Ethnography and gualitative design in educational research. Orlando: Academic Press.

Goldhammer, R. (1969). Clinical supervison. New York: Holt, Rinehart, \& Winston.

Good, T., \& Brophy, J. (1974). Changing teacher and student behavior: An empirical investigation. Journal of Educational Psychology, 66, 390-405.

Grossnickle, D. R., \& Cutter, T. W. (1984). It takes one to know one - advocating colleagues as evaluators. NASSP Bulletin, 68(469), 56-60.

Haring, N. G. (1974). Perspectives in special education. In N. G. Haring (Ed.), Behavior of exceptional children: An introduction to special education (pp.

3-33). Columbus: Merrill.

Halling, B. B. (1976). Looking for good teaching: A guide to peer observation. St. Louis, MO: Danforth Foundation Faculty Fellowship. (ERIC Document Reproduction Service No. ED 186380 ).

Helmstadter, G. (1970). Research concepts in human behavior. NY: Meredith Corporation.

Hill, K. L. (1972). The effects of two types of supervision on selected teacher behaviors when employing microteaching and videotape feedback (Doctoral dissertation, University of Idaho, 1972). Dissertation Abstracts International, 33, 05A, 2218 .

Holm, L. L. (1978). An experimental study of the effects of a collegial evaluation program on the attitudes of physical education teachers and interns (Doctoral dissertation, Stanford University, 1978). Dissertation Abstracts International, 39, 06A, 3449 .

Hopfengardner, J. D., \& Walker, R. (1984). Collegial support: An alternative to principal-led supervision of instruction. NASSP Bulletin, 68(471), 35-40. 
Horton, W. D. (1974). A study to measure the attitudes of teachers toward self and peer evaluation (Doctoral dissertation, Pennsylvania State University, 1973). Dissertation Abstracts International, 34, 08A, 4625.

Jick, T. (1983). Mixing qualitative and quantitative methods: Triangulation in action. In J. Van Maanen (Ed.), Qualitative methodology (pp. 135-148). Beverly Hills: Sage.

Joyce, B. R., \& Showers, B. (1981, April). Teacher training research: Working hypothesis for program design and direction for further study. Paper presented at the annual meeting of the American Educational Research Association, Los Angeles, CA.

Kagan, N., \& Krathwohl, D. R. (1967). Studies in human interaction: Interpersonal process recall stimulated by videotape (Report No. 5-0800). East Lansing: Michigan State University, College of Education.

Koran, M. L., Snow, R. E., \& McDonald, F. J. (1971). Teacher aptitude and observational learning of a teaching skill. Journal of Educational Psychology, $\underline{62}(3), 219-228$.

Krajewski, R. J. (1971). A study of the effects of videotaping and $\mathrm{Flanders}$ interaction analysis matrix recordings on secondary masters of arts in teaching degree interns (Doctoral dissertation, Duke University, 1971). Dissertation Abstracts International, $\underline{32}, 2958 \mathrm{~A}$.

Lawrence, D. (1985). Controversy and apprehension among principals nearly killed the Toledo plan. American School Board Journal, 172(7), 22-23.

Lempesis, c. (1984). Peer observation improves teacher performance. NASSP Bulletin, 68(471), 155-156.

Levine, S. (1978). Training in classroom observation and videotape self-observation: The effects on teacher's verbal classroom behavior. (Doctoral dissertation, New York University, 1978). Dissertation Abstracts International, 39, 12A, 7292 .

Little, J. W. (1982). Norms of collegiality and experimentation: Workplace conditions of school success. American Educational Research Journal, $19(3), 325-340$. 
Logan, F. A. (1971). Incentive theory, reinforcement and education. In R. Glaser (Ed.), The nature of reinforcement (pp. 45-61). New Ycrk: Academic Press.

Mattaliano, A. P. (1982). Self-help for teachers: Collegial supervision in an urban school. Hartford, CT: Author. (ERIC Document Reproduction Service No. ED 234 114).

McClintock, C., Brannon, D., \& Maynard-Moody, S. (1983). Applying the logic of sampie surveys to qualitative case studies: The case cluster method. In J. Van Maanen (Ed.), Qualitative methodology (pp. 149-178). Beverly Hills: Sage.

McDonald, F. J. (1973). A behavior modification view of video playback: Microteaching. Paper presented at the meeting of the American Educational Research Association, New Orleans, LA.

McDonald, F. J., \& Allen, D. W. (1967). Training effects of feedback and modeling procedures on teaching performance (Technical Report No. 3). Stanford, CA: Stanford University, School of Education, Center for Research and Development in Teaching.

McDonald, F. J., Allen, D. W., \& Orme, M. E. (1967). The effects of self-feedback and reinforcement on the acquisition of a teaching skill. Stanford, CA: Stanford University, School of Education, Center for Research and Development in Teaching.

McEaul, S. A., \& Cooper, J. M. (1984). Peer clinical supervision: Theory vs. reality. Educational Leadership, $41(7), 4-9$.

McGee, J. C., \& Eaker, R. (1977). Collegial supervison and teacher anxiety: A collegial approach to the problem. Contemporary Education, 49, 24-28.

McPike, L. (1984). Teacher excellence: Teachers take charge. [An interview with Dal Lawrence, president of Toledo Federation of Teachers]. American Educator: The Professional Journal of the American Federation of Teachers, $\underline{8}(1), 22-29$.

Miles, M. B. (1971). Innovations in education: some generalizations. In M. Miles (Ed.), Innovation in education (pp. 631-662). New York: Teachers College Press. 
Miles, H. (1983). Qualitative data as an attractive nuisance: The problem of analysis. In J. Van Maanen (Ed.), Qualitative methodology (pp. 117-134). Beverly Hills: Sage.

Miles, M., \& Huberman, A. (1984a, May). Drawing valid meaning from qualitative data: Toward a shared craft. Educational Researcher, 20-30.

Miles, M., \& Huberman, A. (1984h). Qualitative data analysis. Beverly Hills: Sage.

Miller, N. E., \& Dollard, J. (1941). Social learning and imitation. New Haven: Yale University Press.

Mohlman, G. C. (1982, March). Assessing the impact of three inservice teacher training models. Paper presented at the annual meeting of the American Educational Research Association, New York: NY.

Mohlman, G. C., Kierstead, J., \& Gundlach, M. (1982). A research-based inservice model for secondary

teachers. Educational Leadership, 40(1), 16-19.

Moore, J., Schaut, J., \& Fritzges, C. (1978). Evaluation of the effects of reedback associated with a problemsolving approach to instruction on teacher and student behavior. Journal of Educational Psychology, 70, 200-208.

Moretti, R. N. (1976). The relationship between the principal perception of classroom observation and the teacher perception of classroom observation in the city school district of Niagara Falls, New York (Doctoral dissertation, State University of New York at Buffalo, 1976). Dissertation Abstracts International, 37, 09A, 5500.

Nelson, J. E. (1971). Collegial supervision in multi-unit schools: A study of an inservice program for primary teachers in newly formed units in schools which have received two forms of organizational development training (Doctoral dissertation, University of Oregon, 1971). Dissertation Abstracts International, 32, 09A, 4925 .

Nelson, J., Schwartz, M., \& Schmuck, R. (1974). Collegial supervision: A sub-study of organizational development in multi-unit schools. Eugene: University of Oregon, Center for Educational Policy and Management. 
Oriich, D. (1978). Designing sensible surveys. Pleasantville, NY: Redgrave Publishing Co.

Orlich, D. C., Harder, R. J., Callahan, R. C., Kravas, C. H., Kauchak, D. P., Pendergrass, R. A., \& Keogh, A. J. (1985). Teaching strategies: A guide to better instruction (2nd ed.). Lexington, MA: D. C. Heath.

Pfeifer, R. S. (1987, April). Variations on a theme: An analysis of peer involvement in teacher evaluation. Paper presented at the annual meeting of the American Educational Research Association, Washington DC.

Phelps, M. S., \& Wright, J. D. (1987). Peer coaching: A staff development strategy for rural teachers. Cookeville, TN: Tennessee Technological University, Education Research and Service Consortium.

Robinson, J. J. (1978). The observation report - a help or a nuisance? NASSP Bulletin, 62(416), 22-26.

Rogers, E. M. (1965). What are innovators like. Chapter 4 in Change Processes in the Public Schools. Eugene, Oregon: University of Oregon, Center for Advanced Study of Educational Administrators.

Roush, R. E. Jr. (1969). A study of change in selected teacher evaluation interns' behavior using videotape recordings (Doctoral dissertation, University of Houston, 1969). Dissertation Abstract International, 30, $02 \mathrm{~A}, 607$.

Salek, C. (1975). Helping teachers vs. evaluating teachers. NASSP Bulletin, 59(392), 34-38.

Salomon, G., \& McDonald, F. J. (1969). Pre and post-test reactions to self-viewing one's performance on videotape. Stanford, CA: Stanford University, Center for Research and Development in Teaching.

Schmuck, R., \& Runkel, P. (1970). Organized training for a school faculty. Eugene, Oregon: University of Oregon, Center for Advanced Study of Educational Administrators.

Sharken, W. W., \& Tremba, E. A. (1978). Strategies to improve instruction. NASSP Bulletin, 62, (412), 27-30.

Showers, B. (1983, April). Transfer of training. Paper presented at the annual meeting of the American Educational Research Association, Montreal, Canada. 
Showers, B. (1984). Peer coaching: A strategy for facilitating transfer of training. Eugene, University of Oregon, Center for Policy and Management.

Showers, B. (1985). Teachers coaching teachers. Educational Leadership, $42(7), 43-48$.

Shreeve, W. E. (1978). A comparison of the effects of videotape feedback, instructor feedback, and checklist feedback on medical student performance of the physical examination (Doctral dissertation, University of Virginia, 1978). Dissertation Abstracts International, $40,02 \mathrm{~A}, 656$.

Skinner, B. F. (1954). The science of learning and the art of teashing. Harvard Educational Review, 24, 86-97.

Skinner, B.F. (1969). Contingencies of reinforcement: A theoretical analysis. New York: Meredith Corp.

Skinner, B.F. (1978). Reflections on behaviorism and society. Englewood Cliffs: Prentice-Hall.

Smyth, W. J., \& Colin, H. (1983, November). A case study experiment of a collaborative and responsive form of professional development for teachers. Paper presented at the annual meeting of the Australian Association for Research in Education, Canberra, Australia.

Sparks, G. M. (1983). Inservice education: Training activities, teacher attitudes, and behavior change (Doctoral dissertation, Stanford University, 1983). Dissertation Abstracts International, 44, 05A, 1427.

Standard College Dictionary (1973). New York: Funk \& Wagnalls.

Storm, B. E. (1981). When teachers observe teachers: A study of peer supervision (Doctoral dissertation, Harvard University, 1981). Dissertation Abstracts International, $42,06 \mathrm{~A}, 2624$.

Thomas, V. S. (1980). Cognitive dissonance theory: The relationship between feedback and behavioral change. (Doctoral dissertation, University of Iowa, 1980). Dissertation Abstracts International, 42, 01B, 415.

Thompson, J. C., III. (1979). On models of supervision in general and on peer-clinical supervision in particular. Curriculum Specialist, Intermediate Unit I, 1148 Wood Street, California, PA 15419. Author. (ERIC Document Reproduction Service No. ED 192 462). 
Tremba, E. A. (1975). The effectiveness of videotape feedback with microteaching and modeling in charging teacher behavior (Doctoral dissertation, Lehigh University, 1975). Dissertation Abstracts International, $36,09 A, 5728$.

Tuckman, B., \& Oliver, W. (1968). Effectiveness of feedback to teachers as a function of source. Journal of Educational Psychology, 59, 297-301.

Walz, G. R., \& Johnson, J. A. (1?63). Counselors look at themselves on videotape. Journal of Counseling Psychology, 10, 232-236.

Ward, P.M. (1970). The use of the portable videotape recordur in helping inservice teachers self-evaluate their teaching behavior (Doctoral dissertation, University of California, Berkeley, 1970). Dissertation Abstract International, 31, 08A, 3794.

Warner, A. C., Cooper, J. M., \& Houston, W. R. (1980). The way I see it.. . quick fixes don't work. Educational Leadership, $37(5), 424,443$.

Williams, P. A. F. (1981). The deveiopment and testing of a conceptual model of peer supervision (Doctoral dissertation, University of Houston, 1981). Dissertation Abstract International, 42, O4A, 1432.

Yin, R. K. (1984). Case study research: Design and methods. Beverly Hills: Sage.

Young, D. A. (1970, March). A preliminary report of the effectiveness of colleague supervision on the acquisition of selected teaching behaviors in a micro-teaching series. Paper presented at the annual meeting of the American Educational Research Association, Minneapolis, MN.

Young, D. B. (1968, February). Effectiveness of self-instruction in teacher education using modeling and videotape feedback. Paper presented at the annual meeting of the American Educational Research Association, Chicago, IL.

Zahorik, J. A. (1987). Teacher's collegial interaction: An exploratory study. Elementary School Journal, 87 $(4), 385-96$. 
APPENDIX A

PARTICIPANT VOLUNTEER FORMS

Peer observation volunteer corms were distributed to the faculty by the principals. Teachers volunteered by completing the questions and returning them to the office. Forms are for the investigaton years 1984-85 and 1985-86. 
LAKE OSWEGO HIGH SCHOOL

T0: $\quad$ AlI Faculty

FROM: $\quad$ Bill Korach

DATE: $\quad$ September 27, 1984

PLEASE RETURN THE FOLLOWING INFORMATION TO KAREN HARFST TODAY.

NAME

1. I am a probationary or temporary teacher and DO NOT wish to be included in peer coaching.

2. I am a probationary or temporary teacher and DO wish to be included in peer coaching.

3. I am a permanent teacher and would like the REGULAR EVALUATION PROCESS for 1984-85.

4. I I am a permanent teacher and would like to be involvet in PEER COACHING rather than the regular evaluation process in 1984-85.

We will be developing a list of all teachers who will be trying peer coaching.

1

$B$ Le

Bill Korach 


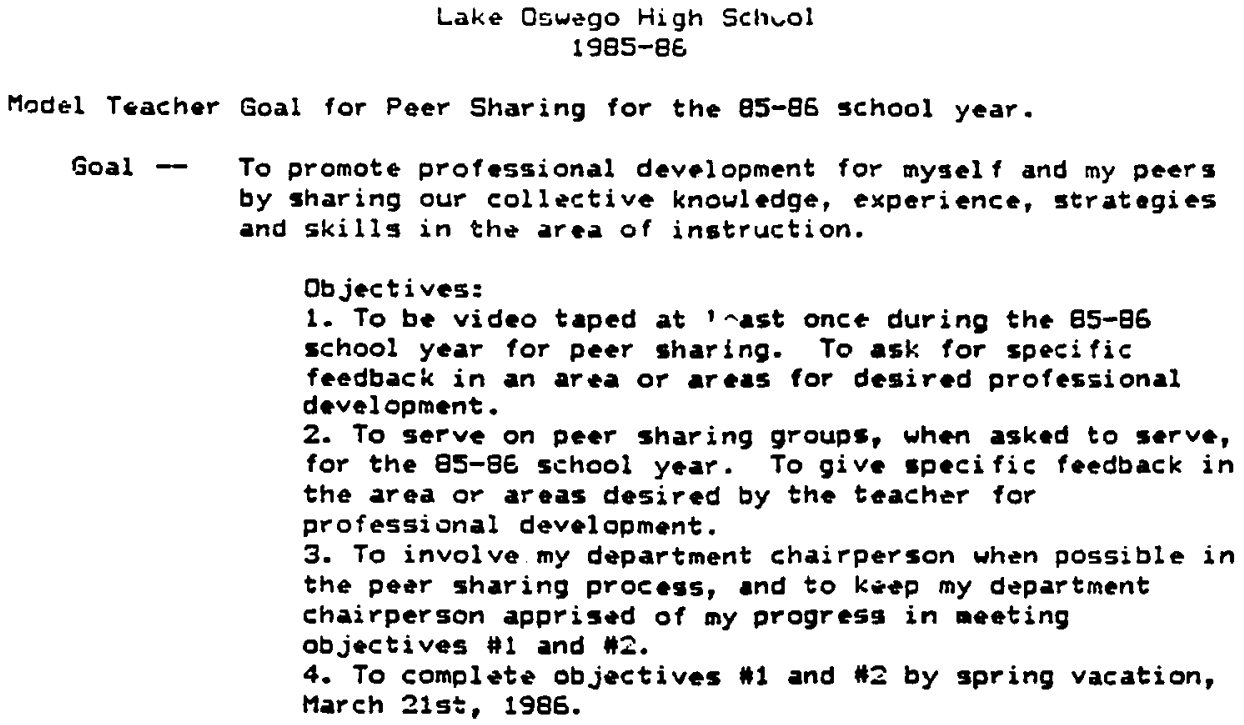

Lake Oswego High Sehool 1985-86

Staff Survey on Peer Sharing:

Name

1. I want to make peer sharing ons of my goals for 85-8E.

Yes _.... No

2. If the answer to $\| 1$ is yes, I wish to have my department chairperson involved (where there are department enairpersens! in peer sharing only or in both peer sharing and my evaluation

3. If the answer to 11 is yes, I wish to use my video tapes for only peer sharing. Yes No

I would like to use my video tapes for evaluation at my diseretion. Yes___. No ___.

Please return to Karen in the main office by Thursday October loth. 
LARE OSWEGO HIGH SCHOOL

PEER COACEING - QUESTIONNAIRE

While feedback will be gathered from participants who selected the peer coaching process, it is likewise as aluable 0 understand why this: process was not chosen. Because you have selected the District Evaluation process, I am asking for your feedback to better understand how you perceive both the peer coaching process and the District Evaluation Process.

Do not identify yourself and please return this questionnaire to my mailbox by Tuesday, October 9th. I respect your time and appreciate your thoughtful responses. If you are interested in the compilation of responses just let me know.

Thank you, Lelex

Helen Hanna

1. Would you please share your thoughts on why you selected not to participate in the Peer Coaching Process this year? 


\section{APPENDIX B}

PEER DISCUSSION REPORT FORMS

Peer discussion report forms were designed for written feedback on the group discussion of the videotaped lesson. In 1984-85, two forms were used, one for the teacher being observed and one for each teacher observing. Completed forms were given to the observed teacher for analysis and then turned into the main office. In 1985-86, one discussion report form was created to serve as a means of verification that a peer observation session took place and an instructional goal had been completed by a teacher. The completed form was returned to the department chairperson for proof of peer observation completion. 
IAKE OSWEGO HIGH SCHOOL

PEER COACHING

1984

Peer Coaching Video Discussion:

Dace Discussion Held:

Name of the Paer Coach:

Name of the Observed Person

1. Identify the areas for which feedback was sought:

2. Did you feel you were able to provide the feedback soughe?

3. In what way was this process helpful to your own teaching?

4. In what way could this process be more helpful to you as a peer coach? 
LUEE OSWEGO HIGH SCHOOL

PEER COACHING

1984

Peer Ciaching Video Discussion:

Dace Discussion Held

Faculty Person Observed:

Coaches:

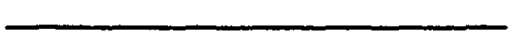

.

1. Identify the areas in which feedback was sought:

2. Did you receive the type of feedback requested?

3. In what way was this process helpful to your ceaching?

4. In what way couid this process be more helpful to you as a teacher? 


\section{Lake Oswego High School} 1998-8E

Peer Sharing Verification Form

Teacher Name

Tadihing aria on which fiectback was riquestid:

Mimber of the petr sharing team:

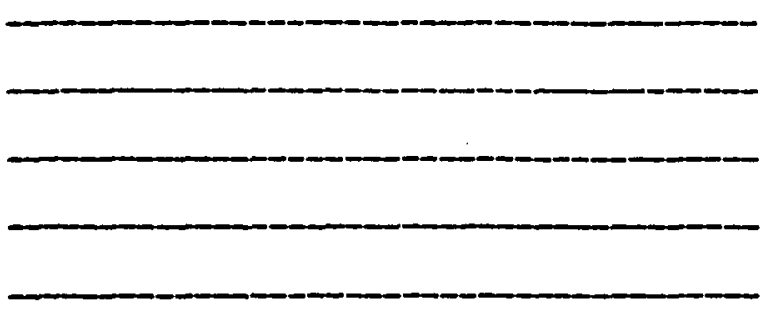

Date of the petr sharing session:

To be returned to the Department Chairperson where aporopriate. 


\section{APPENDIX C}

PRINCIPAL QUESTIONNAIRE

The principal distributed a questionnaire to all faculty at the end of the 1984-85 school year. The question asked was whether peer observation activities should be continued as a building goal for 1985-86. Teachers were to respond by agreeing or disagreeing with continuance of peer observation. Open-ended comments on reasons and suggestions were encouraged. Teacher responses, comments, and suggestions are included. 
SCHOOL-HIDE GOALS SURVEY RESULTS

May 1985

\section{INSTRUTIION}

We showi continue e school-wide instruetional goal to share our solleetive experiences, knowiedge, and skills ejrough pear coaching.

Agree 45

REASON:

1. This is a veluable cool for instructional improvement, though I'd like so see the peer coacriting grcups reduced in size.

2. We need some avenue fo: this kind of sharing and I think peer-cosching sight provide is.

3. Pee: coacting is a becier, more meaningiul evaluation process.

4. This has providied both the impesus and the structure for sose of our nos: produc: $v$ te deparment meerings.

5. That video is effective.

6. Ver; good method for staff to observe people in other depa:zents.

7. It's a positive aicernative to one pariod eraiuations by one person.

8. The peer coaching axperiente was the best cool for improving that I have seen yer. It reail; was geids.

9. Agree as leng as form is changed to be acre helpful to teacirer being evaluated. Present one is confuring arid dosen' I zenerace the kind of Feedback we need.

10. It was a very worthwhile experience.

11. Just beginning to be seen as helpful zzcher than stressful. Coaching sessions have been encouragille and educacional. Potensial too great to stop now. 
Page Four

12. The interplay of staff should be helped.

13. We've only just begun to feel comfortable with the concept.

14. Beneficial to both the teucher and the coach.

15. This has been a valuable experience.

16. I nave thoroughly enjoved watching the videos this year. Of the five I have been invited to wateh I have learned something from each one of them.

17. It keeps instructional tecinniques uppermost on stafis mind. We need to work together to find ways to improve.

18. There's a tremendous source of ideas on tnis staff. If it takes peer coashing to make (or encourage) people to share, then it's worth the time and effort.

19. Like the idea of sharing experiences, skill, etc. Glad to do more.

20. Most innovative thing I've seen in reaching evaluation.

21. We are just beginning the process and need more time with it.

22. Powerful learning.

23. I need more time/experience in front of video camera - to feel at each both in watching myself teaci: and having others watch me and eventually more readily accept evaluators suggestions, critiques of ochers. It's useful to see other's strategies for teaching same type of thing.

24. We are just getting started. It can be of more help to some teachers than anything we have done.

25. I think it has a positive value which cannot be contested.

26. I have enjoyed peer coaching after first being fearful of having myself taped.

27. I think this is a worthy program and look forward to getting into it next year.

28. Peer coaching was helpful to me on both ends, receiving and giving feed back. It also is a way to implement goal one.

29. We are just getting it going and I feel there will be benefits.

30. An excellent approach.

31. We've just begun to develop the model, why stop now? I believe that it's been somewhat successful, and needs to continue as one aspect of evaluation. I think the greatest benefit is to see other teachers in action.

32. The peer coaching system should be more formal in pre-coaching behaviors to be observed, and post-coaching evaluation. I realize the resistance to this, but it would make the process more valuable.

33. Possitive, productive way toprovide for instructional growth as well as new ideas.

34. I'm not sure how much that $I$ have gained, but it is a reiaxed technique and whatever I've gained, it was more than the old method.

35. I have learned neli ideas, techniques and concepts that have helped me in my own teaching.

SUGGESTION:

1. I had to do my evaluavion with m: sefarsment which is GK but. I hope that this isn't a trend. I believe the original goal of being evaluated by teachers farm different departinents is also good.

2. Compile what teachers :hink those collective experiences, knowledge, and skills are.

3. Continue to make the focus improvement of instruction rather than teacher evaluation.

4. Continue to allow the meisel to deveiop in a fiexible manner to meet the needs and concerns of each indivitual in askinf for feedback and selecting hisher coaches.

5. Use the inservice day to do sume of the eviluations.

6. Continue - Cood Propram!

7. This has been a rare optoritinity to viow others teaching and to examine your own. Continue. 
Page Five

8. Conzinue to use the same peer coaching plan as this year but have people choose different people to view their tape and make suggestions. It would be helpful to have them chonse teachers not in their same department but somewhat removed. Also choose a different objective than they had this year.

9. The proble!n is zetting the camera access and then getiing togecher with our peers.

10. Work within each department first. Be spe ific about what each participant wants to get out o fthe session and what heishe actually got from the experiencs.

11. Work with related departments, i.e. (math, physics, chem., etc.)

12. Although it is in it's first scage peer coaching has some strong points. You are able to collectively evaluate your teaching - suggestions are offered by your peers as to what you might do differenily. Probably would be betcer if you were evaulated twice.

13. Continuing peer coaching will become even no:e valuable as the staft in general has practice using and having a tez=er understanding of- ITIP.

14. Teachers with same course sharing same lesson. More use of inservice time for sharing video tapes.

15. Tape by content areas within department.

16. Absolutely. This is the best thing we've done in evaluation. Very non-threatening.

17. Same problem: TINE - not enought of it.

18. Some one needs to be in charge of a group oi teachers and work out a schedule for times, i.e. You will be filmed 4th period on next Tuesday etc. Teacher has input.

19. It should continue to be voluntary.

20. Change the form that is handed into the office - it becomes very redundant after three or four sessions.

21. Perhaps devise an "observation" report form to be given to the teacher being observed by the peer coaches.

22. Work within departments until process is familiar and then go cross disciplines.

23. Make the video taping instructions more explicit as to focus on students/instructor.

24. Have one major, specific area of focus for evaluators, i.e. active participarion, task completion, etc. as well as a general evaluation of the stccess of that particilar teacting segment.

Disagree 3

REASON:

1. A better help iould be ro visit cther schnols on a special instructional education day.

2. It was an interesting one- ine experience, but the returas are limited when meastred against the time conbitiment.

3. I think that brings in some professional speakers (who are presently teaching or were past reachers) $1 .$. jive a couple of inser:see workshops on zechniques of teaching would i: more beneticial. ! 1 -20 minutes on tape can be very unrealistic ant faise. 
APPENDIX D

1985 INVESTIGATOR QUESTIONNAIRE AND COVER LETTER

At the end of the first year of peer observations, a questionnaire was distributed at a faculty meeting seeking responses from teachers who had completed all of the peer observation activities, some of the activities, and none of the observation activities. Teachers were asked to complete the forms as soon as possible and were to turn them into the main office. Responses to the questionnaire were to be anonymous. 
LAKE OSWEGO HICH SCHOOL

TO: Peer Coaching Participants

FROM: Helen Hanna

DATE: May 31,1985

RE: ASSESSMENT FOR STUDY OF PEER COACHING RROCESS

The peer coaching process this year was developed to provide a means for teachers to share reaching experiences, knowledge, strategies, and skills. The goals were two-fold: one, to encourage meaningful thinking about personal instructional improvements; and two, to develop a process for improving instruction that works better than the district approach of administrator-teacher observation. Two factors were changed to-encourage use of the peer coaching process; one was to separate the peer process from evaluation for teacher recention and the other was to encourage voluntary participation (substitute peer coaching process for formal district evaluation process).

This is the time to assess the peer process goals. Were these goals met, partialiy met, or not met at all? In asking for your assessment help, I need evervone to return the assessment form. I will ask for demographic information and also a brief comment if you changed your mind during the year and decided not to participace in the peer process.

The form is divided into two sections; the first part deals only with your assessment of the peer coaching process goals as a teacher being observed by peers. The second part deals only with your assessment of the peer coaching process goals from the point of view of a peer coach. If you did nor participare as a peer coach, please so indicate at the top of Part Two.

Thank you for giving thought to this assessment at the end of the year when you are faced with extreme demands on your limited time. Please return this assessment in the folder on Karen's desk and check your name off the faculty list in the folder. I need this check only to be certain I have accounted for the total population in this study. The form is intended to be anonymous.

Sincerely,

Sellu,

Helen Hanna 
Page 1

Total years of teaching

Teaching years in district

Male

Female

Age

No. of times you were a peer coach

Part I. ASSESSMENT BY TEACHER BEING OBSERVED

A. Below is a list describing instructional characteristics. On the left, place a check next to the item(s) on which you requested coaching feedback. On the right, place a check next to the items on which you received feedback. Add items at the bottom not included here.

Requested

_ Clarity of lesson objectives

Lesson organization
Clarity of task instructions
Active participation by students

$\longrightarrow$ Reinforcement

Tone or climate

$\longrightarrow$ Appropriate level

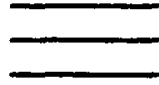

$\longrightarrow$

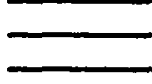

$\longrightarrow$

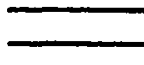

$\longrightarrow$

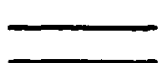
Discussion techniques

Teacher mannerisms

Speaking clarity

Closure

Monitoring and adjusting

Teaching enthusiasm

Lesson alternatives

Suggestions for change

Received

B. In the above list, did you receive more checks in one column than in the other column? If yes, please explain why you feel this occurred. 
Part I.

C. List in order of priority (number 1 having highest value) the three most valuable items of feedback you received on your observed lesson.

1

3.

D. Do any of the three items listed above have additional value to you in teaching other lessons? If yes, list the characteristic you are thinking of and how that feedback has been extended to other lessons, (i.e. active participation = students to write down response first).

1.

2.

3.

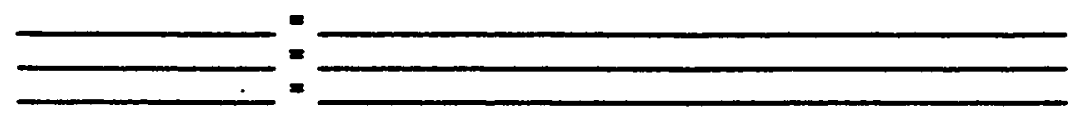

E. This question asks you to think back to the fall before the peer process was introduced. While you are thinking in the past, answer the following questions by placing an " $X$ " along the appropriate scale.

a. Rate yourself on your degree of personal "instructional improvement awareness".

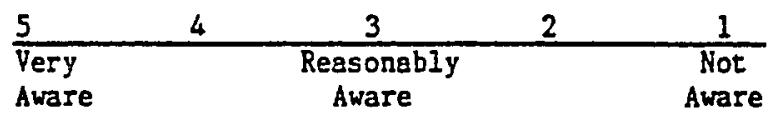

b. Rate yourself on your "conscious effort" to implement improved instructional techniques.

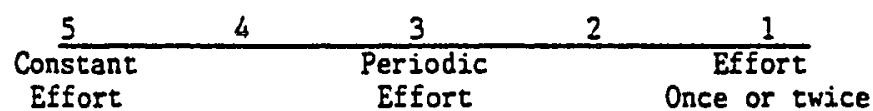

c. Rate yourself on your "actual implementation" of improved instructional techniques.

$\begin{array}{lcccc}5 & 4 & 3 & 2 & 1 \\ \begin{array}{l}\text { Every } \\ \text { Lesson }\end{array} & & \begin{array}{c}\text { Some } \\ \text { Lessons }\end{array} & & \text { No } \\ \text { Lessons }\end{array}$

F. This questions asks you to think about the peer coaching process after your experience of being video taped, observed, and discussed by others. Now, rate yourself on the previous three questions in $\mathrm{E}$. above. Place a " $\checkmark$ " along the appropriate scale.

G. Was there a change in your ratings because of the peer coaching process? Did you learn and/or grow from this experience? If yes, on which scale (a) awareness, (b) effort, (c) implementation and in what direction? What reasons would you give for any changes noted? 
B. Think of your motivations in the fall for participating in peer coaching. Below is a list to which you may add. Circle the 2 or 3 items you feel were most powerful in motivating you to participate.

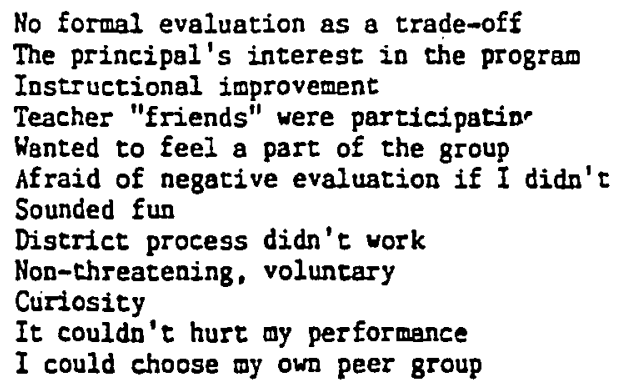

I. Identify the composition of the peer group you selected by cireling the categories that represent your group.

Departmental only Interdepartmental Dept. Chairperson(s) Administrator(s)

a. Plesse give reasons for your choices in peer group composition which you circled above.

b. Please list any reasons why you might compose a different group next time.

J. Can you identify a technique, method, or idea that is a part of your teaching today that came from this peer process? Please explain below. 
Page 4

\section{Part II ASSESSMENT BY PEER COACH}

I did not participate as a peer coach

A. This question asks whether you received instructinal improvement benefits from being a peer coach. Using the list on Page I, Part I, Question A, write below any items which were mentioned or observed in the coaching discussion that also provided you " afulness to your instructional improvement.

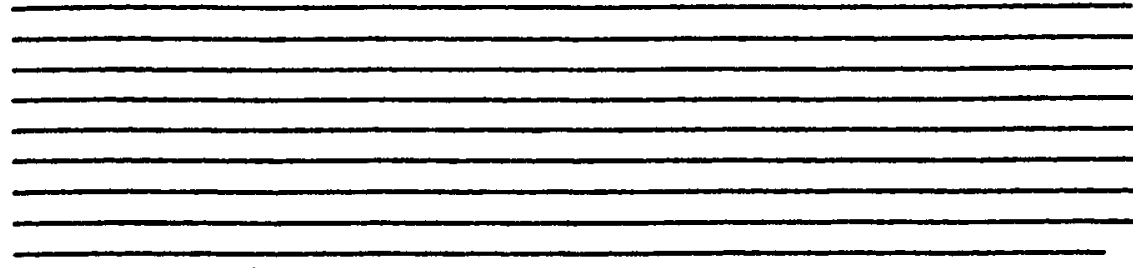

B. In your opinion, how productive were peer group discussions related to instructional improvement?

$\begin{array}{ccccc}5 & 4 & 3 & 2 & 1 \\ \begin{array}{c}\text { Very } \\ \text { Productive }\end{array} & & \begin{array}{c}\text { Somewhat } \\ \text { Productive }\end{array} & & \text { Not } \\ \text { Productive }\end{array}$

a. Please explain below the reasons for your rating.

C. As a peer coach, check the coments below that describe your feelings and behavior when coaching the person being observed. Add others not included

\begin{tabular}{l} 
I was careful to stick to requested feedback \\
I felt like I didn't have anything to contribute \\
I saw and discussed areas not requested \\
I talked about what other peer coaches contributed \\
I didn't talk in the discussion \\
I noticed everyching everyone else noticed \\
I most worried about the feelings of the observed person \\
I was relaxed and natural in the group discussion \\
I was nervous and tense in the discussion \\
I felt everyone was positive about feedback \\
I felt some feedback was wrong and said so in the group \\
I felt pleased to be asked to be a coach \\
\hline I felt people got off the track \\
I felt it was taking too auch time and not useful \\
I felt all ideas were useful to we \\
\hline$\square$
\end{tabular}


Page 5

Part II

D. Both peer coaching and the district process of administrator-teacher observation are intended to develop meaningful instructional improvegents. Rate each process on how well you feel each process achieves improvement.

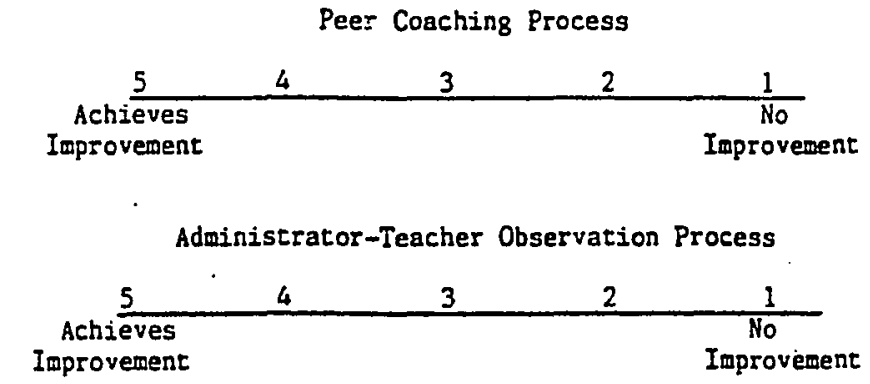

a. For the process you rated highest in achieving instructional irprovement, please state the reasons for your rating.

E. If you were to describe the role of a peer coach, as you know it, to someone unfami?.iar with the idea, what would you say? 
APPENDIX E

1986 INVESTIGATOR SURVEY

In the fall of 1986, a final survey on peer observation activities was distributed at a faculty meeting by the investigator. This survey solicited information about who had identified peer observation as an instructional goal and who had completed the goal, part of the goal, or none of the peer observation goal. This survey was necessary because records were not available at the end of the 1986 school year on teachers who selected peer observation as a goal or on teachers who had completed this goal. General and specific comments were solicited from the staff. Teachers were asked to return the forms to me. An agreement giving permission for teacher responses to be used in the case study was also presented with this survey. 
To: Faculty

Date: October 20,1986

From: Helen Hanna

Re: Peer Observation 1985-86 School Year

Staff Name

I an asking your help in two ways for my case study on peer observation. One request is to get the number of people who participated last year, and the other request is a release to me for peraission to use actual rather than ficticious names in the case study.

1. Would you please respond to the questions below so that I can tabulate numbers of participants for last year, 1985-86.

Yes Ho 1 identified peer observation as a personal goal

on the 1985-86 professional growth form.

Yes No I videotaped a segment of my teaching.

Yes Ho I asked a peer group to view ky videotapes.

Yes No I gave each peer group member information on lesson

objectives.

Yes No I identified the areas in which I wanted feedback.

Yes Ho A peer group discussion took place.

My peer group nembers were: dept. only__ interdept'? dept. chair

Comments general or specific on the peer observation process for 1985-86 year.

2. Please read the following statement. If you are willing to give me permission to use your name in a professional context, please sign the release.

\section{WRITTEN RELEASE}

I, agree that my name, perceptions, and comments given freely may be used in the dissertation text and other articles or presentations made by Helen $\mathrm{J}$. Hanna regarding the peer observation process implemented at LOHS.

It is understood that my contributions will be used in a professional manner intended for the purposes of research data collection and for furthering knowledge in this area.

Signature of participant:

Date: 
APPENDIX F

INTERVIEW QUESTIONS FOR DEPARTMENT CHAIRPERSONS

During the summer of 1986 , the seven department chairpersons were contacted for an interview. Interviews were held at times and in locations convenient to the interviewees. The list of questions was given ahead of time and points of clarification were made before the interviews started. Permission to tape the interview was granted by all chairpersons. Unless requested otherwise, the tape $r$ an continuously throughout the interview and few comments were made by the investigator. Interviews ranged from 10 to 15 minutes each. Transcripts may be requested under separate cover for inquiries related to this study. 


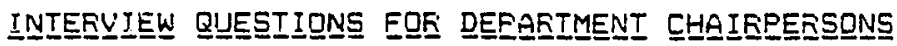

Name of Interviewee

Date

Location

1. Did you thoose peer observation in school year 1985-86? would you explain the reasons for your choice?

2. When you consider a peer observation process, what are your perceptions about the feedback given via videotape, peer discussions, and written peer observations?

¿. When you consider a peer observation process, what are your pereeptions about reinforcement--the idea of reward?

4. What is the role, as you see it, for modeling in a peer observation process?

As a peer observer, did the video tape presentations serve as models for effective teaching behaviors? Why?

5. What are your perceptions of the peer discussians held after tape vi ewing?

Were written comments from the peer observers useful?

6. From your perspective, what role did peer observation play in the improvement of instrustion? Do you feel instruction was improved using peer observation?

7. OFEN ENDED: What are your perspectives of the peer observation process implemented at LoHS? Froblems? Fotential? Modifications? Role of principal? Impaç on staff? Long-term effect? Recommendations? Informal observations you observed and shared with others?

THANK YOU FOF YOUF: TIME AND THOUGHTFUL RESFONSES! 


\section{APPENDIX G}

\section{INTERVIEW QUESTIONS FOR PRINCIPALS}

In the summer of 1986 , the two pricipals during the time of this investigation were contacted for an interview. Interviews were held in locations and at times convenient to the principals. The questions were given ahead of time and points of clarification were made before the interview began. The principals gave permission for the interview to be taped, and few comments were made by the investigator. The interviews were 30 and 45 minutes long. Transcripts may be requested under separate cover for inquiries related to this study. 


\title{
INTEFUIEW QUUESTIQNSS EQRE FRINCIFALS
}

\author{
Bill Korach, 1984-85 Frincipal; implemented peer observation \\ John Turchi, 1985-86 Acting principal; continued process as \\ a part of teacher evaluation
}

1. What were your goals for the peer observation process at LOHS?

2. What was your role in the process? Organizational tast:s? Decision-making needs? Implementation responsitilities? Cost concerns? Instructional improvement input? Foer observation participation?

3. Assess the peer observation process relative to its potential for feedback to the teacher. Strengths and weaknesses? Comparison to traditional observation by administrator and/or supervisors?

4. Assess the reinforcement to teachers as it might relate to the peer observation process. Are there rewards, as you see it, for teachers to repeat their participation in this process?

5. Assess the peer observation process relative to:

a) modeling via videotape of classroom taaching.

b) peer discussions about videotape segment.

c) written follow-up reports by peer observers.

b. Assess peer observation relative to instructional improvement. Did improvement occur? What evidence do you have that might support your previous answer?

7. OFEN ENDED: Ferceptions of peer observation? froblems? Potential? Modifications? Role of principal? Impact on staff? Attitudes? Generalizations?

THANY YOU FOF: YOUR THOUGHTFUL RESFDNSES! 